University of Rhode Island

DigitalCommons@URI

Open Access Dissertations

1997

\title{
Indicated Silences in American Novels
}

Catherine Adamowicz

University of Rhode Island

Follow this and additional works at: https://digitalcommons.uri.edu/oa_diss

\section{Recommended Citation}

Adamowicz, Catherine, "Indicated Silences in American Novels" (1997). Open Access Dissertations. Paper 419.

https://digitalcommons.uri.edu/oa_diss/419

This Dissertation is brought to you for free and open access by DigitalCommons@URI. It has been accepted for inclusion in Open Access Dissertations by an authorized administrator of DigitalCommons@URI. For more information, please contact digitalcommons-group@uri.edu. 
INDICATED SILENCES IN AMERICAN NOVELS

BY

CATHERINE ADAMOWICZ

A DISSERTATION SUBMITTED IN PARTIAL FULFILLMENT OF THE REQUIREMENTS FOR THE DEGREE OF

DOCTOR OF PHILOSOPHY

IN

ENGLISH

UNIVERSITY OF RHODE ISLAND

1997 
DOCTOR OF PHILOSOPHY DISSERTATION

$\mathrm{OF}$

CATHERINE ADAMOWICZ

APPROVED:

Dissertation Committee

Major Professor

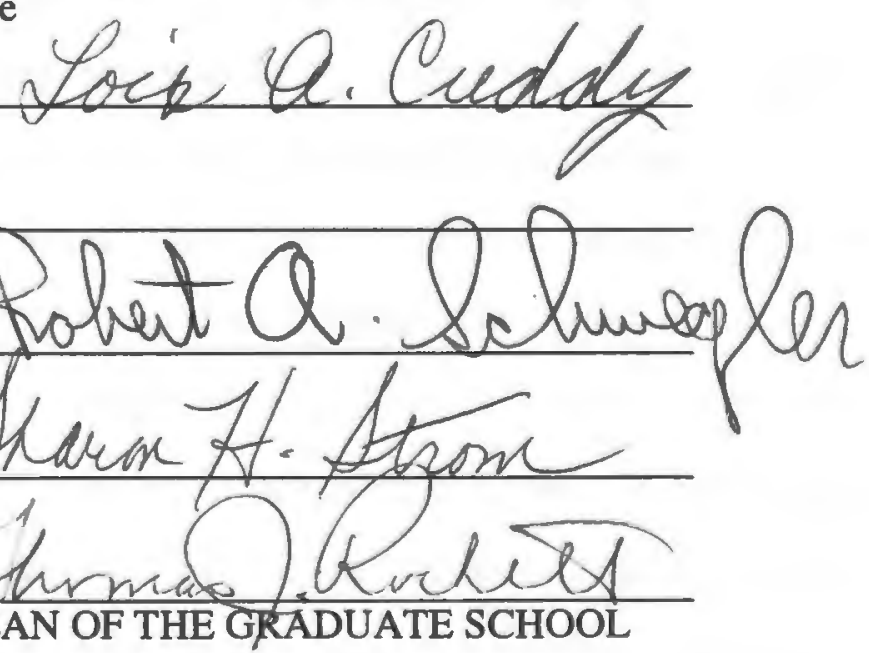

UNIVERSITY OF RHODE ISLAND

1997 


\section{ABSTRACT}

Studies have tended to focus on implied, not indicated, silences and/or to define silence as the opposite and inferior condition of speech, reproducing and reinforcing the man/woman hierarchical binary.

This study, defining silence as the complement of speech, analyzes the significance of silences indicated by words and/or punctuation. Its purpose is to illustrate that an author's uses of silence reflect her subject position during a particular historical moment, that trends in uses evolve gradually, and that their direction can be predicted. The principal novels and authors used as exempla are At Fault and The Awakening by Kate Chopin, Contending Forces and Winona by Pauline Hopkins, and Plagued by the Nightingale and The Underground Woman by Kay Boyle.

The introduction reviews critical perceptions of silence; informed by texts of $\mathrm{M}$. M. Bakhtin, Chris Weedon, George Kalamaras, and King-Kok Cheung, redefines silence; and posits new possibilities for understanding silence. The conclusion briefly analyzes Paule Marshall's Brown Girl, Brownstones and Praisesong for the Widow.

Beginning with Chopin's novels, some of the protagonist's silences reflect the extent to which she conforms to the image of the Southern lady. Beginning with Hopkins's novels, the extent to which the protagonist develops a sense of self different from her subject position depends upon her speech community and whether members of it sometimes remain silent. Beginning with Boyle's novels, the community includes a person of a race and/or gender different from the protagonist, and the protagonist, with the help of her community, uses silence to develop a new subjectivity.

All of these trends are confirmed in Marshall's novels, and, in the foreseeable future, they may be expected to continue in novels by women. 


\section{ACKNOWLEDGMENTS}

I thank my primary speech community at the University of Rhode Island: Lois Cuddy, Sharon Strom, Sally Burke, and Robert Schwegler. In telling me, "Say what you mean in the simplest, most direct way," Lois reminded me to do as I teach my own students. She also provided an ocean of calm in the midst of seemingly endless turbulence. Pointing me in the directions toward which I needed to go, Sharon challenged me to dig deeper and deeper for historical relevance. Sally always found my dangling modifiers and subject/verb disagreements, and she never failed to draw my attention to newly published texts related to my study. When Sally took her sabbatical leave, Dr. Bob graciously agreed to take her place. From past experience, I know he will help me to further my work on silences. I also thank Karen Stein and Lynn Pasquerella at the University of Rhode Island for becoming members of my primary speech community.

My secondary speech community has also been important to me throughout this study. Susan Dearing, my friend and colleague, patiently listened to my complaints as well as to my ideas for more months than I want to admit. Additional colleagues at Wheaton College, including Bev Clark, Paula Krebs, Dick Pearce, Jean Pearce, Sheila Shaw, Frances Shirley, Sue Standing, Steve Strang, Kathleen Vogt, and Shay Youngblood nudged me gently by asking me, now and again, how my study was progressing. Marilyn Todesco, my friend and co-worker, made me realize that my outdated word-processing program would not do me in; she gave her time and skills to ensure that it would not. My long-time friend and former colleague, Riva Westlund, offered her wry humor and realistic perspective when I most needed them. Usually, she did that by telephone, but, sometimes, she managed to travel the many miles to do it in person. Other friends and colleagues, past and current, including Susan Reed, Elaine Craghead, and Emily Rogers, encouraged me to pursue my initial interest in silences. 
I also thank James Nagel for having enhanced my interest in literature of the United States, in part by appointing me editorial assistant for Studies in American Fiction during my graduate study at Northeastern University, and Alan Gifford for having provoked me to meet Jim.

Family members have mattered to me. Knowing that my sister, Anne Adamowicz, was only a phone call away always made me feel good. Thanks to my parents, Statia Adamowicz and Walter Adamowicz, and to my uncle, Peter Wajda, I did not have to teach on more than one campus to pay my bills.

I cannot imagine having been able to concentrate on this study as well as I did without the constant support of Paul Callahan. Cal did the grocery shopping, and he cooked the meals. He did the laundry, and he planted the gardens. He listened, and he gave me the space that I needed. If anyone was as present as Cal was, it could only have been Clio, my feline companion who has had the dubious pleasure of seeing me through all the years of my graduate work.

Words cannot express my gratitude to Joan Harrison, who helped me to better appreciate people whom I have mentioned, and to Marcie Richardson, who led me to Joan. 
CONTENTS

ACKNOWLEDGMENTS

INTRODUCTION $\ldots \ldots \ldots \ldots \ldots \ldots \ldots \ldots \ldots \ldots \ldots \ldots \ldots$

Perceptions, $(\mathrm{Re})$ Definitions, and New Possibilities

Chapter

1. SLENCES IN AT FAULT AND THE AWAKENING: LACK OF A

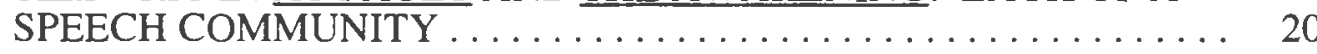

2. SLENCES IN CONTENDING FORCES AND WINONA: WHAT A DIFFERENCE A SPEECH COMMUNITY MAKES . . . . . . . . . . 53

3. SILENCES IN PLAGUED BY THE NIGHTINGALE AND THE UNDERGROUND WOMAN: THE GRADUAL EMERGENCE OF A SPEECH COMMUNITY . . . . . . . . . . . . . . . . . . . . . 94

CONCLUSION ............................... 175

Confirmations and Predictions

NOTES ................................ 183

BIBLIOGRAPHY ............................... 190 


\section{INTRODUCTION}

\section{Perceptions, (Re)Definitions, and New Possibilities}

Within the past two decades, critics have primarily studied silences that they imagine to be present in American literature. Two early critics, for example, believe that some textual events symbolize characters' inexpressiveness. Frances Malpezzi argues that Gertie Nevel's cessation of carving in Harriette Arnow's The Dollmaker represents her loss of voice, while Josephine Donovan contends that moments of decision-making by women characters in Sarah Orne Jewett's "A White Heron" and Mary E. Wilkins Freeman's "Evelina's Garden" mirror the tension between a pre-oedipal (matriarchal) silence and a post-oedipal (patriarchal) voice which destroys the pre-oedipal silence. More recent critics assume that silences are implied in dialogues and narratives, and they often create texts to fill the supposed silences. With that assumption, Stephen Portch looks for implied silences in the terse dialogue of Ernest Hemingway's "The Killers" and "Hills Like White Elephants," and Carolyn Porter, Ronald Schleifer, William Scheick, and Catherine Rainwater search for implied silences in the narrative discourses of works by Anne Beattie, Grace Paley, Annie Dillard, and Anne Redmon, respectively. Suzette Henke argues that novelists, in general, tend to write texts that remain silent on sexual issues, such as the use of birth control; Janis Stout claims that Jane Austen's, Willa Cather's, Katherine Anne Porter's, and Joan Didion's works remain silent on points that are made after their texts have stopped.

While all of these studies are interesting in that they explore silences the critics as individual readers imagine to be there, and I occasionally make reference to silences that I perceive to be implied, my study primarily concerns silences that authors have actually written into texts. Some of these silences that unequivocally indicate a character's nonvocalization of thought and/or feeling are indicated by unconventional uses of punctuation, and I do examine those types of indicated silences. More often than not, however, the 
indicated silences that I examine are indicated solely by the words of an omniscient narrator. For example, the narrator may say that a character is thinking, or feeling, or being silent. Why I think these narrative words merit attention equal to that of a character's words becomes clear when considered from the perspective of M. M. Bakhtin's essay, "Discourse in the Novel." Since the arguments made by Bakhtin to which I refer deal only with discourses, I discuss them only in relation to narrative words, but I think that his arguments apply equally to punctuation that an author uses unconventionally.

In "Discourse in the Novel," Bakhtin says that "[a] speaking person's discourse in the novel is not merely transmitted or reproduced; it is, precisely, artistically represented and thus ... it is represented by means of (authorial) discourse " (Dialogic Imagination 332). To clarify his distinction between words that are "transmitted or reproduced" and words that are "artistically represented," he compares a witness's court testimony that a stenographer records with "[a] speaking person's discourse in the novel" that an "author" creates. In that a narrator conveys information to readers, I consider a narrator to be a type of "speaking person." Thus, I believe that a narrator's "discourse" merits the same attention that a character's words do because the author has chosen to write it into the text. In his essay, "The Problem of the Text," Bakhtin ponders the relationship between social forces impinging upon a novelist and the novelist's creation of a character's discourse. Like my argument in the previous paragraph, I think the point that he makes about the impetus for the creation of a character's discourse may well be applied to the catalyst for the making of the discourse of an omniscient narrator. He says that although "[t]he speech of the characters ... does not enter directly into the ideological dialogue of contemporaneity ... the author occupies a position precisely in this real dialogue and is defined by the real situation of the day" (Speech Genres 116). Here, Bakhtin says that the novelist "is defined" by the historical moment or "the real situation of the day" and takes a part in or "occupies a position" in the social discourse of that moment or the "ideological dialogue of contemporaneity," and he implies that the novelist's creation of characters' 
"speech" has something to do with that social discourse. In other words, Bakhtin implies that characters' discourses are, to some extent, a reflection of both the novelist's position in society and the novelist's dialogue with society. Since a narrator's discourse, as I argue, is also a discourse created by the novelist, it follows that a narrator's discourse is also, to some extent, a reflection of the novelist's position in, and dialogue with, society. Thus, discerning the particular significance of the discourse of an omniscient narrator, including words that indicate a character's silence, requires an understanding of both the novelist's subject position and the "ideological dialogue" occurring during the historical moment in which a novelist composes.

In addition to Bakhtin's contention that a novelist's creation of characters' discourse reflects, to some extent, both the novelist's subject position and her (or his) dialogue with society, my study is informed by Chris Weedon's argument that "a theory is useful if it is able to address the questions of how social power is exercised and how social relations of gender, class and race might be transformed" (20). More specifically, I use my theory about indicated silences--that the words of an omniscient narrator, and, sometimes, the unconventional use of punctuation, which indicate characters' silences merit the same attention that characters' speeches do--to discern both what protagonists' silences written into novels by American women may indicate about American women's subject positions at given historical moments and whether any changes in the uses of the silences from one moment to the next suggest a change in women's subject positions or a means by which women can move beyond them. In other words, I am looking at how women's silences may reflect and affect their sense of self. Having said that, I want to make clear that the indicated silences which I examine in my study are neither solely those of the protagonist nor only those of female characters, but, since the majority of the silences which I examine are those of the protagonist, unless there is a reason for me to do otherwise, in this introduction, I make reference to the protagonist. 
To gain the breadth necessary for this type of study, I decided to examine six novels in depth--two novels by each of three authors--published, roughly, over the last one hundred years and to refer to two additional novels by a fourth author--at least one of her novels to be more recent than any of the others--to confirm any trends that I perceive to have evolved over the century and to predict the direction of them. With regard to my decision to select two novels for each author, I wanted to look for any differences in the individual authors' uses of indicated silences, so I chose an early and a later novel written by each author. In selecting the novels for an in-depth examination, I worked from the assumption that women's subject positions are primary topics of social discourse when women, as a political group, are, or have recently been, both visible and, to some degree, successful in their endeavors. Thus, I decided to select novels written during such significant cultural moments: the 1890 s and into the beginning of the twentieth century, the 1920 s, and the 1970s.

My selection of authors for these cultural moments resulted from a combination of desires and assumptions. I wanted to establish a solid baseline for my examination of indicated silences, so I decided to choose two authors who were writing during the initial cultural moment, the 1890 s and into the beginning of the twentieth century. Further, I wanted to look at the latter two moments, the 1920s and the 1970s, as well as to account for the several decades between them, from a consistent point of view. Thus, I decided to choose an author whose literary career spanned those fifty years. Along with these desires, my selection of authors resulted from the assumption that, in the United States, the subject positions available to women during any given historical moment are a function of racism, as well as of sexism and classism. Thus, to consider how racism in particular may influence uses of silence, I decided to select authors not all of the same race. 1

Since the primary purpose of my study is to discern both what each author's use of indicated silences may reveal about "how social power is exercised" at a given cultural moment and whether any changes in the authors' uses of indicated silences from one 
cultural moment to the next suggest "how social relations ... might be transformed" (Weedon 20), I focused each chapter on one author and arranged the chapters in almost perfect chronological order by the publication dates of the novels. In chapters 1 and 2, both of which concern novels written during the initial cultural moment, I examine, respectively, Kate Chopin's At Fault (1890) and The Awakening (1899) and Pauline Hopkins's Contending Forces: A Romance Illustrative of Negro Life North and South (1900) and Winona: A Tale of Negro Life in the South and Southwest (1902). In chapter 3 , which concerns novels written during the second two cultural moments and which accounts for the decades between those novels or moments, I examine Kay Boyle's Plagued by the Nightingale (1931) and The Underground Woman (1975); and, in the conclusion, which confirms trends I perceive to have evolved over these past one hundred years that Chopin, Hopkins, and Boyle wrote and which predicts the direction of them, I make reference to Paule Marshall's Brown Girl. Brownstones (1959) and Praisesong for the Widow (1983).

Thus, within each chapter of my study, I primarily make comparisons between the indicated silences of the two novels by one author, but, beginning with the second chapter, I also make comparisons between that chapter's pair of novels and the novels in the chapter(s) preceding them. In that the first two chapters concern novels by Chopin and Hopkins, respectively, authors who wrote in the same cultural moment but who were of differing races, the comparisons that I make between the silences in their novels are particularly informed by the fact that they were writing from different subject positions. In that the third chapter concerns novels by Boyle, an author who wrote in cultural moments subsequent to the moment in which both Chopin and Hopkins wrote, the comparisons that I make between the silences in Boyle's novels and their novels are as much informed by differences in the cultural moments as they are by the fact that Chopin and Boyle, both of the same race, wrote from a subject position different from that of Hopkins. Also in the third chapter, at the same time that I explain directives that only Boyle employs for 
indicating the silences--the unconventional use of punctuation which I previously mention-I explain trends that I perceive to be emerging in her novels. In the conclusion, I refer to the silences in Marshall's novels to confirm those emerging trends and to predict the direction of them.

Not so much because the study proceeds chronologically by publication dates but, more importantly, because I believe that in the moments that Boyle and Marshall composed the novels in this study, women lived (and, I think, yet live) within the shadow of the turnof-the-century subject positions from which Chopin and Hopkins wrote, the derivation of those positions and the positions themselves need to be understood in order to consider the significance of the protagonists', as well as other female characters', indicated silences. Although "the real situation of the day" (Bakhtin, Speech Genres 116) for virtually all Americans at the turn of the century was such that their subject positions were clearly delineated according to their race and class as well as their gender, it seems that that was especially true for Americans living south of the Mason-Dixon line.

In the South, these delineations had been motivated mainly by middle- and upperclass white, particularly Anglo-Saxon, male desire for political and economic dominance. As Paula Giddings explains, in order for those Southern men, after the Civil War, to have the control that they had gained through the system of slavery, a rationalization was needed to argue that all other people were inferior to them (78). More specifically, to solidify the basic argument that middle- and upper-class Southern Anglo-Saxon men should be in power, a means had to be devised to belie whatever political and economic gains that, in particular, middle- and upper-class Southern white women and Southern blacks had made during and immediately after the Civil War years. While, during the war, those white women "had shown their resourcefulness when ... forced to manage plantations and their own lives without chivalrous shoulders to lean on" (80), Southern blacks "had made substantial economic gains in the postwar period ..." (79). Further, both of those groups had gained visibility on a national level through the post-war establishment of such 
organizations as the mainstream Women's Christian Temperance Union, created in 1874 (Hymowitz and Weissman 188), and the National Colored Labor Union, an association of women and men begun in 1869 (Giddings 68). Perhaps most important, with the ratification of the Fifteenth Amendment in 1869, black men gained the right to vote, which, in turn, prompted women--primarily Northern white women at that time--to argue vociferously for enfranchisement (E. DuBois 848).

A primary means used to contradict and, thus, to undermine those achievements of white women and blacks appeared largely under the guise of science or, more exactly, social Darwinism; and the undermining served to return those groups to bipolar subject positions. Earlier anthropometric theories, which concerned the measuring of the brain and other features of the human body to determine social fitness, were used to reposition blacks (as well as to position recent Eastern European immigrants). From those theories, "the image of Blacks changed [after the end of slavery] from that of children to dangerous animals" (Giddings 79). Of course, that "image" served to justify the increasing post-war lynchings of black men by white men (79) and to declare black women to be "immoral scourges" (82). Whites rationalized that without white supervision, the freed blacks "had regressed to a primitive and thus criminal state" (27).

Concurrent with, and in opposition to, the changed image of blacks, the antebellum image of white women, especially the image of the middle-to-upper-class Southern lady, was renewed and intensified (Giddings 81). As Anne Firor Scott explains, "this ... creation was described as a submissive wife whose reason for being was to love ... [and] obey ... her husband, [and] to bring up his children" (4). Of course, along with being "beautiful and graceful," this "submissive wife" was "self-denying ... and . . given to suffering in silence ..." (4). As a whole, the image of the Southern lady dovetailed very neatly with an argument made by social psychologists about women: their reasoning abilities were extremely limited, and any type of formal education was not only an impossibility but also a danger to their reproductive functioning (Giddings 80 ). Thus, 
social psychologists provided reasons why any middle- and upper-class white woman should "obey ... her husband, [and] . . b bring up his children" (Scott 4).

In addition, and in opposition to the image created of blacks as being "dangerous animals" (Giddings 79), white men placed special emphasis on the image of white women as being particularly pure and moral beings (81), which not only reinforced the appropriateness of their roles as wives and mothers but also provided a rationale for white men's monitoring of their actions or, phrased euphemistically, protection of them. Given the belief among whites that black men found white women particularly attractive and had a tendency to rape them (27), those women were placed in a position of needing protection, which virtually guaranteed their acquiescence to white men's gender expectations. As Jacquelyn Dowd Hall says, "[t]ogether the practice of ladyhood and the etiquette of chivalry functioned as highly effective strategies of control over [white] women's behavior as well as powerful safeguards of caste restrictions" (152).

In essence, this image of the Southern white lady that, as Scott argues, "was part of the larger American culture" (x), became the image by which women of color were--and, I believe, are--defined, and in that the image was the referent, women of color were positioned as being the undesirable Other. Patricia Hill Collins explains the danger of such binary thinking when she says that "because oppositional dichotomies rarely represent different but equal relationships, they are inherently unstable [and] [t]ension is resolved by subordinating one half of the dichotomy to the other" (70). In other words, components of binary systems or of "dichotomies" are not usually understood as being "oppositional" in the sense of being simply "different," but as being adversarial. Thus, binary oppositional thought usually assumes an "[in]equal[ity]" to exist between the components, so it "subordinat[es]" or makes inferior "one half of the dichotomy" or one component of the system. As Collins explains of black women within this system, they "occupy a position whereby the inferior half of a series of these dichotomies converge ..." (70). Indeed, implicit in the image of the Southern lady is the notion that black women, as Other, 
represented "the inferior half of a series of ... dichotomies" whose attributes range from general demeanor to virtuousness to sexual status to attractiveness: quiet/loud, moral/immoral, pure/impure, beautiful/ugly.

Since this image of the Southern lady served as the determining referent for womanhood, white women were, and yet are, in a position superior to the position of black women, but this hierarchical binary was, and is, detrimental to both black women and white women for at least two reasons. (I also believe that this type of opposition is detrimental to men, but an exploration of its effects on them is beyond the scope of this study.) First of all, the turn-of-the-century positions of both white women and black women, albeit in different ways, severely limited the identity of each group and, thus, each individual woman's sense of self. While black women were led to believe that they were loud, immoral, impure, and ugly, white women were taught that they were quiet, moral, pure, and attractive. Along with the fact that the assumptions about black women were denigrating and the standards for white women were stultifying, this system of hierarchical binaries that defined both groups of women was, and is, detrimental to all women because it defines women in opposition to, or as being other than, and inferior to, men. Just as black women were defined by what dominant society believed they were not, all women are defined by what they have not or what they lack. From the Freudian perspective, for example, woman is other than, and inferior to, man in that she lacks a penis.

Not surprisingly, some feminist criticism focuses on the ramifications of the man/woman hierarchical binary. From the perspective of cinematic production, Teresa de Lauretis contends that woman is "[r]epresented as the negative term of sexual differentiation" (15), and, perhaps to dramatize the consequences of woman being "represented as the negative term," she adds that "woman is . . the looking glass held up to man." That is, woman does not exist without the male gaze, or she exists only as the image of male desire--much like the image of the Southern lady exists. From a more general perspective, Helene Cixous, as Weedon explains, argues that "a set of binary 
oppositions ... which rely for their meaning on a primary binary opposition of male/female ... guarantees and reproduces the patriarchal order" or, in other words, "serves to subordinate the feminine to the masculine order" (66). Apropos of that argument, Ann Rosalind Jones urges women to free themselves from their inferior position by "mov[ing] outside that male-centered, binary logic altogether" (93).

In that these feminist scholars interrogate what has long been a standard way of thinking in our society, they can be perceived as being representative of the "speech community" about which Patricia Yaeger writes within her essay on one of the novels in my study: "a group of fellow speakers who ... encourage the growth of ... thought and its translation into praxis" (215). As this "group of fellow speakers" was emerging, other feminist scholars from various disciplines were defining silence from "that male-centered, binary logic" which A. Jones warns against (93), and, as would not perplex Jones, they, in effect, reinforced and reproduced the inferior position in which such "logic" places women. For example, in Women's Ways of Knowing: The Development of Self, Voice, and Mind, psychologists Mary Field Belenky et al. define silence as being other than speech, "the absence of voice," and "denial of self" (24); and, since they premise their study on the notion that, as a result of social conditioning, women tend to be silent and men, vocal, Belenky et al. link voice/silence with man/woman, power/powerlessness, and self/lack of self.

Further, some feminist scholars who defined silence according to the man/woman hierarchical binary intimated that it is impossible for women to empower, or to define, themselves. In "Education, Ideology, and Class/Sex Identity," Noelle Bisseret Moreau, a sociologist of language-related gender theory, claims that "[s]ilence is often the language of the powerless, the only possible solution when the contradictions are insurmountable" (60). She contends that, as members of the "powerless" class, women may attempt to define themselves by speaking, but because the "dominant" class--i.e., white men-perceives their speech as "'frivolous' language," they become silent (60). ${ }^{2}$ Although 
Moreau considers silence as well as speech to be a type of "language," her argument implies that neither language allows women self-definition. In other words, women might as well be silent as vocal; neither condition alters their "powerless" status. Feminist scholar Shirley Ardener evidently does not perceive silence to be a type of language, but, like Moreau, she perceives it to be a negative condition and speech to be a condition through which women cannot define themselves. Ardener suggests that women "'are silent on matters of special concern to them for which no accommodation has been made"' (qtd. in Spender 201-02). ${ }^{3}$ According to Ardener, then, women cannot define themselves because there is "'no accommodation,"' or no language, in a patriarchal society for them to express their views; so, they "'are silent.'"

Any number of reasons may explain why Belenky et al., Moreau, and Ardener defined silence from the dominant perspective and, thus, reinforced and reproduced the inferior position in which that perspective places women. For example, since these scholars were defining silence from the man/woman hierarchical dichotomy around the same time that de Lauretis, Cixous, and A. Jones were arguing against that dichotomy, it is possible that they were unaware of the arguments made, as Yaeger would say, by their "fellow speakers" (215). Certainly, for Belenky et al., Moreau, and Ardener--as much as for any of the protagonists in the novels of my study or, for that matter, any woman, especially--unawareness of the deleterious consequences of thinking from the man/woman dichotomy would lead them to continue thinking from that dominant perspective. As Weedon explains, "[w]hat an event means to an individual depends ... on the discourses available to her at any particular moment" (79).

Of course, simply hearing or reading "discourses" that challenge those which have been "available" (Weedon 71) does not guarantee that we will consider them, for they both challenge our sense of self and are reacted against strongly by the discourses that have defined us. As Weedon also explains, "[t]he individual who has ... an already discursively constituted sense of identity may resist particular interpellations ..." (106). 
Given that the man/woman schema has been in existence since at least biblical times, when Eve was said to have been created from one of Adam's ribs, and has been reinforced by Freudian ideology as well as by many institutions in our society in addition to the church and schools of psychology, we "may resist ... interpellations" of it because they threaten the very foundation of our "sense of identity." We may even avoid considering ideas that might lead us to reject the "identity" given us by mainstream institutions and to seek a different sense of self because, as Weedon points out, "[f]orms of subjectivity which challenge the power of the dominant discourses ... are carefully policed [and] [o]ften ... are marginalized as mad" (91).

Indeed, the title of Sandra Gilbert and Susan Gubar's text, The Madwoman in the Attic: The Woman Writer and the Nineteenth-Century Literary Imagination, intimates that "[f]orms of subjectivity which challenge ... the dominant discourses . . are marginalized

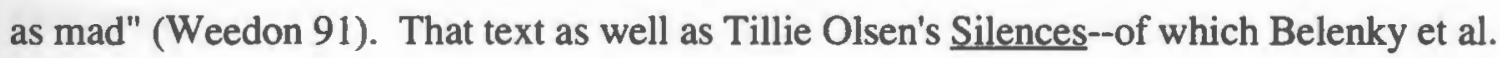
were aware (17)--suggest that women authors, whose act of writing is a "form of subjectivity which challenge[s] dominant discourses," have been "marginalized," or silenced, in various ways by those "discourses" (Weedon 91). Of the authors in my study, at least two were probably silenced because their novels debunk the subject positions imposed upon them by a patriarchal and racist society. Chopin wrote comparatively little after an overwhelming number of reviewers condemned The Awakening. Of the protagonist's ardor, a critic, whose judgment of the novel is relatively representative of other critical assessments, said that it is too "'sensual and devilish'..." (qtd. in Seyersted 30). Although Hopkins continued her literary career after the publication of Contending Forces, it "was released with ... apparently no comment from the white mainstream literary community" (Yarborough xliv). In essence, this critical silence denied the existence of both the novel and its creator, and Contending Forces was not again available to the public until nearly a century after it had been written. That novel, published one year after 
The Awakening, has, as one of its two protagonists, a black woman who was raped by a white man. 4

Given the reality that women authors have been silenced in various ways by "the dominant discourses" (Weedon 91), it might be assumed that all of the female characters' indicated silences in novels written by women of the United States represent some form of patriarchal, as well as racist, silencing; in fact, for one reason or another, it might be disconcerting to some scholars not to make that assumption. However, very recent arguments made by scholars about silence would suggest such an assumption to be overly simplistic, if not wrong. Of particular significance to my study are George Kalamaras's Reclaiming the Tacit Dimension: Symbolic Form in the Rhetoric of Silence and King-Kok Cheung's Articulate Silences: Hisaye Yamamoto, Maxine Hong Kingston. Joy Kogawa. Perhaps because Kalamaras and Cheung have had more of an opportunity than their predecessors had to become aware of the discourses of such feminist critics as de Lauretis, Cixous, and A. Jones--indeed, both of them refer to Cixous in their texts--they each begin their texts by arguing against the viewing of silence from the perspective of hierarchical oppositions.

Kalamaras, in attributing hierarchical oppositions to Western thought, flatly states that "this casting of silence ... as a negative condition is largely erroneous" (3). Although his definition of silence is much more complex than can be fully explained in a few sentences or even a few pages, Kalamaras essentially views silence and "language, . . . the human capacity for vocal and written utterance" (8), much like, as he explains, Chinese Taoist philosophers view yin and yang: "[c]ompeting tendencies ... that . . . do not oppose but rather complement one another" (7). More specifically, he believes that "silence and language act in a reciprocal fashion in the construction of knowledge" (8). According to Kalamaras, "language can be a vehicle that enables one to experience the nondiscursive or nonconceptual realm of understanding" (121)--in other words, "understanding" that cannot be expressed by language. He says, for example, that "lyric poetry can conjure an 
awareness similar to that experienced through practices of silence [meditations]" (125). In turn, this "awareness," which can also be "experienced through ... silence," makes possible the "expanding [of] one's conceptual sensibilities" or one's ability to use language (123).

Although Cheung directs her argument against hierarchical oppositions to critics of works by Asian Americans, and her study does not particularly address protagonists' indicated silences, her points about the limited nature of oppositional thinking and its impact on feminist criticism, as well as her method of avoiding that limitation, are important to my study. In saying that critical studies "must ... interrogate the ... ethnocentric and logocentric perspectives that still inform much of mainstream feminism, perspectives that result in attributing silence solely to patriarchal constructions of womanhood" (3), Cheung is not denying that silence can be a reflection of "patriarchal constructions of womanhood." Her point is that critics who view silence "solely" from that standpoint do not recognize silence as "also carr[ying] other functions and meanings ..." (3). More particularly, she believes that perceiving silence as the opposite of, and inferior to, voice "blinds [critics] to the positive ... manifestations of reticence" (8). Further, like Kalamaras, Cheung recognizes the value of both silence and speech, including their potential to complement one another. ${ }^{5}$ For example, she describes "[s]ilence and words [as] coupl[ing] ..." (167). Indeed, she says that "pronouncing silence as the converse of speech or as its subordinate can ... be [as] oppressively univocal [as privileging silence over speech can be]" (6). To avoid thinking of silence from an oppositional perspective, Cheung "emphasize[s] the different manifestations of ... silence" (19-20), such as "oppressive, inhibitive, protective, stoic, and attentive silences ..." (26).

In agreement with Kalamaras and Cheung about the limited, if not erroneous, nature of hierarchical oppositions, I do not define silence as the opposite of, and inferior to, voice; I suggest that, when the protagonist is being silent or when another character is being silent toward her, the silence has the potential to benefit the protagonist. Like 
Cheung, I believe that assuming all of the protagonists' indicated silences necessarily to be direct representations of women's oppression would produce a reductivist reading. It would be too simplistic to assume that all of the silences highlight moments during which the protagonists are doing what patriarchy expects of them. Rather, I assume that the silences highlight moments during which, for example, the protagonists may be thinking about what they might say and/or about something that has been said. As Kalamaras argues, it is possible for silence and speech to complement each other. After all, were we to speak without prior thought, we might not speak in a way that best represents our thought; and were we not to reflect upon spoken thoughts, we might not further refine our thinking. The idea that thought prior to speech can enhance speech and that speech reflected upon can enhance thought suggests that, as Kalamaras claims, silence can be a component of knowledge production.

Apropos of Kalamaras's claim, when I take into consideration Weedon's contention that "knowledge brings with it the possibility of power and control" (14), the significance of indicated silences increases in that the directives may highlight moments during which the protagonists acquire "knowledge" or new ideas and, thus, allow for "the possibility of power and control" or altered subjectivities. Defining silence as a possible space for reflection, especially reflection that might lead to new ideas and subjectivities different from those assigned them by dominant discourses, suggests that silence is not necessarily, as Belenky et al. argue, "denial of self" (24), or as Moreau contends, "the language of the powerless" (60), or as Ardener says, an indication that "'no accommodation has been made [in language for women to express their experiences]"' (qtd. in Spender 202).

On the other hand, while I posit that the protagonists' indicated silences may highlight moments during which the protagonists are thinking, I do not assume that whatever thinking occurs necessarily leads to new ideas and subjectivities. I do not even assume that all of the silences highlight moments during which the protagonists are thinking; in some instances, they may be simply feeling. Yet because, as I have argued, 
the authors composed from their own subject positions, I do assume that whatever the protagonists are thinking or feeling during the indicated silences somehow concerns women's subject positions. With this assumption, like Cheung, I wish to distinguish among possible meanings of the silences or, phrased differently, to discern what the protagonists' indicated silences may highlight for readers.

Within each novel of this study, I argue that a protagonist's indicated silence draws readers' attention to one or more of the following moments: when she thinks only from the perspective of hierarchical opposition--in other words, when her thought process reflects the position to which she was socialized; when she is unwilling to speak on a topic outside the realm of her position; when she feels a desire to fulfill or, at least, to identify with specific aspects of a position; when she feels some satisfaction or peace as a result of having fulfilled or, at least, having identified with aspects of a position; when she feels ashamed, guilty, angry, alienated, and/or confused as a result of not having fulfilled or identified with a position; when she resists adherence to a position, feels a desire to escape the confines of it, and, sometimes, succeeds in doing so.

While the indications of the silences, alone, do not reveal the significance of the silences, knowledge of critical response to the authors' works, awareness of biographical details about the authors, understanding of the "ideological dialogue" about women during the moments in which the authors composed (Bakhtin, Speech Genres 116), as well as consideration of various discourses in the novels make it possible for me to argue what the silences may mean. Toward these ends, after I begin each chapter by introducing my argument--which, beginning with the second chapter, refers to the chapter(s) before it--I follow it with these components: critical response to the author's works and biographical information as well as historical background relevant to the novels. After presenting these components, I separate my analysis of the silences into two sections, one for each of the two novels, and these sections are ordered chronologically by publication date. My 
conclusions about both novels, together, follow my analysis of the second novel and are in a section separate from it.

The two exceptions to this pattern of development are in the chapter on Boyle's novels and, of course, in the conclusion. Because the two novels by Boyle were written decades apart from each other, when I give biographical information and historical background for them, I do so for each one. After I introduce my conclusion, I discuss trends confirmed in Marshall's novels, and I predict the direction of these trends.

These exceptions notwithstanding, the way in which I consider the indicated silences of each protagonist in relation to other discourses within the novel is essentially the same. When the protagonist's indicated silences occur while no other character is in her presence, I consider what the narrator reveals about her thoughts and feelings during that moment as well as during other moments and what she says during other moments. When the protagonist is being silent in the presence of another character or another character is being silent in her presence, I consider what the narrator reveals about her thoughts and feelings and about those of the other character during that moment as well as during other moments, what she and the other character say around those moments as well as during other moments, and what type of relationship she and the other character have with each other.

In that I approach an understanding of the indicated silences in relation to additional discourses in the novels, as well as to critical commentary, historical background, and biographical information, this study is reflective of Kalamaras's argument about the complementary nature of silence and language. In other words, because the directives-whether they be narrative words and/or punctuation that is used unconventionally--drew my attention to the silences, they allowed me the opportunity to reflect upon the significance of the silences, and the additional textual discourses, both within the novels and outside of them, helped me to posit the significance of the silences. Of course, in thinking about this study, discussing it with others, and writing it, I have experienced the 
complementary nature of silence and language; and, in that this study is a representation of my thoughts and a means by which readers of it may reflect upon them, it, too, is a reflection of the complementary nature of silence and language.

Before beginning my analysis of the novels, I want to address three concerns that I had at the outset of this study. While my primary purpose in doing this study is to contribute to scholarship that challenges the hierarchical opposition which has limited the subjectivities of women (and men) for centuries--Kalamaras points out, for example, that "the West's perception of silence as a negative condition ... can ... [be] trace[d] ... in the theories of Plato and Aristotle" (1)--I realized that, as an American, I have been socialized to think from that perspective. I hope that this self-awareness has enabled me to reduce, if not eradicate, such thinking from my analyses, except, of course, when the silences themselves appear to concern binary thought. In addition, I initially thought that the nature of this study would place me in a paradoxical position: excluding the exposure of silences directly imposed upon women by a patriarchal and racist system, to explore what the protagonist's indicated silences may mean seemed to undermine the reflective value of silence, a type of value that our society has not thought women capable of appreciating. However, I strongly feel that those narrative words and/or unconventional uses of punctuation are directives, and as such, they encourage readers to explore their significance.

Finally, at the same time that I, a white woman, chose to include in my study an analysis of two black women's novels, I recognized the need for black women to define themselves through, for example, their writings as critics as well as authors. Abena Busia's essay, "Words Whispered over Voids: A Context for Black Women's Rebellious Voices in the Novel of the African Diaspora," makes that point very clear, and Minrose Gwin and Barbara Christian's debate in "A Theory of Black Women's Texts and White Women's Readings, or ... The Necessity of Being Other" and "Response to 'Black Women's Texts,"' respectively, well illustrates the troubling nature of white women 
critiquing black women's writing. Nonetheless, a comment made by Audre Lorde, in relation to a theoretical example of a white woman's hesitancy to teach literature by black women, supports my decision to include Hopkins's and Marshall's novels in this study. Lorde says that "where the words of women are crying to be heard, we must each of us recognize our responsibility to seek those words out, to read them and share them and examine them ..." (631). As I have argued, narrative words that indicate protagonists' silences are "words . . . crying to be heard," and I want to explore their significance in novels by black women as well as by white women. 


\section{CHAPTER 1}

\section{SILENCES IN AT FAULT AND THE AWAKENING: LACK OF A SPEECH COMMUNITY 1}

\section{Introduction}

According to my reading of Kate Chopin's two extant novels, At Fault (1890) and The Awakening (1899), ${ }^{2}$ the indicated silences of the protagonists, Therese Lafirme and Edna Pontellier, respectively, draw attention to the image of the Southern lady to which middle- and upper-class Southern white women of the late nineteenth century were especially pressured to conform. While some of the qualities of that image are present in both protagonists' silences, one particular quality manifests itself in each protagonist's silences or, in other words, distinguishes one protagonist from the other. Therese is a woman "'most deeply interested in the success of every scheme which curbs the passions and enforces a true morality"' (qtd. in Scott 4-5), and her silences suggest that she uses silences to sublimate intense emotions and to act according to social principles. Edna, on the other hand, is a woman whose "sensibility and intuition [a]re highly developed" (4), and her silences reveal that she uses silences to feel and to act according to her feelings.

Given our society's tendency to privilege reason over emotion, one might assume that the particular quality of the image of the Southern lady that Therese's silences suggest is superior to the particular quality of the image that Edna's silences reveal, but it is not. Therese no more acts from rational thought than Edna does. In fact, both protagonists' silences draw attention to one of the qualities that they share and that provides a rationale for our society's subordination of women to men: "absence of reasoning capacity" (Scott 4) or, as I argue, undeveloped "reasoning capacity." Just as Therese tends not to use silences to question why certain social principles exist, Edna tends not to use silences to question why she feels as she does. On the rare occasion that either protagonist uses silences to think, she reveals the inability to think with clarity and logic. In that the protagonists have 
been socialized not to "reason," I assume that they have the "capacity" for it, and any reference that I make to the protagonists' inability to "reason," or to think, should be read with that understanding. However, another quality that they share stunts the development of their mental ability: "suffering in silence" (4).

Thus, the protagonists' indicated silences draw attention to the fact that the image of the Southern lady reinforces and reproduces the inferior half of the man/woman, reason/emotion, voice/silence hierarchical oppositions. Indeed, Patricia Yaeger makes related claims about Edna that not only apply equally to Therese but also explain why neither protagonist can use her silences to challenge, successfully, her inferior position: "the heroine's capacities for thought are shut down" (203), "not [because of] her own inadequacy ..., but [her] lack of a speech community that will encourage ... the growth of her thought and its translation into praxis" (215). Without "a speech community"-which, in this late nineteenth-century unabashedly patriarchal and racist society, would almost have to be women--neither protagonist's "thought[s]" will "grow" and "translat[e] into praxis" different from that taught her by the image of the Southern lady.

\section{Critical Response}

Few critics make reference to the indicated silences in Chopin's novels, and none links it specifically with the image of the Southern lady. Although Peggy Skaggs, whose analysis of At Fault is the only in-depth criticism of it, argues that the women characters represent "most of the different possible roles into which Chopin envisions women moving" (73), she does not mention the image of the Southern lady; and, except for noting that one woman character "remains silently in Paris" (74), she does not refer to silences.

Interestingly, three critics of The Awakening make reference to the same indicated silence, but they link it only minimally with Edna's subject position. The scene to which they all refer is the one in which Edna "silently" retrieves her rings, at least one of which is presumably a wedding ring that she wears on other occasions, from her husband, who had pocketed them while she went into the water (Chopin, The Awakening 882). Skaggs does 
not even quote the narrative directive; instead, she says that Edna "wordlessly" retrieves the ring, which, to Skaggs, simply means that, "[1]ike many couples, [Edna and her husband] often communicate without words" (98). Although Nancy Rogers uses the word "silently" when describing Edna's action, she does not quote it, and, about the scene, she simply notes that "little communication takes place between husband and wife" (136). Anna Shannon Elfenbein acknowledges that Edna "'silently"' retrieves the rings, and, in claiming that "[t]he connection between Edna's badge of class, white skin, and her status as a married lady is forged [in this scene]" (309), she more exactly defines Edna's subject position and more clearly suggests a link between it and Edna's "'silen[ce]"' than either of the other two critics does. However, she does not develop that link.

Skaggs as well as Yaeger make reference to additional scenes in which the narrator indicates Edna's silences, and, in some instances, the narrative directives are quoted. Yet, neither critic considers the particular significance of these directives. ${ }^{3}$ Certainly, in comparison with other textual aspects of both The Awakening and At Fault, the directives are few. Their being comparatively few, however, does not make their inclusion insignificant. In fact, the significance of the indicated silences can be traced back to a shift in strategy by the woman suffrage movement, for, at least in part as a result of that shift, the image of the Southern lady was revived.

\section{Biographical Information and Historical Background}

Emily Toth, author of an extensive biography on Chopin, comments that, in 1869, Chopin--then O'Flaherty--highlighted a reference to women's "rights" in her diary "but did not indicate whether she agreed or disagreed with the words" (90). Nonetheless, it is likely that nineteen-year-old O'Flaherty was aware not only of the women's rights movement in the United States but also that it "increasingly referred to itself as the 'woman suffrage movement"' (Evans, Born for Liberty 122). Just weeks before O'Flaherty highlighted that reference, "a delegation of ten women's rights women [that] traveled [from St. Louis, the city in which Chopin was living] [,] to Jefferson City to lobby the legislators" had been 
sent by the "Woman-Suffrage Association of Missouri," which had been formed in St. Louis in 1867 (Toth 88-89).

O'Flaherty might also have been aware that woman suffrage associations were growing out of the imminent failure of the federal government to give women the right to vote and that these associations were developing a new strategy to argue for enfranchisement that related closely with the image of the Southern lady. According to Ellen Carol DuBois, when it became apparent that Congress was going to ratify the Fifteenth Amendment, giving black men but no women the right to vote, leaders of the women's movement shifted their strategy from arguing for enfranchisement of all citizens to arguing for enfranchisement of women in particular (848). In other words, the strategy shifted from sameness between the sexes to differences between them, and, in making this shift, the suffragist leaders used language that mirrored the language of dominant discourses. Just a month before Congress ratified the Fifteenth Amendment, Elizabeth Cady Stanton argued at the National Women's Suffrage Convention, "'[W]hat we need today [sic] in government, in the world of morals and thought, is the recognition of the feminine element ..."' (qtd. in E. DuBois, 849). In that the connection between "'morals'" and "'the feminine element"' that Stanton implicitly made is like the image of the Southern lady "'most deeply interested in the success of every scheme which ... enforces a true morality"' (qtd. in Scott 4-5), it is not surprising that the movement "bec[a]me more compatible with conservative ideas about social hierarchy" (E. DuBois 852).

Indeed, as Marjorie Spruill Wheeler explains, "in the 1890s, a few Southern [white male] politicians favored the suggestion put forward by [white] suffragists ... that they solve 'the negro problem' [black men's right to vote] through woman suffrage" (18), but, when Northern suffragists, such as Stanton, first introduced their strategy of difference by making political the image of the Southern lady, "Southern conservatives insisted that Southern white women continue to play this traditional [non-political] role ..." (7). Of course, "this traditional role" or the ideal of "lady" had been imposed upon women for 
centuries in patriarchal societies, but it especially served to support the slave system crucial to the Southern economy. After the South's defeat in the Civil War and the ratification of the Fifteenth Amendment, it undoubtedly became particularly important to Southern white men to assert their assumed position of political and racial superiority by reinforcing the image of the Southern lady. So important was this image to Southern culture that, as Anne Firor Scott explains, "[f]rom earliest childhood [white] girls were trained to the ideals of perfection and submission" (7), and any Southern lady who challenged the image in a manner that her culture deemed unacceptable was likely to be "unsexed, rejected, unloved ..." (21). More particularly, and undoubtedly because of a combination of ostracization and few employment possibilities, an unacceptably rebellious lady "w[ould] probably starve" (21).

Significantly, especially during the historical moment in which Chopin composed At Fault and The Awakening, middle- and upper-class Southern white women would have been expected to conform to the image of the Southern lady, as evidence about lynchings during the 1890s suggests. Keeping in mind that the increased number of lynchings of black men immediately following the Civil War was based upon the rationalization that Southern white ladies especially needed protection from black men rather than upon the reality that white Anglo-Saxon men feared losing control of the South especially to black men, a subsequent increase in lynchings would suggest that Southern white men were again feeling threatened. Indeed, as Jacquelyn Dowd Hall explains, "through the 1870s and '80s, southern [white] farmers suffered a sustained decline in agricultural prices" (131); and, during the 1890s, when large landowners essentially "forced small farmers off the land" and those farmers "pragmatically allied with blacks," the number of lynchings increased dramatically (131-32). In 1892, "255 persons were killed by lynch mobs," which was, according to a publication that Hall quotes, "'the most staggering proportion ever reached in the history of that crime'" (132). 
Even if seventeen-year-old Kate O'Flaherty did not realize the role that the woman suffrage movement was playing during the latter half of the $1860 \mathrm{~s}$ in leading Southern white males to intensify their efforts to make white women conform to the image of the Southern lady and forty-something-year-old Kate Chopin did not realize that those efforts were again being made during the early 1890s, Kate O'Flaherty, never mind Kate Chopin, certainly understood what was expected of a Southern lady, for she was raised to be one. While Kate's father had emigrated to the United States from Ireland, by the time that she was five years old, "his net financial worth qualified him as one of the 'solid men of St. Louis"' (Toth 30), and his second wife, Kate's mother, came from an "ancestry [that] could be traced back to the earliest days of St. Louis" (29). Years before Kate was born, her "family [had] settled in a large, handsome, two-story southern-style home" (30), and, during Kate's childhood, the family "own[ed] four slaves ..." (30). In 1868, the year before she underlined the words in her diary about women's rights, Kate "entered St. Louis society" (85), and, in 1870, she married Oscar Chopin (100).

In fact, except that, within the first ten years of Chopin's marriage, she bore six children (Toth 128), several parallels can be made between her life and the lives of her protagonists Edna and Therese, whom I argue to be representations of the image of the Southern lady. Toth comments that "[m]ost of Kate Chopin's life during the New Orleans years ... is . . unknown" (125). However, among other basic details, we know that, like Edna, she lived in "New Orleans"; like Edna's husband, Chopin's husband was a "cotton factor[,] . . . the middlem[a]n who sold cotton for the planters" (129); and, like the Pontellier family, the Chopins vacationed on Grand Isle (137). After two bad seasons for the cotton crop, "the Chopins, to save expenses, moved to Natchitoches Parish" (139), the rural area in northwestern Louisiana where Therese lives. Like Therese, Chopin's husband died and left her his estate (159-60). However, there, the parallels end, for, unlike Therese, Chopin "[had not] inherited an unencumbered plantation guaranteeing her support for the rest of her life" (160). 
Given Chopin's upbringing and life as a Southern lady, it may seem difficult to believe that she would, or perhaps even could, write novels that interrogate the image which defined such a lady. However, during her childhood, she was exposed to discourses different from the dominant discourses. According to Toth, by 1863, the year in which Kate O'Flaherty and her best friend Kitty "were separated by war" (51), the girls, "[t]hrough novel-reading, ... [had] learned about women's lives and women writers, few of whom they read in school" (52). That O'Flaherty read those novels is important in itself; that she had been able to discuss them with another girl is also significant. In addition, prior to her maternal great-grandmother's death in 1863, "[f]rom [that woman's] ... [oral] stories, Kate ... discovered that she came from a long line of determined maternal ancestors" (35). That "line" originated in Montreal with a woman who, in 1658, left northern France "to be a 'frontier bride'" (36) and led to St. Louis where O'Flaherty's Catholic great-great-grandmother, "in 1785, obtained a legal separation [from her husband], the first one ever granted in [that city]" (36-7).

Further, within the two years following her husband's death, Chopin made a decision that enabled her to surround herself with discourses different from the dominant ones and that highlights a major difference between her life and Therese's life: she left Natchitoches Parish. More exactly, she returned to St. Louis. There, she "ma[d]e a . . . community of friends ... who read Guy de Maupassant and the latest fiction writers, who questioned established religions, and who devoted themselves to intellectual clubs ..."

(Toth 181). Indeed, within about a year of her return, "Chopin abandoned the [Catholic] [C]hurch" (20)--a most patriarchal institution--which probably would have been difficult to do in Natchitoches Parish since there was "virtually only [one] Protestant in town" (143); and, for about two years, she was a member of the elite "Wednesday Club of St. Louis" (208). Although "Chopin was not an activist" (182), all of her "women friends ... supported suffrage ..." (184). And, not surprisingly, just a few years after her return to St. Louis, "Chopin began writing with a professional career in mind" (175). Toth sums up 
the significance of Chopin's return nicely: "Had she stayed in [Natchitoches], she would not have found her avant-garde circle of writers and journalists; she might never have written for publication" (188).

According to Chris Weedon, to achieve "power and control," one must "challeng[e] ... what constitutes useful knowledge" (14). Since Chopin was one of the thousands of Southern white women who were raised to conform to the image of the Southern lady and, within that training, "w[ere] taught not ... to challenge the wisdom and authority of Southern [white] males" (Wheeler 7), it would take discourses different from those of "Southern males" to "challenge [their] wisdom" or, in other words, "what [they] constitute[d] [to be] useful knowledge" (Weedon 14). I think that, by reading novels about women and by women, listening to stories about ancestors who were pioneering women, and choosing to find friends who "w[ould] encourage the growth of her thought and its translation into praxis" (Yaeger 215), Chopin achieved "power and control" over her own life (Weedon 14). I also think that, through her novels, Chopin encouraged women readers, especially, to achieve the same.

\section{Silences in At Fault}

Ironically, perhaps the story that Chopin's great-grandmother told her about her great-great-grandmother's becoming the first person in St. Louis to have a legal marital separation (Toth 36-7), in part, prompted Chopin to create a protagonist who, as Skaggs notes, "believe[s] that she can, by applying a moralistic formula, prescribe solutions to everyone's problems" (77). Certainly, Chopin's maternal ancestor achieved something which no one before her had achieved in St. Louis, but, "[s]ince divorce was not possible for Roman Catholics" (Toth 36) or, in other words, because it went against "a moralistic formula" (Skaggs 77), she was allowed only to separate and, thus, never to have a culturally acceptable relationship with another man--unless she were to become widowed. Perhaps for that reason as well as because Chopin herself had tired of being expected, as a Southern lady, to encourage "'every scheme which curbs the passions and enforces a true 
morality"' (qtd. in Scott 5), she used indicated silences to draw attention to the fact that, within them, her protagonist "'curbs [her own] passions'" toward a divorced man of the Unitarian faith as well as "'curbs [the man's] passions'" toward her in order to "'enforce a true morality'"--even though the man's ex-wife is an active alcoholic who shows no desire to become abstinent.

Further, perhaps because Chopin imagined how difficult it is to think differently from the dominant discourses without having the input of other discourses, she also used indicated silences to draw attention to the fact that, on the couple of occasions when, within them, her protagonist tries to question the validity of such discourses, she cannot. And, perhaps because Chopin knew, firsthand, how insular northwestern Louisiana was, she did not include in her protagonist's immediate social milieu any woman who could help her to question that validity with any degree of success.

Perhaps through all of these indicated silences combined, then, Chopin wanted women readers, especially, to realize three things: that the image of the Southern lady encourages Southern ladies not to think logically and clearly or, in other words, not to challenge their subject positions; that it requires the encouragement of a more enlightened woman to help a Southern lady to think differently; and that, while such a woman may not be found in isolated areas of the country, she may be found through the pages of the novels that she has written.

Early in At Fault, it becomes clear that Therese manages her own life as well as the lives of those close to her with impeccable adherence to the morals of her culture. Prior to her awareness that David Hosmer is divorced, Therese reveals a romantic interest in him, but, from the moment that she learns that he is divorced, she sublimates her interest to the principle that divorce is wrong. Some months after David opens a lumber business on the plantation that her deceased husband left to her, Therese stops by his office and initiates a flirtatious conversation with him (745). A few days later, when he more than reciprocates her interest by telling her that he would find the rural setting of the plantation unbearable 
should she not be a part of it (758), she is bedazzled. Alone in her bedroom, Therese sits "in a semi-stupor" (761). Later the same day, just before leaving her company, David tells Therese that he loves her (762), and although she has not an opportunity to respond, Therese demonstrates her continuing interest in David by asking his sister, Melicent, about him. Among various pieces of information, Melicent tells Therese that David is divorced. Upon revealing his marital status, Melicent senses "that she had yielded to an indiscretion of speech" (763) in that David apparently had not told Therese himself, so Melicent quickly changes the subject to something having nothing to do with David. In turn, Therese no longer asks questions about David, and, the following day, when David visits her to apologize for having failed to tell her of his marital status, Therese makes clear the withdrawal of her romantic interest in him, saying, "'I had better tell you at once that there must be no repetition of ... what you told me last night [his profession of love for her]'" (765).

As David remains in Therese's company to explain the circumstances leading to his divorce, the narrator indicates three times that Therese is silent. When David describes his view of the circumstances that led to the divorce--in particular, his former wife's alcoholism--"Therese . . . remain[s] perfectly silent ..." (768). After "sa[ying] nothing for a while" (768), she then asks a couple of questions, the latter of which is whether Fanny still drinks. In response to David's affirmative answer, Therese "again bec[o]me[s] silent" (768). Ultimately, Therese tells David that he should do "'what is right"' (769), which, according to the principle that Therese follows, is that he should remarry Fanny.

While one might naturally assume that, during the silences, Therese is listening to his story in order to arrive at a reasoned conclusion, the validity of that assumption is doubtful. More than likely, Therese's silences signify her unconscious adherence to a principle from higher authorities--in this instance, the Catholic Church and the legal system. First of all, Therese's motivation for encouraging David to tell his story functions in a way similar to that of a Catholic confession: "she fancies he would feel better for the 
telling" (766). Further, Therese's listening to David's story and then making a pronouncement about it is similar to a priest's listening to a confessor's story and then reminding the confessor of the principles that a good Catholic must follow, no matter what the circumstances surrounding the confessor's transgression. Significantly, Therese believes that she is thinking for herself, for she tells David that "'religion doesn't influence"' her decision to reject his love but that "'her moral principle'" does (766). However, the narrator reveals that "the prejudices of her Catholic education color[ed] her sentiment [about divorce]" (764), so at least one source of her "'principle'" is a "religion." It is also likely that the legal system, "color[ed] her sentiment." By the turn of the century, as Rosalind Rosenberg explains, "legislators ... reduced the statutory grounds for divorce from four hundred to fewer than twenty" (14), thus sending a clear message to their constituents that divorce was largely unacceptable.

Acting from the Catholic and, undoubtedly, the legal principle that divorce is wrong, Therese not only encourages David to remarry Fanny, but also, after he follows her advice, she supports him by asserting the correctness of his act, which, ironically, prompts him to seek her affections. The first time that David and Therese are alone together after his remarriage, Therese almost immediately affirms her belief that he did what is "'good and right"' (816). By making this reaffirmation, Therese also reaffirms her position as the preserver of morals and the queller of passions. In turn, however, David attempts to regain her romantic interest by eliciting her sympathy. He describes his remarriage as horrific, and he asks her to reveal to him, somehow, her awareness of his misery. At this point, Therese begins to use silence to reinforce the principle and to maintain her distance from him.

Because "Therese th[inks] it best to interrupt the situation" (816) or, in other words, because she thinks she must discourage any further romantic overtures that he makes toward her, she "silently ... prepare[s] to mount her horse" (816). Even though, as David helps her mount, he kisses her hand intimately--palm as well as back--Therese's 
only reaction is to "r[i]de ... in silence ..." (816). Finally, when David not only makes one more attempt to garner her sympathy by indicating that death would be preferable to his remarriage but also makes clear her importance to him for "'moral support," Therese, no doubt feeling an obligation to provide David with such "'support,"' martyrs herself both by withdrawing her recent suggestion that he and Fanny live somewhere other than on her plantation and by intimating that she enjoys his company (817). As though fearing that David might misunderstand her sentiments, however, Therese maintains her preserver-ofmorals position by "sa[ying] no more ..." (817), and they go their separate ways (818).

Thus far, Therese does not seem to question the principle that divorce is wrong, and, when she is confronted with something that challenges the principle, she becomes silent. In this instance, the silence indicates not only that she is "shocked" (835); it also highlights the difficulty that Therese has in dealing with ambiguity. Upon making an unannounced visit to the Hosmer household, Therese finds the front room in total disarray and Fanny, visibly drunk. Therese's reaction to the scene is that "for a while she c[an] say nothing" (835). While it certainly is understandable that a person who has never lived with an alcoholic could not imagine all of its ramifications, David had described a similar scene to Therese the day that he explained the circumstances leading to his divorce. He told her about having "'found Fanny ... lying on the sofa ... look[ing] ... wildly and in striving to get up grasp[ing] aimlessly at the back of a chair"' (768). Thus, upon actually seeing Fanny drunk, Therese may be surprised, but, had she really listened to the story that David told her, she would not have accused him, as she does now, of "'[n]ever telling [her] a word of it"' (836). In this scene, Therese's silence and her comment to David, combined, only lend credence to my point that Therese's silences during the moments that David relates the circumstances of his first marriage do not suggest reasoned reflection but blind adherence to a principle.

When she does try to deal with the ambiguity caused by having seen Fanny drunk, Therese begins to reason, but, ultimately, she cannot get herself to think beyond the 
principle that divorce is wrong or, more broadly, beyond a binary perspective, which is not surprising given her subject position, her religion, and the law. Some days after making her unannounced visit, Therese thinks about Fanny's alcoholism, and she asks herself again and again, "'[W]as I right [about urging David to remarry Fanny]?'" (840). She then begins to consider that the answer may not necessarily be "yes" or "no." As the narrator explains, Therese "had always thought this lesson of right and wrong a very plain one," adding that "[f]or the first time in her life [Therese has] a staggering doubt as to its nature" (840)--that is, its binary quality. Upon having this "doubt," however, she thinks no further and, in fact, feels overwhelmed. "Her inability to unravel it stagger[s] her" (840), and Therese ends her ruminations by returning to the same question with which she began and that by "its nature" requires a yes/no response.

It is not that Therese is intellectually incapable of "unravel[ling]" (840) the principle's binary perspective. To do so, however, she would have to recognize that it is not a principle which she created but a principle of the Catholic Church and of the legal system. In essence, she would have to question the sagacity of those patriarchal authorities whom she, as a Southern lady, had been taught not to question. However, because she now asks herself whether she, not the Church and the legal system, "'was . . right"' (840), Therese apparently does not have that awareness.

Were Therese a member of a community of women who challenged principles or, more broadly, binary thinking, she might well be encouraged to extend her doubt about the principle that divorce is wrong and, at the very least, might choose not to martyr herself further by allowing both the man whom she loves and his wife to continue living under her very nose. However, the only women with whom Therese has frequent contact are her servants, David's wife, Fanny, and his sister, Melicent. Not only because Therese is her servants' employer but also because she, as a member of nineteenth-century, upper-class Southern white culture, probably feels racially as well as socially superior to her servants, it is highly unlikely that she would confide in them and/or think their ideas to be of any 
value. As for Fanny, even if she were not an active alcoholic, Therese would not confide her thoughts about divorce to Fanny and/or consider Fanny's ideas to be without bias; after all, Fanny is David's wife. And even if Melicent were not David's sister, Therese would probably not confide in her and/or consider her ideas to be well-founded since Melicent revealed her own immaturity when, rather than suggest that Therese ask David about his past, she blurted out that he was divorced.

One might argue that Therese could broaden her society of women by joining a group whose very existence challenged the principle that middle- and upper-class white women belonged only in the home. It is true that, during the 1880 s, "Southern women ... became increasingly involved ... in the Woman's Christian Temperance Union and women's clubs" (Wheeler 9), and, in doing so, they "gained new knowledge of conditions beyond the home and a new level of interest and involvement in public affairs" (9). As a result of their "interest and involvement in public affairs," they might even have felt more empowered at home, too. Indeed, because these groups challenged not only the idea that a Southern lady belongs at home but also the idea that, within the home, she is in a position of subservience to her man, "[m]any Southern men and women found these changes in the activities of women profoundly disturbing" (9); but the existence of "these changes" indicates that they were tolerated and, thus, available to women such as Therese.

On the other hand, there are obstacles particular to Therese's situation with which she would have to contend to join a women's club. First of all, women who partook in these "activities" had "the leisure to do so" (Wheeler 9), and Therese's running of a plantation allows her little free time. Further, given the remote location of her plantation, Therese would have to travel several hours to reach an area likely to have women's groups. For example, travel by train between her plantation and New Orleans "[i]s a full day's journey ..." (Chopin, At Fault 869$).{ }^{4}$

While neither of these obstacles is insurmountable, Therese's tendency to think from only one perspective is a major problem. Even to imagine that a women's group 
might give her the pleasure and sense of empowerment equal to, if not greater than, the feelings of pride and control that she gets from being in "her beloved woods" (744), Therese would almost need to develop a close relationship with a woman from such a group or, at the very least, with a woman receptive to the idea of such a group. And, assuming that Therese acquires the desire to become a member of a women's group, her difficulty in reasoning through ambiguity would necessitate that woman's helping her to figure out how to satisfy her desire. Of course, as Chopin did, Therese could move to a cosmopolitan area. She could sell the plantation, or she could have an overseer manage the plantation completely. In neither case, would she compromise her position as a Southern lady. However, since she seldom leaves her plantation, I doubt that Therese can imagine having a lifestyle any different from the one that she has.

Not surprisingly, then, by the conclusion of the novel, Therese is no closer to thinking beyond a binary perspective than she was at its beginning, as one more indicated silence highlights. During the scene in which, by happenstance, she encounters the recently widowed David--Fanny having died by accidental drowning (868)--Therese does not reason from her observation of a change in his appearance. Upon "bec[o]m[ing] silently absorbed by the consciousness of [his] nearness" (871), she notices a new "firmness and fullness of [his] hand" (872). Although this silence reflects Therese's surprise at having met David, it also draws attention to a moment during which, when confronted with evidence that belies the principle that divorce is wrong, Therese does not reason that the principle may be faulty, for this change in the appearance of "[his] hand" suggests that David is healthier now that he is no longer burdened with an alcoholic spouse. Although, almost wryly, the narrator comments that Therese "had not the opportunity to define" the significance of David's changed hand (872), it seems that this silence also draws attention to the likelihood that Therese no longer gives herself even "the opportunity" to doubt the binary nature of the principle. In fact, she does not, as the remainder of the scene confirms. 
In response to David's breaking the silence and declaring what a wonderful wife she would be, Therese reveals herself to be yet rooted in binary thinking. Although she says, "'I have seen myself at fault in following what seemed the only right,"' she ends by asking, "'[D]o you think . . . that it's right we should find our happiness out of that past [David's divorce, his remarriage, and Fanny's subsequent death]?"' (872). "'[W]hat seemed the only right"' suggests that Therese has released herself from the limitations of binary thought, but "'do you think ... that it's right"' negates that suggestion. Further, when David offers a sentiment that, in essence, reinforces binary thinking in that it assumes the validity of the concept of truth and, thus, of the true/false dichotomy, Therese apparently accepts it without question. The scene draws to a close with David saying, "[T]he truth in its entirety isn't given to man to know'" (872), and the final chapter begins with the news that Therese and David are married. Although David's having become a widower frees Therese from grappling with the Catholic principle that divorce is wrong and with the law which implies that divorce is wrong, both her acceptance of David's principle that "'truth in its entirety isn't given to man to know"" and her subsequent marriage to him reveal that Therese is yet relying upon a patriarchal authority to direct her life, an authority who, by definition as well as by instruction, reinforces binary thought and, thus, his wife's . subject position.

The indicated silences in At Fault, then, draw attention to four moments during which Therese, the preserver of morals, conforms to a principle with no apparent, or only limited, thought: the first time, when David tells his story about events leading to his divorce; the second time, when the remarried David entreats her to sympathize with his plight; the third time, when Therese sees Fanny drunk; and the fourth time, when Therese notices a change in the appearance of the widowed David's hand. Although, the third time, she attempts to address the contradiction between the principle that divorce is wrong and the chaos in the Hosmer household, Therese cannot deal with the ambiguity because she cannot think beyond the binary perspective of right/wrong, which sustains her role as 
preserver of morals; and there is no woman in her immediate social milieu who might encourage her to extend her thinking beyond that perspective. At the very least, such encouragement might have led Therese to cease martyring herself by allowing the man whom she loves to live on her plantation with his wife. At best, such encouragement might have led Therese to move to an area where she could receive more encouragement and, before it was too late, discover that men like David Hosmer are dangerous to love because they only reinforce binary thinking.

Thus, the indicated silences in At Fault perform an important function in that they draw attention to a significant limitation inherent in the image of the Southern lady to which middle- and upper-class white women were socialized: the inability to think coherently and rationally and, thus, the inability to imagine a lifestyle that is at least somewhat different from the norm and that might both satisfy the woman in some way and at least be tolerated by her culture.

\section{Silences in The Awakening}

While the inability to think coherently and rationally is repeated within Edna's silences, it may not be as apparent as it is in Therese's silences. The repetition may not be as apparent because Edna's silences also reveal a particular quality of the image of the Southern lady upon which she acts that is more appealing than the particular quality that Therese's silences suggest and upon which she acts: "sensibility and intuition . . . highly developed" (Scott 4). 5 Since the quality that Therese's silences suggest, "[the] tendency to 'restrain man's natural vice and immorality"' (4), is "[l]ess endearing" than other qualities of the image (4), one might think that, from one novel to the next, Chopin altered her protagonist to suit her own preferences, if not to make the protagonist more "endearing" to her readers. However, according to Toth, "by $1890, "$ which was nine years before The Awakening was published, "Chopin was ... no sentimentalist" (188). Thus, she would not have been apt to find Edna's immersion in her own feelings especially attractive. 
Rather, I think that Chopin imbued each of her protagonists with a specific quality of the image because she was dissecting that image.

Further, in that Chopin gave her second protagonist, as well as her first protagonist, not only the "absence of reasoning capacity" (Scott 4) or, as I argue, undeveloped "reasoning capacity," but also the tendency to "suffering in silence" (4), I think that Chopin very much wanted readers to focus on those qualities--more particularly, on the relationship between them. Indeed, the only major difference between Therese's and Edna's uses of their silences when they try to reason is that Therese tries to challenge the validity of a principle and Edna tries to figure out why she feels as she does. Whatever the perspective, the result is the same: failure. On the other hand, unlike Therese, Edna occasionally confides in women in her immediate social milieu, but these conversations do not encourage her cognitive development. Further, although Edna, unlike Therese, lives in New Orleans and, so, has ready access to a society of women beyond her immediate social milieu, she does not seek out that society. Like Therese, Edna does not especially appreciate the society of women; like Therese, she "suffer[s] in silence." At least in part because of her underappreciation of other women, Edna can no better use her silences to think beyond her particular perspective than Therese can use her silences to think beyond her particular perspective.

Despite the similarities between Therese and Edna, because Edna's circumstances are different from Therese's, what Edna has difficulty reasoning about is also different. While, until the end of At Fault, Therese is a widow in love with a divorced, then remarried, man, throughout The Awakening, Edna is the wife of a man who thinks of his spouse as his property. Unlike Therese who is confronted with the notion that divorce is wrong, Edna is confronted with the notion that a wife is the property of her husband. In the opening chapter of The Awakening, as Edna walks toward her husband, Leonce "look[s] at his wife as one looks at a valuable piece of personal property ..." (882). Indeed, during the historical moment of Edna's marriage, husbands, in essence, owned 
their wives. As Rosalind Rosenberg explains, "the marriage contract . . . resembled an indenture agreement between master and servant ... a husband promised to support his wife in return for her promise to serve and obey him" (14). Edna's silences, then, concern the difficulty that she has in thinking about, and dealing with, the contradiction between her feelings of oppression within her marriage and her culture's belief that a wife belongs to her husband.

In two scenes, the first within the first few pages of the novel, Edna becomes silent in conversation with Leonce, and while, during the second silence, she makes an attempt to understand her feelings, during the first silence she makes no such attempt. In this first scene, Edna has just returned from checking on her two children after an inebriated Leonce disrupts her sleep not only to insist that one of them is ill but also to accuse her of neglecting them. After returning from checking on them, Edna "sa[ys] nothing, and refuse[s] to answer her husband when he question[s] her [about the children's health]" (885-86). While, as it happens, this silence apparently serves to protect her from any further immediate criticism by Leonce, it does not help Edna to reason from her feelings. As she sits alone on the porch, crying, she feels "[a]n ... oppression, which seem[s] to generate in some unfamiliar part of her consciousness, [and which] fill[s] her whole being with a vague anguish" (886). Although the silence provides an opportunity for her to think about that "oppression," and despite the fact that "[s]uch experiences as the foregoing [Leonce's criticism of her] [a]re not uncommon in her married life," Edna "c[an]not ... t[e]l[1] why she [i]s crying" (886). Were she able to reason during the silence, Edna might realize that her crying is a reaction to her feelings of oppression and that her culture's belief, reinforced by law, in a wife's obligation to obey her husband contributes significantly to her feelings. However, given that Edna's socialization into the image of the Southern lady includes the teaching that a lady is not to question patriarchal authority, it is not surprising that such thoughts would be "unfamiliar ... [to] her consciousness." 
During a later scene with Leonce, Edna again becomes silent, and, although she realizes that she is angry with him, she does not understand that her anger, like her crying episode, is a reaction to her feelings of oppression. Edna "d[oes] not reply" to Leonce's asking why she is sitting outside late one night (911), a question that, in essence, indicates Leonce's expectation that she go to bed. Upon his subsequent and direct order that she go to bed, Edna "perceive[s] that her will ... blaze[s] up, stubborn and resistant" (912). While, this time, she recalls similar moments in which Leonce had given orders to her, Edna "c[an]not realize why ... she ... yielded, feeling as she ... d[oes] [now]" (912). Reacting to her feelings of anger, Edna uses a defense immediately available to her to deter Leonce from issuing further orders; she tells him that she will not respond to additional edicts from him. As in the previous scene, Edna's use of silence protects her, temporarily, from further retort, but she apparently does not use it to think. While she is aware that her husband's ordering her around makes her angry, Edna does not reason that the anger is a reaction to her feelings of oppression which, in large part, result from her culture's expectation that wives will obey their husbands. In fact, Edna's inability to "realize why" she obeyed Leonce in the past suggests the extent to which her feelings control her thoughts. After all, as a Southern lady, Edna, at some level, must know that it is her duty to obey her husband.

Edna is also silent when she begins to have sexual feelings toward men other than her husband, and while the silences, like Therese's silences, may indicate Edna's automatic adherence to cultural expectations--in Edna's case, that ladies be chaste or faithful to their husbands--they also draw attention to moments during which Edna is only feeling and not thinking about why she may be having those feelings toward those men at those particular times. On the first occasion, Edna and a friend of the family, Robert Lebrun, sit outside her husband's summer cottage. After she responds noncommittally to his asking whether he should remain longer, "[n]either [Robert nor] Mrs. Pontellier speak[s]" (911). During the silence, Edna experiences "the first-felt throbbings of desire," and when Robert utters 
parting words, she "d[oes] not answer him" (911). In addition to the distinct possibility that Edna may be protecting her subject position by not voicing her attraction to Robert, the silences also reflect her not thinking about, but only feeling, "desire."

Concerning this moment of Edna's not thinking but only feeling, although Suzanne Jones does not refer to this scene when noting the animal imagery that Chopin sometimes uses to describe Edna (115-16), the narrator's description of Edna is animalistic, which suggests non-reasoning. Just before becoming silent, Edna observes Robert from a perspective similar to that of a nocturnal animal, such as a cat. Edna "watche[s] his figure pass in and out ... of the moonlight," and, after she remains silent to Robert's parting words, she "[a]gain ... watche[s] his figure pass in and out ... of moonlight ..." (911). Especially since the animalistic imagery frames Edna's silences, it seems as though Chopin wanted to make clear that, during the silences, Edna is feeling but not thinking about anything, including reasons for her attraction to Robert.

One might assume that Edna feels attracted to Robert simply because she is a sexual being, but at least two additional reasons may account for the attraction. First of all, Edna's encounter with Robert occurs not long after the earlier-mentioned scene in which Leonce rebukes her for neglecting their children, so Edna's attraction toward Robert may be as much a reaction to her feelings of oppression as her crying episode and her anger toward Leonce are. Further, just hours before being with Robert, Edna experiences a feeling of empowerment, which, of course, is the very feeling that she lacks in her marriage. More particularly, Edna swims for the first time, and while swimming, she "feel[s] . . . as if some power . . . ha[s] been given her to control the working of her body and her soul" (908). "[F]eeling ... [em]power[ed]," she might become more able to experience her sexuality. It is also quite possible that, through her feelings of attraction to a man who is not her husband, Edna especially feels a sense of "control ... [over] her body and her soul." While her husband, by law, essentially owns her, any man who is not her husband does not, so men such as Robert may be especially attractive to Edna. Although, 
as her silences with Robert highlight, Edna does not think about anything, including reasons for her attraction to him, it seems that her attraction to men not her husband is a reaction to her feelings of marital oppression and, possibly, to a newfound feeling of empowerment.

A few months later, when Edna also begins to feel sexually attracted to Alcee Arobin, a neighborhood rake with whom she has recently gone to horse races, she also becomes silent in conversation with him and for reasons similar to those that explain her attraction to Robert. One evening while her husband and children are out of town, Edna has Alcee stay for dinner. The conversation flows easily until Edna holds his hand lightly to examine a scar on his wrist. At that moment, "[a] quick impulse ... impel[s] her fingers to close ... upon his hand" (959). Sensing her sudden sexual attraction to him, Alcee attempts to take advantage of "her awakening sensuousness" by requesting her company in the near future (959). Edna, however, responds negatively to his several requests, and, ultimately, she "ma[k]e[s] no response" (960). While Edna may be using silence to discourage Alcee from making additional advances that would further compromise her position, she does not also use it to think about likely reasons for her sudden sexual attraction to him, of which there are a few.

First of all, Leonce had recently criticized her, in essence, for not being the type of wife and mother that her culture expects middle- and upper-class women to be. More specifically, he accused her of neglecting social visits intended to benefit his business (932), of failing to oversee their cook (933), and of not spending more time with the children (929). Not surprisingly, when Leonce, as well as their children, leaves town "for a comparatively long stay" (954), Edna is "relie[ved]" (955). She cannot identify "[a] feeling that [i]s . . . very delicious" (955), but it must include a sense of "relief" in not having to hear Leonce's criticisms for a while. Since her entire family is away, the "delicious" feeling may also include a sense of independence similar to that which she felt upon swimming for the first time. However, on this occasion when she may be feeling a 
sense of independence, Robert is not available to her, for some weeks before Leonce and the children left town, Robert went to Mexico for an indefinite length of time (924). Alcee, however, is available, and since Edna has him to dinner within days of her, albeit temporary, independence, it seems that he becomes Robert's replacement as a means for Edna to combat her underlying feelings of marital oppression through her sexuality.

It is likely, then, that Edna's rather sudden attraction toward Alcee results from a combination of the oppression that she experiences within her marriage, her temporary feeling of independence from that oppression, and Robert's unavailability, but Edna thinks about none of that during her silence toward Alcee. At the end of this scene, however, when Edna again becomes silent, she makes some attempt to reason from her feelings, but her thinking is faulty. Upon "ma[king] no response" to Alcee's final entreaty, Edna "fe[e]l[s] . . like a woman who ... . is betrayed into an act of infidelity" (960), and, as she experiences that "fe[e]l[ing]," "[t]he thought ... pass[es] vaguely through her mind, 'What would he think?"' (960). While one might assume that the "'he'" refers to Edna's husband, it does not. As the narrator reveals, Edna "d[oes] not mean her husband; she [is] thinking of Robert Lebrun" (960). That is, this one cloudy "thought" does not concern her husband's response should he discover that, during his absence, Edna had Alcee alone to dinner with her. Instead, she is "vaguely" wondering how Robert would respond were he to know her "infidelity" to him. This notion, of course, makes little sense because Edna does not have a type of relationship with Robert that would allow her to commit "an act of infidelity" against him. Of course, she does have such a relationship with Leonce, and the fact that she does not even consider his response to her actions suggests the extent to which, once again, her feelings control her thoughts.

As becomes apparent during her silence while in a conversation with Mademoiselle Reisz, one of the two women friends whom she has and in whom she occasionally confides, Edna's inability to reason well--more particularly, her inability to make a connection among her feelings of marital oppression, her temporary feeling of 
independence, and her feelings of sexual attraction to both Robert and Alcee--leads her to make a decision that endangers her position in the community. Significantly, the day following the above scene with Alcee, Edna tells Mademoiselle that she will move a couple of houses away from the Pontellier home (962), and while she offers a number of explanations for her decision, Mademoiselle says that her "'reason is not yet clear ..."' (963). Here, Mademoiselle may be trying to help Edna to clarify her thoughts, but, as happens again at the end of this scene, which I discuss later, she does not follow through with that attempt. In response to Mademoiselle's statement, Edna "s[i]t[s] for a while in silence" (963), and, when she finally speaks and it is on a mundane topic, Mademoiselle does not return her to the more serious one.

During this silence, Edna apparently realizes one aspect of her decision to move, for "she ... resolve[s] never again to belong to another than herself" (963). However, she does not think any further than that. Not only does she not consider what her temporary independence from Leonce and her new sexual attraction to Alcee as well as to Robert may have to do with her desire "never again to belong to another," she also does not consider the likely consequences of her move. Edna "d[oes] not know how it would be when he [Leonce] return[s]," and, further, "[c]onditions would some way adjust themselves, she fe[e]l[s] ..." (963). So strong is Edna's "fe[e]l[ing]," it takes precedence over her undoubted awareness of her culture's expectation that wives accept the position of "belong[ing] to another." Predictably, shortly after Edna moves into the house, members of the community react. Adele Ratignolle, Edna's other woman friend, warns her that "'someone was talking of Alcee ... visiting you'" (979), and she urges Edna to have another woman live with her. Edna, however, simply implies that she prefers to live alone, and she apparently thinks no more about it.

Not only does Edna seem to fail to recognize the reality that living alone endangers her position in the community, but she also fails to realize that neither living alone nor having an extramarital relationship, which living alone makes it more possible for her to 
do, will dispel her feelings of oppression. Just hours before the actual move, Edna has a dinner party at the Pontellier house. Even though the party is intended to be in celebration of her move, Edna does not feel gay. Rather, "she fe[e]l[s] ... the hopelessness which so often assail[s] her ..." (972). Apparently, when Edna experiences "hopelessness," which is an aspect of oppression, she thinks about Robert: "[t]here c[o]me[s] over her the acute longing which always summon[s] into her ... vision the presence of [Robert] ..." (972). And, as an earlier mentioned scene reveals, when Robert is not available, Edna turns to Alcee. After the party, Alcee accompanies Edna to her new residence, and she still feels oppressed. Not only does she appear "disheartened" (975), but she also admits that she is "'miserable"' (976). Thus, it seems that Edna's "becom[ing] supple to his gentle, seductive entreaties" (976)--in other words, her having sex with Alcee--is, at least to some extent, an attempt on her part to dispel her "'miser[y]."' However, the last time that she has sex with Alcee, Edna experiences the ultimate oppression, feeling nothing, "n[either] despondency ... nor hope" (989). While one might argue that Edna's "acute longing" (972) would be satisfied by her having an affair with Robert, it apparently would not be.

As the scene that culminates in her last indicated silence reveals, even when Edna anticipates a likely sexual relationship with Robert, her feelings of oppression remain, and she even articulates the reality underlying them. The night that she and the recently returned Robert kiss for the first time, Edna is summoned to comfort Adele through labor and delivery (991-93). Intimating confidence in a continuation of their lovemaking upon her return, Edna says to Robert, "'I shall find you here [in my new residence]'" (993). After the delivery, however, as Edna walks back to her rented house in the company of Dr. Mandelet, a friend of the family, her initial response to his asking whether she will go to Europe with her family reveals the major source of her oppression. Answering Dr. Mandelet's question, Edna first says, "'Perhaps--no... I'm not going to be forced into doing things. I don't want to go abroad. I want to be let alone'" (995). Indeed, a few days prior to this scene, Edna receives a letter from Leonce in which he does not ask her 
whether she would like to go to Europe; he tells her that, upon his return home, "they would get ready for that journey abroad ..." (988).

On the one hand, since Edna's oppression concerns, as she says, "'be[ing] forced into doing things'" such as "'go[ing] abroad"' (995), one might argue that she is reasoning well. However, the remainder of her response to Dr. Mandelet reveals her inability to reason with logic and clarity, and it causes her to silence herself. She says, "'Nobody has any right--except children, perhaps--and even then, it seems to me--or it did seem--'" (995). Significantly, at this point, Edna recognizes the fact that she is not reasoning well, and it is that self-recognition which makes her silence herself. Immediately after referring to "'children,"' Edna "fe[e][[s] that her speech [i]s voicing the incoherency of her thoughts, and [she] stop[s] abruptly" (995).

Edna's "fe[e]l[ing]" that her "thoughts" are "incoheren[t]" (995) or, in other words, lacking in reason, is accurate. However, her reasoning that, at least in part, her children prevent her from "'be[ing] let alone'" (995) is not based upon reality. Because she is of the middle-to-upper class, Edna does not have to spend a great deal of time tending to her children's daily needs. As indicated early in the novel, her two boys are primarily cared for by a nanny. It is "[t]he quadroon nurse," and not Edna, who "button[s] up waists and ... panties and brush[es] and part[s] [their] hair" (887-88). Further, the children themselves apparently demand little of her attention. For example, "[i]f one of the boys ... tumble[s] whilst at play, he [i]s not apt to rush crying to his mother's arms ... ; he would more likely pick himself up ... and go on playing" (887).

On the other hand, since it is true that the society in which Edna lives places great importance on middle- and upper-class white women's maternal role, one might argue that the primary source of Edna's oppression concerns her awareness that her own views about that role do not strictly agree with those of society. In an article appearing in Ladies' Home Journal just a few years after publication of The Awakening, Ex-President Grover Cleveland proclaims that "no [middle- or upper-class white] woman who estimates 
motherhood as less than her highest, holiest function and privilege is fit to be a mother" (3). Yet, Edna seems undisturbed by the fact that she does not consider mothering to be "her highest ... function." With her "mind ... quite at rest ... she c[an]not see the use of ... making winter night garments [for her children] the subject of her summer meditations" (888-89).

Despite Adele's last words to Edna--apparently precipitated by Adele's concern about a scandal should Edna continue to live alone--to "'[t]hink of the children'" (995), it is not they who cause Edna to feel oppressed. Those feelings result from the thought that she initially implies to Dr. Mandelet but then apparently dismisses from her mind: Leonce's "'right,"' as a husband, to "'force [her] into doing things'" (995), which range from going overseas with her family, to checking on their sleeping children, to sleeping with him when she does not desire him.

What Edna's final conversational silence highlights, then, is the extreme difficulty that she has in grasping the reality that the primary source of her oppression is not her children but a culture that vehemently believes in a wife's subjugation to her husband, and it is that lack of reasoning about her condition, which all of Edna's indicated silences highlight, that at least contributes to her decision to end her life. The day after reading a note from Robert, implying his unwillingness to have an affair with her, Edna kills herself. While it may seem that Edna commits suicide because Robert discourages their having an affair, that is not her main reason, as the narrator's recounting of her thoughts the night before her drowning reveals. Although, at first, Edna thinks that "[t]here [is] . . no human being whom she want[s] . . except Robert," her next thought suggests that, to some extent at least, she understands that whether or not she were to have an affair with Robert, her feelings of oppression would remain: "she ... realize[s] that the day would come when he, too, and the thought of him would melt out of her existence, leaving her alone" (999). Edna's final thoughts, however, indicate not only that she fails to understand 
that her children are not the source of her oppression but also that she bases her decision to commit suicide upon her misunderstanding. Immediately after thinking that her "children ... s[eek] to drag her into the soul's slavery for the rest of her days," she thinks that "she kn[o]w[s] a way to elude them" (999). Since the "them" refers to her children, it is they whom she thinks that she must "elude" through suicide.

One might argue that, even if Edna had been able to grasp fully the principal source of her oppression, she would probably have still chosen to kill herself. Yet, had she been aware of that source, she would at least have had the opportunity to deal with it--more specifically, with the ambiguity that would result from her awareness that her culture's expectations that wives will naturally obey their husbands directly contradict her feelings of oppression. Moreover, were Edna to have had women friends both capable of thinking beyond a limited perspective and willing to help her think beyond that perspective, she not only might have realized the major source of her oppression, she might also have considered actions that, at the very least, could have both offered her some constructive relief from her oppression and been tolerated by her culture.

However, neither Adele nor Madamoiselle helped Edna to reason well, if at all. Adele, "the embodiment of every womanly grace and charm" (888), is not someone who could have encouraged Edna to think at all because she, fulfilling in every way the image of the Southern lady, does not like to think. Early in the novel, while she and Edna sit in the shade near the water and Edna offers to describe her train of thought, Adele says, "'It is really too hot to think, especially to think about thinking'" (896). In fact, a few minutes later, when Edna confides in Adele a sense of frightening confusion, saying, "'[S]ometimes I feel . . . as if I were walking . . . aimlessly, unthinking and unguided,"' all that Adele says in response is "'[p]

On the other hand, because Mademoiselle, a musician who lives frugally yet independently, is not a Southern lady, she probably could have helped Edna to clarify her thinking--that is, had Mademoiselle chosen to do so. For example, later in the conversation 
during which Edna tells Mademoiselle that she will move a couple of houses away from her husband (962), Mademoiselle asks her whether she loves Robert. When Edna responds affirmatively, Mademoiselle asks, "'Why do you love him when you ought not to?'" (965), which, with further prompting upon Mademoiselle's part, might have led Edna to think. As an independent woman, Mademoiselle might have been able to encourage Edna to realize that her desire for Robert was not so much a physical attraction as it was a reaction to her feelings of oppression resulting from her culture's belief that wives are their husbands' property. Had she that understanding, Edna might have realized that acting upon her desire would not alleviate but, more than likely, would aggravate her feelings of oppression, for a married woman's being in an affair would eventually remind her of her marital position. With that realization, Edna might have begun to consider other actions that might have at least alleviated her feelings of oppression. However, perhaps because Mademoiselle, a relative recluse, fears that Edna will not visit her again should she discourage Edna from fantasizing about Robert, she "laugh[s]" at Edna's response that indicates her physical attraction to Robert and says, "'Because you do [love him], in short"' (965).

Given the historical moment during which Edna lived, her options for dealing constructively with her culture's restrictions and in a way that her culture would at least tolerate were limited, but options nonetheless existed and with fewer obstacles than Therese had. Unlike Therese, Edna was neither physically isolated from other women nor lacking leisure time. Edna could have, for example, joined the Era Club of New Orleans (Wheeler 51). It even seems unlikely that Leonce would have objected, for, in response to Dr. Mandelet's sarcastically asking him whether Edna belonged to "'a circle of pseudointellectual women," Leonce says, "'That's the trouble ... she hasn't been associating with any one [sic]"' (948). In addition, since Southern suffragists, to further their cause, used an "idea characteristic of their race and class ... that suffrage was not a right of all citizens [black men in particular] but the privilege and duty of those [middle-to-upper-class 
whites] best qualified to exercise it" (Wheeler 101), Leonce might even have tolerated Edna's involvement in the Southern suffrage movement.

Although none of these organizations would have been a panacea for the primary source of Edna's oppression--especially since "[t]he suffragists did not go so far as to suggest liberalization of the strict codes regarding divorce in the South" (Wheeler 88)-Edna's participation in them, at the very least, would have given her an opportunity to listen to and talk with women willing to challenge some cultural assumptions about Southern ladies. Had Edna joined the suffragist movement, she would have been able to participate in its efforts to win "basic legal rights[,] [such as] the right of married women to own and dispose of property [and] to conduct business transactions with all the privileges of single women ..." (79-80).

However, as Leonce's response to Dr. Mandelet indicates, Edna did not "'associat[e]'" with many people (948). More accurately, she devoted a significant amount of her time to thinking about and being with men, which, to varying degrees, any woman socialized to conform to the image of the Southern lady would spend her time doing. Therese does it as well, but Edna does it to a greater extent. As Yaeger argues about Edna, "the concept that most binds her . . . [is] an obsessive attachment to men" (215), which, of course, does not challenge a Southern lady's subject position but, in fact, reinforces it.

Although Yaeger is referring to Edna's "obsessive attachment to men" when she says that it "valoriz[es] ... the masculine" (198), the same can be said of Therese's "attachment to"

David Hosmer. Indeed, because Edna, like Therese, was unable to imagine that relationships with other women can be valuable, she, like Therese, would not have thought about joining a women's group, which might have encouraged her to think beyond her limited perspective. In Edna's case, however, that inability to imagine did not simply preclude her from challenging her subject position; it also led her to kill herself.

The indicated silences in The Awakening, then, perform a crucial function in that they draw attention to six moments during which Edna, in representing that particular 
quality of the image of the Southern lady, "sensibility and intuition ... highly developed" (Scott 4), responds to her feelings with no apparent thought or with limited thought: the first instance, when Leonce orders her to check on her children; the second, when Leonce insists that she come to bed; the third, when she and Robert sit alone together outside the Pontellier cottage; the fourth, when Alcee begins to seduce her; the fifth, when Mademoiselle Reisz says that she does not understand the reason for Edna's decision to move out of the Pontellier house; and the sixth, when Dr. Mandelet asks her whether she will go to Europe.

In the first and third instances, Edna simply feels; she does not try to reason from her feelings. In response to Leonce's drunken badgering of her about her attention to their children's health, she cries without asking herself why she is crying, and a similar scenario is repeated when she is alone with Robert outside her husband's summer cottage. She feels a sexual attraction to Robert but does not consider why she is attracted to him.

During the other instances, Edna thinks about her feelings, but only to a limited extent and, in two cases, in a misdirected way. When Leonce insists that she go to bed, Edna realizes that her anger emanates from his giving her edicts, but she cannot discern why, in the past, she obeyed his edicts. When Alcee begins to seduce her by asking for promises of her future company, Edna recognizes her feelings of sexual attraction to him, but, as with Robert, she does not consider reasons for them. In addition, while feeling attracted to Alcee, she recognizes her feelings of unfaithfulness, yet she thinks that she is being unfaithful to Robert, not to her husband, the man to whom she pledged fidelity. When Mademoiselle Reisz expresses confusion about Edna's reason for moving, Edna realizes that she does not want to be a possession of any man, but she fails to consider how her move will affect her position in the community. And when Dr. Mandelet asks her about her plans for going to Europe, while she at first alludes to the major source of her feelings of oppression--Leonce's prerogative, as her husband, to rule over her--she 
erroneously concludes that her children oppress her, and she decides to commit suicide based upon that conclusion.

\section{Conclusions}

Keeping in mind my argument that both protagonists' indicated silences draw attention to a major limitation inherent in the image of the Southern lady, "absence of reasoning capacity" (Scott 4) or, as I would phrase it, undeveloped "reasoning capacity," the order in which Chopin wrote her novels suggests to me that she became increasingly concerned with the possible ramifications of that limitation. While her first protagonist's, Therese's, undeveloped ability to reason leads her only to martyr herself to a principle of the dominant discourses and, then, when it becomes possible for her to do so without violating that principle, to marry a man who reinforces and reproduces the binary perspective driving those discourses, her second protagonist's, Edna's, undeveloped ability to reason leads her to kill herself. Indeed, since Edna kills herself, I find the title of Chopin's second extant novel, The Awakening, most ironic.

In her silences, Edna, no more than Therese does in her silences, "[a]waken[s]" to the realization that, to deal with the ambiguity resulting from the conflict between her feelings and the feelings that the dominant discourses essentially tell her that she should have, she needs to hear and/or read discourses different from the dominant discourses. According to the Catholic Church as well as civil law, Therese should not feel romantically toward a divorced man because divorce is wrong; according to civil law as well as the Church, Edna should not feel oppressed by her husband's controlling attitude toward her because male domination is right. Because neither protagonist can reason, not only can she not deal with that ambiguity, but also she cannot perceive the value in listening to and/or confiding in women capable of encouraging her to challenge the dominant discourses, which is, of course, another way of saying that Southern ladies are "given to suffering in silence ..." (Scott 4). 
If the possible ramifications of "suffering in silence" (Scott 4) were not deadly, I might find the idea that that quality of the image of the Southern lady "endear[s] her to men" (4) mildly amusing. However, since neither Therese nor Edna can use her silences, at the very least, to imagine ways of coping with her subject position and, at best, to find ways of challenging that position, I find that idea loathsome. And, since both Therese's and Edna's indicated silences draw attention to the fact that they cannot use their silences to help themselves, I think that Chopin found the idea loathsome as well.

Indeed, given that the indicated silences of Chopin's protagonists draw attention to the protagonists' undeveloped ability to reason, it seems to me that Chopin was trying to help women readers question the image of the Southern lady. In other words, I think that, through the silences, Chopin was attempting to be for women readers what the women writers whom she had read as an adolescent were to her and what her storytelling greatgrandmother was to her but what neither Therese nor Edna had and what neither one of them could imagine the importance of having: "a speech community that will encourage ... growth of thought ... and ... translation into praxis" (Yaeger 215). Interestingly, since the only way in which Chopin can be "a speech community" for today's readers is through language that is usually read silently, it supports George Kalamaras's argument that "silence and language act in a reciprocal fashion in the construction of knowledge" (8).

Perhaps not surprisingly, the importance to women of such a "community" (Yaeger 215 ) is a primary issue in the two novels by Pauline Hopkins, a contemporary of Chopin, examined in my next chapter; and, in varying ways, indicated silences play a direct role in making an argument for the importance of that "community" as well as for the "reciprocal" nature of "silence and language" (Kalamaras 8). 


\section{CHAPTER 2}

\section{SILENCES IN CONTENDING FORCES AND WINONA: WHAT A DIFFERENCE A SPEECH COMMUNITY ${ }^{1}$ MAKES}

\section{Introduction}

In Pauline Hopkins's Contending Forces: A Romance Illustrative of Negro Life North and South (1900) and Winona: A Tale of Negro Life in the South and Southwest (1902), ${ }^{2}$ as in Kate Chopin's At Fault and The Awakening, the indicated silences of the protagonists concern the image of the Southern lady. However, because Hopkins's protagonists are of mixed race, or black, their silences concern both the image of the Southern lady, the subject position which they desire but cannot occupy, and the Other, the subject position which they do not desire but occupy. Thus, their indicated silences draw attention to thoughts and feelings they have as a result of their inferior positioning in a series of hierarchical binaries: Southern lady/Other, quiet/loud, beautiful/ugly, moral/immoral, and, inextricably linked with that latter opposition according to the racist as well as patriarchal society which created these positions, pure/impure.

This dominant society would never have recognized any of Hopkins's protagonists as a Southern lady, but, because that was the privileged position, the protagonists compare themselves to it. For the most part, what each protagonist thinks about and what she feels during her indicated silences depends upon how she does not meet the qualities of the image of the Southern lady. Sappho Clark, one of the two protagonists of Contending Forces, and Winona look white. However, because both of them have been raped, they dwell upon the belief that they are immoral. Dora Smith, the second protagonist of Contending Forces, has never been raped. Yet, because she does not look white, she dwells upon the belief that she is ugly. No matter upon which belief the protagonists dwell, they feel shame. Thus, although their reasons are different, like Chopin's 
protagonists and the image of the Southern lady which Chopin's protagonists represent, Hopkins's protagonists "[a]re given to suffering in silence ..." (Scott 4).

Before Winona is raped, she uses her silences to challenge her position as Other, but, once raped, she cannot sustain that resistance. Indeed, like Chopin's protagonists, the extent to which Hopkins's protagonists reject the racist and sexist ideology underlying their position and the hierarchical opposition which drives that ideology depends upon the "speech community" available to them (Yaeger 215). Unlike Chopin's protagonists, Hopkins's protagonists, at one time or another, have that "community"; and that "community" is older women of color. Further, except in Winona's case, the way in which those women help the protagonists is through silence as well as through "speech." Once again, then, George Kalamaras's claim that "silence and language act in a reciprocal fashion in the construction of knowledge" is validated (8). While Winona loses her "community" (Yaeger 215), Dora and Sappho do not; and, while Winona does not stop feeling ashamed of herself, Dora and Sappho do.

\section{Critical Response}

Since Contending Forces and Winona were not reprinted after their initial publications until Henry Louis Gates, Jr., resurrected them and Oxford University Press published them in 1988 (Gates xvi-xvii, xix-xx), only a few critics have examined them, and none refers to the indicated silences. Compared with Contending Forces, Winona has received less attention from critics, at least in part because it has been viewed as less contentious about, and more conventional toward, race and/or gender issues. In 1985, Claudia Tate argued that while Contending Forces is "very sensitive to the racial issues of $1900 "$ and "[w]omen's issues [are] central to [its] argument," Winona is "essentially an escapist, melodramatic romance" in which women's issues are "abandoned entirely" ("Pauline Hopkins" 61). In 1987, Hazel Carby made a similar assessment of both novels. She concluded that Contending Forces is "the most detailed exploration of the parameters 
of black womanhood" but that Hopkins's other novels, Winona included, reflect "the more popular conventions of womanhood" (Reconstructing Womanhood 144).

Since their initial assessments of Winona, Carby's position has not changed, but Tate's has, twice. Ironically, in the introduction to The Magazine Novels of Pauline Hopkins, of which Winona is one, Carby does not even mention Winona; instead, she focuses on one of the male characters (xlii-xliii). According to Tate's second reading, however, Winona concerns women's issues. Referring to "black women's postbellum sentimental fiction written by such writers as .. . Pauline Hopkins," Tate implies that, "as women's texts[,] ... they ... appropriate the conventions of sentimentality to mask the heroine's growing self-consciousness ... and ... desire to redefine feminine propriety" ("Allegories of Black Female Desire" 103). Upon a third reading, Tate begins to shift the focus from Winona as concerning a black woman to Winona as concerning blacks. She begins by arguing that Hopkins sought "to incite the reader's sympathy for the virtuous mulatta heroine and scorn for those harboring racist viewpoints who threaten the heroine's happiness" (Domestic Allegories 200), but she concludes that "Winona invites an interrogation of turn-of-the-century so-called civilized attitudes about black people" (201).

I do not disagree with the latter half of Tate's claim about Winona, but I think that she tends to downplay, or not to develop, issues particular to the protagonist and, thus, to black women. Indeed, in her third reading of both Winona and Contending Forces, Tate does not seem to explore fully how the protagonists' position as Other may factor into their implied silences. About Sappho's speaking privately but not publicly about her feelings concerning sexism and racism, Tate contends that "Sappho endorses perhaps unwittingly the ideology of female reticence" and that "[such] strategies allow Hopkins to respect the ... patriarchal gender conventions ... [and] to demand that the reader ponder the ... possibilities of an enlarged social sphere for women" (Domestic Allegories 165). About the fact that Hopkins's serial heroines, including Winona, "seldom speak," Tate claims that "Hopkins seems to have silenced the discourse of female agency," and Tate implies that 
Hopkins's "silenc[ing]" of Winona "calls attention to dissolution of the 'heroine's text' of black female authority as an effective strategy for stimulating social reform ..."(208).

Again, I do not necessarily disagree with all aspects of Tate's readings, but I think that she does not carry her ideas far enough, or articulate them specifically enough, and, in some instances, consider other possibilities. I do not think that Sappho's "reticence" can be attributed only to the fact that she is a "female," and I do not think that Hopkins would have used Sappho's "reticence" to make her audience "ponder ... an enlarged social sphere for women" in general (Tate, Domestic Allegories 165). I also do not think that Winona's infrequent "spe[ech]" necessarily suggests Hopkins's "silenc[ing of] the discourse of female agency" or, more largely, "dissolution of the 'heroine's text'.. . as an effective strategy for stimulating social reform ..." (208). Indeed, I think that Hopkins used indicated silences to "stimulate ... reform," and not simply "social reform" but race "reform." I do not think that Tate would disagree with Barbara Smith's contention that "both sexual and racial politics and Black and female identity are inextricable elements in Black women's writings" (174), but, overall, I think that she does not make that point clear throughout her analyses of Hopkins's novels.

\section{Biographical Information and Historical Background}

It is an understatement to say that there is no definitive biography on Hopkins yet. However, the information available suggests to me that, although Hopkins lived in the North and identified with middle-class values, she was aware of, concerned about, and unwilling (if not unable) to deny the dominant culture's attitude toward, and treatment of, blacks--women especially--in the United States as well as people of color in countries around the world.

Much about Hopkins's background indicates that she enjoyed a middle-class lifestyle, if not a middle-class income, and that she was not only aware of, but also interested in, black history, both in the United States and elsewhere. Although "Hopkins was born in Portland, Maine, in 1859[,] . . . [h]er family moved to Boston" shortly 
thereafter (Campbell 183). Her "father was a Virginian who migrated north" (183)-whether he had been a slave is apparently unknown--but "[h]er mother was a descendant of ... [men] who founded Baptist churches in Boston" (183). In Boston, Hopkins "attended public schools ... [and] graduated from Girls High School" (183). In 1880, "[t]he Hopkins'[s] Colored Troubadours performed [Pauline's play, Slaves' Escape: or the Underground Railroad] in Boston[,] . . a and Hopkins herself . . played a central role" (183). She, along with her family, "also gave concerts in the Boston area ..." (Yarborough xxix). During the 1890s, Hopkins lectured publicly "on [a Haitian general and liberator] and other topics," and she worked as a stenographer (xxix). After the newly created Colored American Magazine published one of her short stories in 1900, "Hopkins quickly became one of its chief contributors," and, from 1903 to 1904, she "serv[ed] as literary editor" (xxix).

While all of the above biographical details indicate Hopkins's enjoyment of a middle-class lifestyle and her awareness of, as well as interest in, black history, two particular events in her life suggest to me both her concern about, and her unwillingness (or inability) to deny, the dominant culture's assumption that black women are inherently immoral. In an April 1904 issue of the Colored American, Hopkins refers to that assumption as "'a most malicious slander, an outrage against a worthy class of citizens ..." (qtd. in Yarborough xxxii). Interestingly, after that April 1904 issue, "Hopkins's name no longer appears as literary editor ..." (xlii). Richard Yarborough, from whose introduction to Contending Forces I have drawn some of this biographical information, does not make a connection between the publication of Hopkins's article and her sudden disappearance from the magazine. However, he does suggest that "Hopkins . . . found her own political views in conflict with those of the new regime at the Colored American" (xliii), a "new regime" whose "primary source of support was Booker T. Washington" (xlii), one of the great compromisers in black American history. Indeed, of Hopkins's sudden disappearance from the staff, W. E. B. DuBois had said, "'It was suggested to the 
editor, who was then Miss Pauline Hopkins, that her attitude was not conciliatory enough'" (qtd. in Yarborough xliii).

Why Hopkins may have been "'not conciliatory enough"' about such issues as the "'slander"' against black women (qtd. in Yarborough, xliii and xxxii) can be understood by examining the treatment of black men by Southern white culture in the decade leading up to her severance from the Colored American, for that culture's treatment of them reflects directly upon the attitude of white culture as a whole toward black women. According to Paula Giddings, "beginning with ... Mississippi in 1890, all the southern states were ... disenfranchising Blacks [men, that is]... [S]egregation was becoming the rule, and violence toward Blacks [men in particular] was on the increase" (25). In comparing the number of lynchings in the South with the total number of lynchings in the United States between the 1890s and the 1920s, Jacquelyn Dowd Hall concludes that "[l]ynching had become virtually a southern phenomenon and a racial one" (133). Interestingly, in an 1895 report on lynchings from 1892 through 1894, Ida B. Wells says that "nearly a thousand, including women and children, have been lynched ..." (88). Apparently, however, black men were the most frequent targets.

Because Hopkins lived in Boston, she was not directly affected by lynchings in the South, but, as she says in the preface to Contending Forces about "a fresh outbreak" of lynchings in the South (14), "the old ideas [of antebellum Southern racism] . . . in new forms ... force the whole republic to an acceptance of its principles" (15). A primary "principle" of racism was the belief about black sexuality--of women as well as men--and this belief was the primary justification for the denial of black men's right to vote, as well as for the lynching of them: the belief that blacks were sexually insatiable and, thus, incapable of upholding moral standards. As an educated woman working in the media, Hopkins had undoubtedly heard about the infamous argument made in 1890 by Frances Willard, president of the Woman's Christian Temperance Union, against the enfranchisement of black men. Hopkins may have even read Ida B. Wells's detailed 
account of it in the 1895 publication to which I refer in the previous paragraph. Within the argument, Willard alludes to the belief that blacks are sexually insatiable by saying that "'[t]he colored race multiplies like the locusts of Egypt"' (qtd. in Wells 84).

Indeed, white suffragists used the dominant culture's belief about black sexuality that Willard used to argue for disenfranchisement of black men, and, in using that belief, they implicitly argued against the enfranchisement of black women as well as of black men. Marjorie Spruill Wheeler suggests that at least some turn-of-the-century white suffragists of the South, especially, were more angry that black men had been enfranchised in the late 1860s than they believed that black women should not vote, but, as she notes, "most were willing to use racist arguments to promote woman suffrage ..." (101). It is important to keep in mind that after the Civil War, white suffragists argued that women should vote not simply because they were human beings but specifically because they were inherently moral (E. DuBois 849). Some white Southern suffragist leaders, such as Belle Kearney, used that same argument in an inverse way and to the detriment of black women. In a book published in 1900, the same year in which Contending Forces was published and just two years before the publication of Winona, about blacks, Kearney says that they "'leave their deadly, immoral trail wherever massed in large numbers'" (qtd. in Wheeler 103).

Hopkins undoubtedly knew that black women were affected by this belief in black "'immoral[ity]"' (qtd. in Wheeler 103) not only in terms of enfranchisement but also in terms of white men's sexual abuse of them. Upon commenting about a white man's sexual harassment of Harriet Jacobs, author of Incidents in the Life of a Slave Girl: Written by Herself, Patricia Hill Collins makes clear how Jacobs's experience was relevant to all black women: "fair skin made her physically attractive to white men[,] [b]ut the fact that she was Black, and thus part of a group of sexually denigrated women, made her available to white men as no group of white women had been" (81). In fact, white culture held the belief that black women seduced white men. Referring to this belief as "[t]he image of Jezebel," Collins explains that it "provide[d] a powerful rationale for the widespread sexual assaults 
by white men typically reported by Black slave women ..." (77). Although the institution of slavery had ended before the turn of the century, attitudes toward black women had not. Within Willard's argument against the enfranchisement of black men, she claimed that "'[t]he safety of woman ... is menaced in a thousand localities at this moment ..."' (qtd. in Wells 84). When she said "'woman,"' she meant white only, for implicit in the sexuality-immorality belief was the assumption that black women would not feel "'menaced'" by any sexual approaches.

As Hopkins's April 1904 article in the Colored American and her sudden disappearance from its staff suggest, she had been unwilling to deny the ramifications for black women of the sexuality-immorality belief about blacks in United States, so, despite whatever conflicting feelings she might have had, she must also have been unable to deny the ramifications for black women of England's contemporary colonization of countries populated by blacks. On the one hand, a segment of the religious and journalistic leadership in England had supported both the abolitionist cause and the anti-lynching campaign. ${ }^{3}$ In fact, black American intelligentsia had spoken highly of England and some of its Englishmen. About her initial trip to England, Harriet Jacobs comments, "For the first time in my life ... I was treated according to my deportment, without reference to my complexion" (183). Relating the account of a black priest who left the United States because white clergymen treated him prejudicially, W. E. B. DuBois says that upon "wander[ing] across the sea, a beggar with outstretched hand," the priest was greeted by "Englishmen [who] clasped them" (360).

Nonetheless, by the end of the nineteenth century, "more than half of the land area of the world"--including several African countries--"had been brought under the British flag" (Burns 670), and, if Hopkins understood the underpinnings of the United States in relation to its black women, she must have understood the same about England in relation to black women in its colonies: "to exercise power, elite white men ... manipulate ... 
symbols concerning Black women.... These ... images are designed to make racism [and] sexism ... appear to be natural ..." (Collins 68).

\section{Silences in Contending Forces}

Apropos of the "images" or "symbols concerning Black women" to which Collins refers (68), Barbara Christian claims that "until the 1940s, most black women fiction writers ... refut[ed] ... the negative images imposed upon all black women, images decidedly 'masculine' according to the norms of the times" ("Trajectories" 235). Of Frances Harper and Jessie Fauset, Christian says that "[t]hey constructed their heroines to refute those images ..." (235). In other words, then, "most black women fiction writers" created protagonists who were "decidedly '[feminine]' according to the norms." Other critics have made similar arguments, ${ }^{4}$ but Christian attaches a qualification to her claim that I think is important to consider for anyone examining literature by pre-1940s black women. She says that "the writers emphasize[d] the self-directedness of their heroines, as well as their light-skinned beauty and Christian morality" (235-36). Offering an explanation for the contradiction, she suggests the writers "believe[d] that if Afro-American women were to achieve the norm, they would lose important aspects of themselves" (235).

Overall, my reading of Contending Forces (as well as Winona) is in agreement with Christian's argument. As Christian claims of Harper's and Fauset's "heroines," Hopkins's Dora and Sappho, in some ways, "refute those [negative] images" of black women ("Trajectories" 235). Dora is the embodiment of "Christian morality" (235-36), and Sappho is a "light-skinned beauty" (235). However, in that Dora is not "light-skinned" and Sappho, "according to the norms of the times" (235), is not "moral," neither protagonist completely "refute[s] those images." Nonetheless, in that both Dora's and Sappho's indicated silences draw attention to moments during which they feel shame in their failure to "achieve the norm," I think that Hopkins wanted her readers, black women in particular, to realize that, in comparing themselves to "the norm," they "lose important 
aspects of themselves" (235). In other words, I think that Hopkins used indicated silences to "emphasize the [need for] self-directedness" (235).

While Christian has helped me to make sense of Dora's and Sappho's indicated silences, my reading of other women characters' indicated silences in Contending Forces is in complete disagreement with another claim that she makes. Christian contends that pre1940s black women writers assigned motherly characters insignificant roles to deflect "'the black mammy'" stereotype (Black Feminist Criticism 225). Yet, the indicated silences of older black women, one a mother and the other a mother figure, draw attention to the fact that their silences allow Dora and Sappho to express their feelings of self-shame. Once Dora and Sappho have expressed their feelings, the older women offer comfort and guidance, and Dora and Sappho eventually accept themselves for who they are rather than what dominant discourses dictate that they are. In effect, then, the initial silences of the older women make it possible for Sappho and Dora to challenge successfully the hierarchical oppositions that define them as Other or, in other words, to become "selfdirected" (Christian, "Trajectories" 225).

The first indicated silence between Dora and Sappho occurs as they converse about men in Dora's life. During an afternoon that Dora and Sappho spend together, they devote a portion of that time to discussing Dora's feelings about her fiance, John Langley, and more generally, her thoughts about marriage. The conversation then shifts to Arthur Lewis, a childhood friend of Dora's. Noticing Dora's happy countenance during her recollection of times with Arthur, Sappho playfully says, "'Ah, yes; I think I understand. Poor John!"' (124). Dora "testily" retorts, "'John's all right. Don't shed any tears over him'" (124). At that point, "[t]hey s[i]t awhile in silence ..." (124). In essence, then, Dora "silence[s]" Sappho or, more accurately, Dora silences further discussion about John. When the conversation resumes, John is not mentioned again.

It is possible that the silence between Dora and Sappho involves a mutually recognized difference in social status, a difference which might define the limits of their 
conversations. Dora manages the rental of apartments in her mother's home, and Sappho is one of her tenants. Sappho earns a living by typing, which, later in their conversation, Dora intimates to be a less desirable occupation than teaching (127). Thus, it is possible that Dora feels a tenant should not jest about her fiance and Sappho intuits her feelings. When Sappho resumes their conversation, she discusses Arthur, not John (124); and she jests no more.

The difference in social status between Dora and Sappho may account, in part, for Dora's silencing further discussion about John. However, it more definitely involves Dora's fear that John will find Sappho to be more attractive than she, a fear that may have been provoked by Sappho's innocently teasing Dora about her physical appearance. Prior to their shared silence, and upon discovering that Dora has brought a portion of cream pie, Sappho exclaims, "'That's the fourth time this week. ... You'll be as fat as a seal, and then John ... won't want you at any price"' (119-20). Dora "laugh[s]" in response, but she does so "guiltily" (120), which suggests that her weight does concern her. Dora makes a lighthearted retort to Sappho's saying that the bonbons which Dora removes from her pocket will produce "'forty inches about the waist and only scraggy snags to show ... when you grin'" (120). However, the idea that John might find her to be unattractive has already been placed in Dora's mind, and Sappho's comment about "'scraggy snags"' might only intensify that idea.

Dora is already quite jealous of John's feelings for other women. As she tells her mother on an earlier occasion, "'I'd just drop John ... if I thought he admired any woman more than he did me'" (89). That revelation occurs during a conversation in which Dora describes Sappho as being "'the prettiest creature I ever saw"' and then says that "'all the men in this house will be crazy over her"' (89). In that context, then, it is likely that when Sappho teases Dora about her potential unattractiveness and then about John, Dora silences further discussion about him because she begins to perceive Sappho not only as a potential rival for his affections but also as a likely winner of them. 
Dora's envy of Sappho's physical appearance becomes obvious in a subsequent conversation between Dora and her mother, Mrs. Smith, and the conversation occurs after Mrs. Smith remains silent. Dora tells Mrs. Smith that she is in a foul mood but "'can't tell why'" (179). Mrs. Smith "sa[ys] nothing ..." (179). Dora and her mother share the same social status, and Dora probably does not view her mother as a sexual competitor. Probably for the latter reason especially, Mrs Smith's silence, unlike Sappho's silence, allows Dora to explore her feelings through a combination of her own silence and verbal interchange. "After a silence," Dora asks her mother why Southern blacks (as John is) do not like Northern blacks (as she is), adding that "'mere accidental locality"' seems irrelevant (180). She also says that she senses John's parents would prefer his marrying a Southern woman (as Sappho is) (180). Upon Mrs. Smith's suggestion that Northern blacks' animosity and John's parents' preference may be Dora's fantasy, Dora "d[oes] not reply, and after a moment's silence [she] continue[s]," saying that John thinks Northern women are unattractive and Southern women, attractive (180). After a few words of comfort from her mother, she exclaims, "'Oh, I do wish I was handsome like Sappho Clark! All the men are wild over her'" (180). With her mother's guidance, then, Dora moves from focusing on what Southern blacks in general and the Langleys in particular may feel to what she herself feels about Sappho's beauty and popularity with men.

It is not until later in the novel that Dora begins to understand that the source of her feeling less attractive than Sappho does not concern weight but, rather, the reality that Sappho meets the beauty standards of white women more than she does. However, the "'mere accidental locality"' to which Dora refers when puzzling over her sense that Southern blacks do not like Northern blacks (180) has everything to do with the fact that Sappho looks more white than she does. White men of the South, especially, had been forcing themselves on black women for well over a century. It is no wonder, then, that Sappho, a Southerner, is "fair, with hair of a golden cast" (107) and Dora, a Northerner, 
has a "brown face" and "dark-brown hair" (80). Thus, unbeknownst to Dora, her phrase, "'handsome like Sappho,"' actually means white-looking.

Despite Dora's unawareness that her feelings of physical unattractiveness result from living in a society that functions according to hierarchical and racist oppositions, she is nonetheless correct in assuming that many black men, such as John, would think that Sappho is more attractive than she because they, too, are influenced by those oppositions. In a debate conducted around the historical moment that Hopkins wrote Contending Forces, a black male editor commented that "'Black men who clamor most ... for the purity of Negro blood have taken themselves mulatto wives'" (qtd. in Giddings 115). Thus, Carby's contention that Hopkins included people of mixed race in Contending Forces "to emphasize those sets of social relations and practices which were the consequence of a social system that exercised white supremacy through the act of rape" (Reconstructing Womanhood 140) seems accurate. Collins's claim that "externally defined standards of beauty affect Black women's self-images, [their] relationships with one another, and [their] relationships with Black men" (80) also seems accurate.

All of these related views are borne out by a conversation among Dora's women neighbors. One woman in the group announces that she will no longer deliver eggs to the house of their minister, whose wife "'is too white fer me'" (187). Although "'too white"' could refer to something other than physical appearance--such as educational background, behavior, manner of dress--the very next statement the woman utters indicates that she will no longer make deliveries because the minister married a white-looking black woman. She says, "'Can't tell what is the matter with these colored men; a good wholesome-lookin' colored woman with kinkey hair don't stan' no livin' chance ter git a decen'-lookin' man fer a husban' "' (187). Several others in the group murmur agreement with the woman. In essence, they agree about a number of things: that a woman who "'look[s] colored"' is "'wholesome,"' not pretty; that she is no competition for a woman who looks "'too white'" 
or, in other words, pretty, not "'wholesome"'; and that the woman who looks "'too white"' and, even more, the "'colored m[a]n"' who marries her are to be shunned.

Based upon her feelings of envy toward Sappho, Dora might also choose to shun the light-skinned Sappho, were it not for her mother's initial silence and her subtle but firm additional guidance. That is, largely because Mrs. Smith initially refrains from speaking, Dora ultimately expresses her own feelings, which makes it possible for Mrs. Smith to redirect her thoughts. Upon Dora's expressing envy of the attention that Sappho gets from black men, Mrs. Smith attempts to diffuse that envy by asking, "'[Y]ou don't harbor hard feelings against Sappho on that account, do you?'" (180-81). At first, Dora responds, "'Sappho is the best and dearest girl on earth ..."' (181). However, she then expresses a wish for Sappho to marry soon because "'there won't be a blessed man left to us girls if she remains single long'" (181). Undoubtedly realizing that her daughter is yet envious of Sappho, Mrs. Smith concludes their conversation by addressing, albeit indirectly, the source of Dora's envy. Upon warning Dora, "'Don't allow jealousy to lurk in your heart,"' Mrs. Smith adds, "'And I would have you remember, also, that sectional prejudice has always been fostered by the Southern whites among the Negroes to stifle natural feelings of brotherly love among us'" (181).

Why Mrs. Smith neither defines "'sectional prejudice'" (181) nor makes explicit the connection between it and Dora's "'jealousy'" (181) is unclear, and any number of explanations may account for it. As seems true of her women neighbors, Mrs. Smith may not understand that a means by which whites "'fostered'" (181) intraracial tension among black women was to make white women the standard-bearers of beauty. She may fail to be specific and explicit in her final comment to Dora for the same reason that she failed to concede Dora's suspicions about Southern blacks' animosity toward Northern blacks and their preference for Southern women. That is, Mrs. Smith may prefer to believe that "'surely we [all blacks] have outgrown such ideas ..."' (180). Or her failure to be precise about an ugly topic may be a reflection of the mores of her middle-class status. 
Whatever the reason for Mrs. Smith's only general explanation, it apparently enables Dora to remain friends with Sappho. However, a silence of indefinite duration now exists between them regarding John's attraction to Sappho, and they cannot resolve it together. As the narrator explains, "[t]he two girls ... fe[e]l restrained in their intercourse because, although by tacit consent nothing [i]s said of John's treacherous conduct toward Dora, each kn[o]w[s] that the other ha[s] discovered it" (303). While the direct reason for this silence is clear--"because ... each kn[o]w[s] that the other ha[s] discovered [John's obsession with Sappho]"--the underlying reason is not clear. As with their earlier silence, it is possible, though not especially probable, that Dora's and Sappho's "tacit consent" not to speak of John concerns their unequal social statuses. More likely, both young women feel that such a discussion, at best, would be very uncomfortable and, at worst, could lead to an end of their friendship. Furthermore, they may feel that having such a discussion would not be likely to effect a change in John's attitude toward either one of them.

However, Mrs. Smith's comment to Dora about "'sectional prejudice"' (181) apparently enables Dora to ponder further her feelings about John, as well as to remain friends with Sappho. Dora "resent[s] the wrong done herself [by John], although as yet she c[an] hardly put her thoughts into words" (304). More than likely, what Dora "as yet ...c[an] hardly put ... into words," or what she struggles to comprehend, is that the "wrong" she "resent[s]" concerns not simply John's duplicity but also his preference for a white-looking black woman. That preference is an aspect of the "'sectional prejudice'" about which Mrs. Smith warns Dora in their earlier conversation (181).

When Dora learns of Sappho's rape and John's reaction to Sappho's sexual status, she feels compassion for Sappho, which she probably could not feel had she not had that conversation with her mother. Upon reading a farewell letter that Sappho writes to Will Smith (Dora's brother and the man whom Sappho loves) because Sappho believes herself to be unworthy of Will's love, Dora learns that Sappho had once been forced to bear a child by a white man (328-29). Dora also learns that John has used that knowledge to try to 
blackmail Sappho into having a sexual relationship with him. Sappho writes, "[John] has found out my story, and has offered me the greatest insult that a man can give a woman" (329). After recovering from the shock of such news, Dora exclaims, "'Oh, that poor, miserable girl! think [sic] of her sufferings. ... This terrible curse of slavery! shall [sic] we never lose the sting of degradation?'" (330). As her references to the "'terrible curse of slavery"' and "'the sting of degradation'" suggest, Dora now realizes that Sappho has "'suffer[ed]"' as a result of white men's continuing rationalization that black women, as her rapist once expressed it, "'[a]re a direct creation by God to be the pleasant companions of men of my race"' (261). Or, as Collins expresses it in reference to Harriet Jacobs, "[her being] part of a group of sexually denigrated women made her available to white men as ... no group of white women had been" (81).

With that realization, Dora no longer judges Sappho and herself according to white standards of beauty; nor does she judge Sappho according to white standards of chastity. Upon freeing herself from those standards, Dora becomes able to feel compassion for Sappho and, as her decision about marital partners shows, to think more highly of herself. At the conclusion of this scene, she urges her brother to "'bring [Sappho] back home'" (331). Upon removing the engagement ring that John had given her, she declares that she is "'well rid of such a man'" (331)--that is, "'a [black] man'" who succumbs to racist and sexist standards not only by becoming obsessed with a black woman because she looks white but also by attempting to capitalize on those standards at the woman's expense. When Dora does marry, she chooses a partner whom she can love, a man who is committed to the social, if not political, advancement of black people. Arthur Lewis is a fictional representation of Booker T. Washington.

Unlike Dora, Sappho does not have to struggle with an inability to meet white standards of beauty because she looks white. Yet, because she looks white, she is raped and, so, does have to struggle with the shame that she feels as a result of her inability to meet white standards of chastity. Sappho is forced to confront her feelings about her 
sexual status at a "sewing-circle" (141) held in Mrs. Smith's house. During this meeting, which functions as a black women's club, a hired lecturer speaks about "'the virtuous [black] woman ..."' (148). Mrs. Willis, the lecturer, explains to the group that "'[black women's] ideas of virtue are too narrow,'" and she admonishes them "'not [to] forget the definition of virtue--[s]trength to do the right thing under all temptations"' (149). However, because Sappho cannot stop herself from dwelling upon the "'narrow"' definition of "'virtue"'--physical chasteness--she cannot understand the moral chasteness to which Mrs. Willis refers, as her conversation with Mrs. Willis makes clear.

Apparently, Sappho wants to confide in Mrs. Willis, and Mrs. Willis wants to help Sappho. At the end of the meeting, Sappho says to her, "'So many of us [black women] desire purity ..., but in a moment of passion, or under the pressure of circumstances which we cannot control, we commit some horrid sin ...'" (154). At some level, Sappho apparently realizes that she "'c[ould ]not control'" the actions of her rapist. However, that realization is undermined by her apparent belief that she has "'commit[ted] some horrid sin"' by being raped. Although Mrs. Willis tells her that "'[black women] are not held responsible for compulsory sin, only for the sin that is pleasant to [their] thoughts'" (154), Sappho "'h[o]ld[s] [herself] responsible for [her rape]" to the extent that she can no better fathom a distinction between "'sin[s]'" than she can between "'virtue[s].'" She tells Mrs. Willis that she "'once knew a woman who had sinned"' (156), and Mrs. Willis again makes a distinction between sins by saying that "'God does not look upon the constitution of $\sin$ as we do'" (157).

Had this conversation continued, Mrs. Willis might have been able to get Sappho to understand that she was in no way responsible for the rape. Significantly, however, their conversation abruptly stops when the men join the women's group to partake in an evening of supper and dance. Mrs. Willis tells Sappho to "'have faith and trust [in God],"' and "[a]t this point the entrance of the men ma[k]e[s] an interruption" (157). "Mrs. Willis disappear[s] in a crowd of other matrons," and Sappho "s[i]t[s]" (157). 
In that Sappho only alludes to her rape when she speaks with Mrs. Willis, one could argue that, even if had the men not "interrupt[ed]" them (157), Sappho would not have confided in Mrs. Willis. However, Sappho is the one who initiates the conversation with Mrs. Willis, and that suggests to me her desire to confide in Mrs. Willis. It is true that, at one point in their conversation, "[j]ust as the barriers of Sappho's reserve seemed about to be swept away, there followed ... a wave of repulsion toward [Mrs. Willis] and her effusiveness ..." (155). Yet, by the end of their conversation, "Sappho [i]s impressed ... by the woman's words" (157). As I discuss later, I think it no coincidence that, when Sappho does confide her rape experience to another black woman, they are in a convent, a place where men are not apt to "interrupt" (157) them.

Even before Sappho attends a community meeting assembled to debate possible responses to a rape that allegedly occurred in the South, she knows how a black man would be apt to feel about her. Like black women, black men were socialized to believe that black people are inherently unchaste. Sappho knows that a black man would find it especially difficult to think that a black woman whom he knows to have been raped by a white man was not irreparably damaged. However, one particular speaker at the meeting inadvertently reminds her. Luke Sawyer, the man who had found Sappho after the rape and who assumes her to be dead, refers to her before the rape as a "'beaut[iful] and lovel[y] . . child"' (258), and after the rape, "'a poor, ruined . . creature'" (260). Because Luke refers to Sappho by her birth name, which she does not use, no one at the meeting knows that he is speaking of her. Nonetheless, among the large crowd, "a woman [i]s borne from the auditorium in a fainting condition" (261). That "woman," of course, is Sappho.

Some black men, including Will, the man whom Sappho loves, consider the rape of a black woman to be an appalling transgression against themselves, and other black men try to capitalize on the woman's sexual status. After Will reads Sappho's farewell letter, mentioned above, in which she identifies herself as being the girl about whom Luke Sawyer spoke, Will does not think first about how the rape has affected Sappho. He 
thinks about how it is affecting him. He wonders "[h]ow c[an] he bear this terrible news" (329)--"that horrible violation of chastity ..." (330). Unlike John Langley, Will does not consider taking advantage of the knowledge that Sappho was raped. However, like John, he thinks about it from his perspective.

The various ways a black man might respond to Sappho should he learn about her rape, coupled with the shame she feels about it, lead Sappho to become silent each time that Will indicates his love for her. This conversation occurs before he knows of her rape. When he refers to the biblical example of "'Jacob lov[ing] Rachel,"' she "sa[ys] nothing ." (310). When he asks her to marry him, she "d[nes] not answer . . ." (310). When he emphasizes his love for her, she "[i]s still silent ..." (310). When he asks her to profess her love for him, she finally tells him that she "'care[s] for [him]'" (311). However, beginning with "'I wonder if it is right for me to love you, or to allow you to love me'" (311), Sappho makes a number of comments that allude to her self-shame and suggest her reluctance to confide in him.

Finally, undoubtedly more because Sappho feels undeserving of Will's love than because she thinks she deserves to be rid of the shame she feels, she alludes to the rape. However, Will silences her. She makes a veiled reference to her experience by saying that "' $[t]$ here are things which you ought to know--things connected with the past'--" (312). Earlier in the conversation, Will urges her "'to [t]ell [her thoughts] to him"' (310). Now, he quickly replies that her "'past'" does not concern him (312). Very different from the way in which an older black woman later responds to her when she wants to tell the story of her rape, Will silences Sappho from clarifying her allusion to it. Perhaps he knows that he "c[annot] [easily] . . . bear this terrible news ... ." (329).

Whatever joy that Sappho may feel upon hearing Will's professions of love is soon replaced by a profound silence of shame during the scene in which John confronts her with his knowledge of her past. Just hours after Sappho's conversation with Will, John comes uninvited to her room. Until the moment that he dramatically announces, "'I know your 
secret'" (318), Sappho angrily urges him to get to the point of his visit. Upon his announcement, however, she literally loses control of herself. She collapses to the floor. As she "grovel[s] there" (318), John insists that she consider Will's probable response to the knowledge of her past. At first, Sappho unquestioningly realizes that the rape was not her fault. She exclaims, "'I was a victim! an [sic] innocent child!"' (319). However, once John makes clear that he expects her to be his mistress and not his wife, Sappho accepts in silence the racist fiction that she is an immoral woman. Upon John's declaring that "'[a]mbitious men do not marry women with stories like yours," Sappho becomes "speechless with disgust" (320). Undoubtedly, she feels "disgust" toward John. However, she also feels it toward herself. In addition to calling him an "'[i]nfamous villain,"' Sappho exclaims, "'Never till this moment have I realized the depths of my degradation!'" (320).

Significantly, Sappho refers not to John's "'degradation"' of her but to her own (320). Soon after John's parting threat that should she refuse to fulfill his sexual desires, he will tell Will about her past, she packs her belongings. While her decision to leave immediately, in itself, suggests the extent to which she feels shame for her past, the comment that she makes to herself as she looks in a mirror clearly indicates that she holds her own person responsible for her past, as well as present, circumstances. She gazes at her "pale . . . countenance with scorn" and says to herself, "'Men call me beautiful ... [,] [but] what has beauty been to me but a curse?'" (321). Sappho is unaware that her "'beauty"' does not cause her to be raped and threatened with sexual blackmail. Rather, some men's acceptance of the negative positioning of black women in the Southern lady/Other dichotomy leads those men to abuse her.

Sappho does not totally reject the negative positioning until the last few pages of the novel, but her decision to speak of her history to an older black woman begins the process. As Sappho rests in a New Orleans convent after having been brought there by a nun in whose arms she fainted at the train station (348), "she fe[e]l[s] it her duty to make a 
confidante of the Mother Superior" (350). Apparently, Sappho does not realize that her decision to return the nuns' hospitality by telling the truth of her circumstances demonstrates her having the type of moral chastity to which Mrs. Willis refers during her earlier-mentioned lecture to the sewing circle--"'[s]trength to do the right thing under all temptations"' (149). Since "[n]o questions had been asked her [by the nuns] concerning her life or history" (350), Sappho is presented with the "temptation" (149) to say nothing and avoid possible repercussions. However, her inner "'[s]trength"' enables her to decide "'to do the right thing"' (149).

Sappho's capacity to be morally chaste notwithstanding, it is the Mother Superior's initial silence which allows her to put that chastity into practice. As Mrs. Smith does for Dora, the Mother Superior, by remaining silent, gives Sappho the opportunity to reveal her thoughts. "[G]lid[ing] in[to] [Sappho's room], with her noiseless step and gentle, assuring manner," the Mother Superior hears Sappho's story (350). After listening to it, "[t]he holy woman $s[\mathrm{i}] \mathrm{t}[\mathrm{s}]$ there a long time in silence" (350). The "long . . . silence" is not an indication that the Mother Superior is shocked by Sappho's story; "[s]uch confidences were not new to her" (350). The "silence" is also not an indication of her condemnation of Sappho. Rather, it indicates her acceptance of Sappho, for, after it, she "place[s] a . . . brown hand upon the girl's head with a murmured 'Benedicite"' (350). As does Mrs. Smith and, eventually, Dora, the Mother Superior knows that men's demeaning treatment of Sappho is not Sappho's fault.

Significantly, the combination of the Mother Superior's initial silence, Sappho's storytelling, and the Mother Superior's acceptance of her gives Sappho an opportunity to reclaim the self that had been silenced eight years ago. At that time, Sappho gave birth in the convent where she is now, but a different group of nuns lived there then (348). To protect her from being known as an unwed mother, the nuns changed her name. As Sappho explains in her farewell letter to Will, "You remember the story told ... by Luke Sawyer ... I I am the unfortunate Mabelle Beaubean! I did not die. The good Sisters 
gave out that story in order to destroy my identity" (328-29). Ironically, the Mother Superior to whom Sappho now tells her history offers her an opportunity to continue denying her true self. The Mother Superior suggests that she become a nun (350). In that the Mother Superior's suggestion would preclude Sappho from identifying herself as a mother, it parallels the previous nuns' decision to "destroy [Sappho's] identity" (329). Yet, as the Mother Superior's initial silence functions, her suggestion that Sappho become a nun gives Sappho the opportunity to put into practice her capacity to be morally chaste.

To the extent that Sappho makes a firm decision to embrace motherhood, she practices moral chastity, and her decision leads her to feel some degree of self-acceptance. Sappho accedes to the Mother Superior's later suggestion that she go by the title "'Madame'" rather than designate herself as being unwed (352). However, in response to the Mother Superior's earlier suggestion that she become a nun, Sappho says, "'No; I must accept the desire of God in the child. I will take a mother's place and do my duty"' (350). Thus, the Mother Superior's initial silence not only leads Sappho to tell her story, but it also leads her to negate the silence that had been imposed upon her years ago. Not surprisingly, Sappho feels "comforted by [the Mother Superior's] benign influence" (351), and her "comfort" suggests that the Mother Superior has helped her to feel less ashamed of herself.

Actions that Sappho takes two years after leaving the convent suggest that she eventually sheds all of her self-shame or, in other words, that she has continued to feel "comforted by [the Mother Superior's] benign influence ..." (351). In the first instance, Sappho refrains from committing herself to a man for whom she only feels fondness and, possibly, gratitude. Sappho is "attracted ... by [the] gentleness" of her suitor (354), a widower who hires her as a governess for his children (352-53), and her acceptance of his marital proposal would, as he points out, "'offer [her] an honorable name ..." (357). However, Sappho has shed enough of her shame to tell him that she "'cannot answer [his proposal now]'" (358). That Sappho yet feels some shame is clear. At one point, when 
she decides to go to Will, fear of "'[h]is scorn"' stops her (354). The second action that Sappho takes indicates that she no longer feels the shame she felt those few week earlier. When she and Will meet by accident, she does not run from him.

One could argue that both the shock of meeting Will unexpectedly and after such a long time, as well as the fact that he immediately "clasp[s] her in his arms" (394), play significant roles in Sappho's not fleeing from him. Yet, Sappho cannot know with any certainty Will's reaction to the past that she revealed to him in her farewell letter until he tells her, and her willingness to remain in his company long enough to find out suggests a degree of self-confidence that she can only have acquired by exonerating herself from her past. Sappho's subsequent marriage to Will confirms her total self-acceptance.

Referring to their marriage, Tate credits only Will with "follow[ing] his own desire in selecting his [spouse], rather than institutionalized patriarchal desire for premarital virginity" ("Allegories of Black Female Desire" 122), but Sappho deserves credit as well. According to "institutionalized patriarch[y]," Sappho is not moral because she lacks "premarital virginity." However, Sappho does not marry a man for who she feels only fondness and, possibly, gratitude. She marries a man whom she loves and who, as a fictional representation of W. E. B. DuBois, is clearly committed to the advancement of black people. Thus, one may also credit Sappho with "follow[ing] h[er] own desire ... rather than institutionalized patriarchal desire." Her "select[ion]" of Will indicates that she has "select[ed]" herself. Since Sappho begins to loosen the chains of shame after the Mother Superior allows her to tell her story, it is fair to say that the Mother Superior's silence plays a major role in Sappho's "select[ion]" of herself.

The contrast between Dora's and Sappho's indicated silences and Mrs. Smith's and the Mother Superior's indicated silences is striking. During Dora's silences with Sappho, when Sappho gently teases her about the men in her life and when they both know of John's obsessive attraction to Sappho, Dora is feeling shame, as well as, perhaps, anger, because she does not fulfill the standard for beauty and Sappho does. During Sappho's 
silences with men, first Will and then John, Sappho is feeling shame, as well as, perhaps, anger, because she does not fulfill the standard for purity. Unlike Dora's and Sappho's silences with each other, the older women's silences, Mrs. Smith's silence with Dora and the Mother Superior's silence with Sappho, enable the protagonists to express their thoughts. In turn, the older women's responses to the thoughts both affirm the intrinsic value of them and guide the younger women to think further about them. Eventually, both Dora and Sappho understand that they feel shame because they are comparing themselves to standards that they cannot fulfill, which is a comparison that the dominant discourses wanted them to make.

In other words, through a combination of silence and response, Mrs. Smith and the Mother Superior, respectively, initiate for Dora and Sappho an inner journey that leads them to reject racist and sexist standards for womanhood and to accept themselves as they are. Thanks to the older women's silences, then, as Chris Weedon would say, the protagonists "challeng[e] what constitutes useful knowledge," and, as a result, they gain more "power and control" over their lives than they have ever before had (14).

\section{Silences in Winona}

Without a doubt, Hopkins realized the value of older blacks for younger blacks. In an article appearing between the publications of Contending Forces and Winona, Hopkins lauds activist and author Frances Ellen Watkins Harper as being an inspiration for younger blacks. Of Harper, Hopkins says, "At least we may be allowed to hope that the rising generation will be encouraged by her example to renewed courage in surmounting prejudice and racial difficulties" ("Famous Women" 369). Since Harper was born two generations before Hopkins (Harper was born in 1825, Hopkins in 1859), Hopkins herself may have been "encouraged by her example." Hopkins may have envisioned similar means for "surmounting prejudice and racial difficulties." Harper perceived older black women to be one of those means. As she once said to a friend about an upcoming meeting with Southern freedwomen, "I am going to talk with them about their daughters. ... Now is 
the time for our women to begin to plant the roots of progress under the hearthstone" (qtd. in Sterling 405). I think that Hopkins also believed older women could "plant the roots of progress" in younger women.

With the assumption that Hopkins held that belief, I suggest that her relative exclusion of older women of color from Winona was intentional, and my reading of Winona's indicated silences supports my suggestion. Winona is motherless and living during the Antebellum. Her mother, who was an escaped slave, died during Winona's birth. With her father, a transplanted Englishman, Winona lives in a Senecan community, and an older Senecan woman named Nokomis fosters in Winona a Senecan identity. 5 Until Winona is taken from Nokomis, Winona's silences reflect both her unawareness of, and her resistance to, any beliefs emanating from white culture. Once Winona is enslaved and raped, her silences indicate that she feels intense shame. Without Nokomis, Winona internalizes the dominant culture's belief that she is inherently unchaste. To combat her shame, Winona disassociates herself from her mother's culture and associates herself with her father's culture. Her final silences as well as her marriage to the Englishman who rescues her from slavery reflect that shift in subjectivity.

In other words, Winona's indicated silences trace her journey from embracement of self, to loss of self, to acceptance of a culture that does not advocate slavery but that uses the white-man's-burden ideology to justify its colonizing enterprises. Indeed, along with arguing that Hopkins wanted her black women readers, especially, to understand the need of "self-directedness" (Christian, "Trajectories" 235) and the need of a "speech community" (Yaeger 215) to help them achieve that goal, I think that Hopkins wanted her readers to understand that blind loyalty to cultures which do not advocate slavery and lynchings but do advocate colonization will hinder the achievement of that goal.

Within the first few pages of Winona, a scene takes place in which the yet-free adolescents, Winona and Judah, a black boy adopted by Winona's father, become immersed in an argument. Twice during the debate, Winona becomes silent as Judah, 
ironically, attempts to impose racist as well as sexist ideologies on her. What Winona apparently thinks during those silences suggests not only that she is yet unaware of the race and gender hierarchy but also that she resists thinking according to the oppositionalism that engendered and perpetuates it.

The argument occurs because Judah attempts undermine a belief in a nature-spirit that Nokomis had taught Winona. Referring to Nokomis as "'only a silly old Indian squaw," he tells Winona that when she, "'only a little girl," attends a convent school, she "'will learn ..."' (292). Winona and he are "silent for a time ..." (292). Following the "silen[ce]," she insistently asks Judah whether the nuns--presumably white and, thus, in a position of superiority to both her and Judah--taught him "'[t]hat Nokomis is silly'" (292). In response to his implication that nuns say all beliefs taught by Native Americans are foolish, she again becomes "silent for some time, absorbed in thought" (293). Following her "silen[ce]," Judah insists that she will go to the convent school because her (white) father says that she will, and Winona emphatically responds, "'I will not"' (293).

Judah apparently accepts without thought the belief that whites have knowledge superior to people of color--in this instance, Native Americans--and the belief that men-here, both himself and a white man--should make decisions for women, but Winona does not. In effect, through a combination of silence and speech, she challenges the entire hierarchy. Winona not only rejects the superiority of her father, the nuns, and Judah, but she also validates both her own and Nokomis's thoughts.

Winona's ability to maintain her sense of self as a Senecan becomes undermined when Warren Maxwell, the Englishman whom she later marries, enters the novel around the time of her father's murder. This undermining does not occur because Nokomis silences her desire to continue acting as the older woman-mother figure for Winona or because Nokomis is unsuitable for that role. When Warren implies his intent to assume responsibility for the recently orphaned Winona by vowing that she "'shall not be friendless if [he] can help [her],"' Nokomis attempts to override his intent by telling him 
that she "'will take care of her"' (308). That Nokomis refuses to be silent at this particular moment demonstrates both the courage with which she resists white notions of kinship and family and the extent to which she wants to protect Winona from losing her sense of self or, in other words, becoming white.

Before speaking against Warren's intent to take Winona with him, Nokomis knows that Warren's prejudice against Native Americans has already made him suspect her of being somehow involved in the murder. The minute that Warren declares Winona's father to be a murder victim (305), Nokomis is the first person whom he "regard[s] . . . steadfastly" (306). He apparently determines that "[h]er . . . face [i]s honest enough" for her not to be the actual murderer (306), but he suspects her involvement. When he wonders "[w]ho ... was the assassin[,]" the only person whom he "[a]gain look[s] at [is] Nokomis ..." (307). As he "[a]gain look[s]," Nokomis "intently watche[s] him" (307). Moreover, Nokomis knows that, as an Englishman, Warren is apt to think of Native Americans as "savages" (313). She is a member of one of the tribes whose lands were "g[i]ve[n] up ... before the on-sweeping Anglo-Saxon" only about a decade earlier (287).

Given Nokomis's own recent experiences with "the ... Anglo-Saxon" (287) and her most recent awareness that Warren suspects her involvement in a murder, it is remarkable not only that she speaks out against his intent to take Winona with him but also that she derides his presence, apparently in his presence, for the rest of his stay. While "[e]veryone seem[s] to regard Warren Maxwell as the person in authority . . , Old Nokomis repeat[s] many times a day, 'Surely it was the Great Father must have sent you to us'" (309). Nokomis taught Winona nature-spiritualism and not Christianity, so it is highly unlikely that she is expressing Christian reverence for Warren and the culture that he represents. More than likely, she is expressing extreme bitterness toward the obliteration of Seneca culture and values that white civilization has enacted. In expressing her bitterness, Nokomis takes the risk of being silenced, one way or another, by Warren. 
A combination of related factors--Winona's shock about her father's violent death, her almost immediate attraction to Warren, and the fact that one of Warren's beliefs mirrors that which her father had repeatedly stressed to her--makes Winona vulnerable to Warren's influence. Upon learning that her father is dead, she faints (305). When Warren rouses her to tell her that her father was murdered, he holds her to prevent her from running. Initially, she reacts by "trying with her . . . fingers to unclasp his [fingers]" from her body (308), but, the next day, she "cl[i]ng[s] to him with ... fingers like bands of steel" (309). Winona becomes even more attracted to Warren because he reminds her of her father. As she correctly supposes later in the novel, her "'papa was of the same [country as Warren is]"' (405). Two days after the funeral, Warren tells Winona that he "'could not . . . leave [her] alone and friendless,"' and she recalls that her father "'used to say that we two had only each other to love ..."' (313). Like Winona's father, who had housed Nokomis only in exchange "for h[er] housekeep[ing]" (290), Warren cannot imagine Nokomis as a person for Winona "'to love'" (313). He does not even tell Winona of Nokomis's desire to take care of her. When he expresses his intention of taking her to England, Winona only asks whether Judah will go as well. Unbeknownst to Winona, Warren assumes responsibility for her welfare because he believes that she has been "'cast upon his care"' (313), which is, of course, the white-man's-burden ideology.

Because Winona and Judah are unexpectedly captured by their mothers' former owner and removed to Missouri the day following Warren's temporary departure (314), Winona is not immediately colonized by Warren. However, she is taken from Nokomis. As a result of her separation from Nokomis and her enslavement, Winona's sense of self changes. Before her capture, Winona proudly thinks of herself as being a Native-American woman, which both her faith in Nokomis and her manner of dress make clear. As she tells Judah during their above-mentioned altercation, "'Nokomis know[s] . . [and] speaks truly [about spirits in nature]"' (292), and Winona wears "embroidered . . broadcloth," "moccasins," and "two long plaits of ... hair" (289). At that moment in her life, Winona 
is unaware that the dominant culture identifies her as being a black woman and that such an identification marks her as being both chattel and material for rape. As a white acquaintance remarks shortly before her and Judah's capture, "'they have no idee of thar true position in this unfriendly world'" (310). Needless to say, once removed from Nokomis and placed in her "'true position,"' Winona undergoes the first of two shifts in subjectivity that distance her from her Native-American self and, thus, from her affinity with Nokomis: she becomes aware of her black identification and the accompanying assumption that she is inherently unchaste.

Winona never actually says that she had been raped. Indeed, the experience silences her just as it silences Sappho. Narrative remarks and personal accounts from former women slaves speak for her. Like Sappho's, Winona's appearance comes close to meeting the standard of beauty: "her hair cluster[s] in rich dark rings," and she bears an "olive complexion with a hint of pink ..." (292). That appearance, in itself, makes Winona vulnerable to rape by a white man. Further, because Winona looks white, she becomes a personal slave to her owner's daughter (320). Because she is a house slave, she is a prime target for rape. In one account that Dorothy Sterling gathered, a former slave explains that she became a house slave "'cause I was ... light complected ..." (15). As Sterling comments before presenting other accounts, "[h]ouse servants were particularly susceptible to sexual exploitation" (20). ${ }^{6}$ Winona was no exception. After she flees captivity, the narrator alludes to her having been "sexual[ly] exploit[ed]" by saying that "[i]n the life she had led as a slave, this poor child had learned things from which the doting mother guards the tender maidenhood of her treasure with rigid care ..." (356). As a final reminder of "things" that Winona "learned" from her "[un]guard[ed] ... maidenhood"--in other words, the forced loss of her virginity--the narrator, within the last few pages of the novel, makes reference to "[t]he premature, crushing experiences of her young girlhood, its shocks and shameful surprises ..." (435). ${ }^{7}$ 
Winona's enslavement and rape certainly make her aware of her identification as a black woman and the accompanying belief that she is inherently unchaste. However, the extent to which she is conscious of her subject position depends upon Warren's physical proximity to her. Of course, his white presence would remind her of the belief that she is inherently unchaste, and that reminder would make her recall her rape experience. Indeed, although Winona does not know it, Warren reenters her life because he, not knowing that she has been raped, cannot bear the thought of her becoming unable to meet the standard of chastity. During a chance visit to the plantation on which she and Judah are slaves, Warren learns that they are to be sold "'up the river"' where she would experience "'the fate of a beautiful female slave'" (335). Upon hearing that, Warren pledges to "'save [them] ..."' (336). ${ }^{8}$ Following the rescue, Winona rides horseback near Warren. Daydreaming about any future relationship that she might have with him, she knows that "[o]ne thing [i]s certain: she w[ill] never, never marry, because, of course, it [i]s quite impossible she should ever marry Warren ..." (356). The reason for Winona's assuming that "impossib[i]l[ity]" is not directly stated. However, the next narrative comment concerns her "life ... as a slave" and the "things" she "learned" during that experience (356), so her assumption undoubtedly is an allusion to her rape. Thus, Winona thinks that she cannot be Warren's wife because she does not meet the standard of chastity.

When Warren is away for several weeks, Winona becomes able to ignore the ramifications of her rape experience and to be herself. One day while ensconced in a fugitive-slave camp operated by abolitionists, Winona daydreams about Warren and "g[i]ve[s] not a thought to the difficulties of her position" (376). Apparently, she is able to disregard those "difficulties," including her inability to meet the standard of chastity, because she has instinctively embraced her Native-American self. As the narrator reveals, "[s]ome impulse of the wild things among whom she had lived" compels her to do her daydreaming in a cave (375). 
Significantly, when Winona is herself, she can challenge a white man. Soon after the above scene, she learns that Warren has been imprisoned for having defied the Fugitive Slave Act. Of course, he did that by rescuing her as well as Judah from slavery. She also learns that one of the white abolitionists has decided to infiltrate the prison to gain information necessary for planning Warren's escape. Winona responds to her NativeAmerican self by withdrawing "into the woods ... to think" (380). "In the antebellum South, lynch law helped suppress ... white dissidence" (Hall 131), so Winona undoubtedly incorporates into her "think[ing]" (380) the realization that, if the abolitionist is caught, Warren (as well as he) will probably be hanged. The next day, "she s[eeks] an interview with [the abolitionist leader]" to challenge the other abolitionist's decision to "spy out the jail ..." (380). Similar to the scene in which Nokomis counters Warren's decision to assume responsibility for the newly orphaned Winona by saying that she herself will care for her, Winona apparently counters the abolitionist's decision to infiltrate the prison by saying that she herself will do so. In the next scene in which she appears, Winona is in the prison, posing as "Allen Pinks," a freedman detained "on suspicion of being a fugitive slave..." (386).

Ironically, when Nokomis does not succeed in overriding Warren's decision, she maintains her own integrity, and when Winona succeeds in overriding the white abolitionist's decision, she loses her own sense of self. Specifically, Winona becomes profoundly silent. As long as Warren is unaware that Allen Pinks is Winona, Winona is able to ignore the fact that her disguise as a black man is only a partial disguise. She does not yet acknowledge that while the "boy's attire" which she wears (395) is a mask, "the stain with which she ha[s] darkened her own . . complexion" (396) is not. Indeed, in that the narrator calls Allen a "mulatto" (386) rather than a "'quadroon'" (303), as a white man earlier describes Winona, the "stain" (396) exaggerates her being of mixed race. However, a jailer, within visual range of Warren's cell, scrutinizes Allen. Winona begins to become cognizant of the proactive nature of her "darkened ... complexion" (396), and she 
"involuntarily ... cover[s] h[er] face with h[er] hands" (392). When the jailer, also within auditory range of Warren's cell, recognizes Winona and comments only about her being "'dressed up in boys [sic] clo's"' (392), she must become fully aware that, from a white man's perspective, the facial shading merely enhances her natural skin tone.

Thus, by the time that Winona stands outside the prison next to the just-rescued Warren, the "self-consciousness that render[s] her ashamed" and "silent" (396) undoubtedly results from, and reflects, her additional recollection that, according to the culture which identifies her as being black, she is unchaste. Her "turn[ing] mechanically" toward the escape wagon and "still [being] silent" upon entering it (396) respectively suggest that her double awareness leaves her without a sense of self and deeply "ashamed" of her black identity.

During a later scene with Warren, Winona again becomes silent. As her thoughts during the silence suggest, she is trying not to feel inferior to Warren because of her black identity. However, once Warren unwittingly reveals that he believes blacks to be a particularly inferior group, her sense of inferiority resurfaces. One day, while at the fugitive-slave camp to which they had returned after his rescue from prison, Warren and Winona stand together in admiration of the landscape. During "a silence" (405), she unhappily but rationally concludes that "[f]ate ha[s] fixed impassable chasms of race and caste between them" (404-05). "[R]ace" and "caste" are clearly on Winona's mind, but, since she envisions them as being "chasms ... between" her and Warren, she is trying to think of their identities in terms of difference, not inequality. However, during their ensuing conversation, Winona correctly interprets a comment that Warren makes as being "a reflection upon her Negro origin" and as meaning, "'[b]etter an Indian than a Negro"' (405). In an attempt to prove her worth, she changes the topic of conversation from her "Negro origin" to her affiliation with "Indian[s]," and, upon responding negatively to Warren's general comment that she will eventually marry, Winona says, "'I cannot marry out of the class of my father. . . . It follows, then, that I shall never marry'" (406). 
Warren's response to Winona's attempt to deflect her feelings of inferiority about her black identity only intensifies her feelings. He insists that she will marry because "'[m]ere birth does not count for more than one's whole training afterward, and [she] ha[s] been bred among another race altogether'" (406), and that insistence confirms her assumption that he believes a black identity to be particularly inferior. Whether by "'another race,"' Warren is referring to Winona's white father or to the Native Americans who allowed her father into their community, his comment about "'birth"' does refer to her mother. All of this confirms the fact that Warren does, indeed, believe a black identity to be the least desirable of all three racial identities.

Even though a white American once explained to Warren that "'[t]he child [of a woman slave] follows the condition of the mother"' (315), Warren is apparently unaware of the derogation implicit in his comment to Winona. However, Winona understands it. His comment leads her to allude to her slave status and, related to that, to her sexual status. "In a stifled voice full of pain," she says, "'But the degradation of the two years just passed can never leave me; life will never seem quite the same'" (406). Certainly, being a slave at all, never mind for "'two years,"' must be indescribably "'degrad[ing]."' However, as an additional comment which Winona makes suggests, that feeling which "'can never leave'" her refers particularly to the shame that she feels as a result of having been raped. It also suggests the extent to which she wants to rid herself of her black identity and especially of the sexual status integral to that identity. "[E]nd[ing] with a little laugh, but the voice quiver[ing] beneath it," she announces that she "'shall be a nun"' (406).

Since one quality often associated with nuns is chastity, Winona's announcement indirectly draws attention to her sexual status, but it also implies a way in which she can be chaste, which would explain why she risks drawing attention to her sexual status. Of course, because she has been raped, Winona is not materially chaste. That is, she is not a virgin. However, in becoming a nun or virgin of Christ, she can be spiritually chaste. In that sense, then, Winona's telling Warren, "with a little laugh," that she "'shall be a nun'" 
(406) is a lighthearted and an indirect way of trying to convince herself as well as him that she does have worth because she can be chaste in at least one way.

Despite the fact that Winona's reference to her sexual status is oblique, it unnerves Warren, and he tries to silence Winona. Upon her initial announcement of her decision to become a nun, he "abruptly" advises her to "'just strive to forget all about it"' (404)--that is, her having been a slave. His response suggests that he realizes a connection to exist between her decision to become a nun and her having been a slave, but his advising her to "'forget all about it"' indicates that he does not want her to make that connection clear to him. Indeed, just as Will does to Sappho when she first alludes to her rape, Warren attempts to silence Winona from confiding her rape. Unlike Will, however, Warren undoubtedly does not want to know about his lover's experience not simply because it would destroy his image of her as "innocence personified" (404) but especially because it would manifest, from his perspective, her inherent inability to be chaste. In essence, then, his advising her to "'forget all about"' her having been a slave more largely means that he wants to "'forget all about"' her black ancestry.

Winona's response to Warren's advice suggests that she desires to "'forget all about"' (404) her black ancestry because she attributes her rape to it, and her subsequent silence confirms that desire. Upon saying, "'People will never forget that my mother was an American Negress even if I forget,"' she "conclude[s]" by announcing, once again, that she "'shall go to the convent"' (407). Since she "conclude[s]" that she will live in a "'convent'"--or, in other words, be at least spiritually chaste--from her allusion to being an "'American Negress," Winona reveals that she has internalized the belief that her "'Negr[o]"' ancestry makes her inherently unchaste or sexually impure. In a sense, then, she blames her "'mother[']s'" ancestry, rather than the institution of slavery, for her rape. For that reason, she both wonders "'if [she can] forget"' about her black ancestry and fears that "'[p]eople'"--especially Warren--"'will never forget"' about it. Thus, the "[s]ilence [that] f[a]ll[s] between them" when he tells her that she "think[s] too seriously of [her] 
position"' (407) demonstrates at least two things. It reaffirms both Warren's and Winona's desire to erase her black ancestry because they both blame it for her "'position,'" and it demonstrates that Winona will do almost anything to make Warren as well as herself believe her worthy of him, including disassociate herself entirely from her "'mother'" (407). In being "[s]ilen[t]," Winona demonstrates her willingness to "[s]ilence" an aspect of herself (407).

A final note about this scene, as well as related scenes in Contending Forces, merits consideration for its relevance to silence. Since nuns, who are known for their vow of silence as well as of chastity, are mentioned here, as well as in Contending Forces, one might assume that Hopkins included them to suggest that black women can experience a type of empowerment through the silences within convents. However, I think it is much more likely that Hopkins believed convents silenced black women. Without question, the convent twice serves as a safe haven for Sappho and, importantly, is the one place in which she feels secure enough to relate her past. However, during her first stay, the nuns, in effect, silence her by claiming her to be dead and by changing her name. During her second stay, the Mother Superior, in effect, asks her to silence her motherhood as well as her single marital status. At least in doing and saying these things, the nuns were trying to protect Sappho, but the nuns about whom Winona knows teach white supremacy.

Significantly, when Judah tells Winona the nuns will teach her that Native-American beliefs are nonsense, Winona says, "'I hate nuns'" (293). As the younger Winona apparently senses, even if she were only to attend a convent-school, her sense of self would be silenced. Were the older Winona to follow through on her decision to become a nun, she would probably join a convent occupied by women whose racism would encourage a continuation of her self-silencing.

Winona does not join a convent occupied by white nuns, but she associates herself with a white culture living outside its walls, and, in doing so, she enacts the silence that, in the last-mentioned scene with Warren, she demonstrates the willingness to do. Since 
Winona has internalized the belief that the ancestry which she inherits from her mother caused her to be raped, it is not surprising that, when given the opportunity, through legal inheritance, to embrace her father's culture only, she accepts it. That the inheritance represents white culture only is clear when one considers the fact that Judah, "the mite of black humanity [whom Winona's father] adopted" (290), inherits none of it. When Winona's father entrusted his legal documents to another white man, he instructed him to keep them until, as the friend recalls, "'[his] girl's a re-sponsible [sic] age"' (430).

During the moment that Winona is given the documents, she becomes silent twice. In that these silences reflect a shift in subjectivity, they' are similar to the earlier silences outside the prison. In the silences outside the prison, she is internalizing white culture's identification of her as a black woman along with all of its ramifications. In the silences during the presentation of her father's documents, she is rejecting what she perceives to be a most undesirable aspect of herself--her "'Negr[o]"' ancestry (407)--and accepting the identity of a white woman. In the first instance, Winona "for one instant, ... st[an]d[s] in silent self-repression" (433). She does not yet know with certainty the contents of the documents. However, she has already learned from the man who witnessed her father's murder that her father was, in actuality, "'Captain Henry Carlingford, heir to the great Carlingford estates [in England]'" (426), so she may well imagine that she is about to inherit her father's social status as well as material wealth. At this point, then, Winona's "silen[ce]" (433) suggests that she is readying herself to assume the position of heiress to a white man's fortune by "repressi[ng]" her black "self" (433), and this is an interpretation that her "taking the papers without speaking[,] ... pass[ing] them on to Warren almost mechanically[,]" and saying to him, "'Read them--I cannot"' (433) all support.

One might think that all of these signs are indications of Winona's remaining in the position of a black woman, but they are not. Since Winona never does attend the convent school before being enslaved, one might interpret her statement, "'Read [the documents]--I cannot"' (433), as meaning a literal inability to read. However, a narrative comment 
suggests that she probably learned to read during the time that she was a slave. Prior to Winona's and Judah's escape, the narrator reveals that Winona "had been allowed at lessons with her young mistress and had wonderfully improved her privileges" (320). Even if one assumes that Winona herself had not been taught to read, as many slaves were not, the narrator's additional comment that Winona "wonderfully improved her privileges" suggests that she taught herself by observing the "lessons." 9 Of course, even assuming that Winona does know how to read, one might interpret the other signs--her "selfrepression" and, "without speaking," her "mechanically" handing the documents to Warren (433)--as an indication that, as a black woman, Winona has become accustomed to being controlled by white men. However, during her first silence, she is thinking that the "contents [of the documents] meant life or death to her hopes" (433), and, in the previous scene, she expresses the desire to disassociate herself from "'American Negr[o]"' culture (407). Thus, it is likely that her "hopes" (433) are that she can associate herself with white culture, only, through her father's inheritance.

In this scene during which Winona receives her father's documents, her silences and actions, together, indicate that she is in the process of assuming the deferential and genteel position of an upper-class Englishwoman. Her "silent self-repression" (433) represents not only her "repression" of her African "self" but also her "[ex]pression" of her English "self." Her "mechanically" handing the documents to Warren "without speaking" (433) indicates her automatic acceptance of that English self, and her saying to Warren, "'Read [the documents]--I cannot'" (433), suggests her understanding of the proprieties exacted of upper-class Englishwomen. Significantly, such proprieties include the expectation that such women "'not"' "'[r]ead"' their own futures or, in other words, that they silence themselves. As Christian argues, pre-1940s black women fiction writers "appear[ed] to believe that if Afro-American women were to achieve the norm, they would lose important aspects of themselves" ("Trajectories" 235). Winona has. 
In that the position of an upper-class Englishwoman allows one to live without fear of being literally enslaved, it might be assumed that Winona's acceptance of that position is an indication of self-love or, in other words, rejection of self-shame. That is, one might assume that Winona's becoming an English noblewoman is a sign of her having achieved spiritual as well as physical emancipation. However, that assumption lacks validity. Between the moments that Winona alludes to Warren the fact of her rape and she is handed her father's documents, there is no evidence that indicates she no longer blames herself for the rape. Between those two textual moments, a battle occurs between pro- and antislavery factions. At the end of it, Winona persuades Judah not to kill a disabled and unarmed member of the pro-slavery faction (422), which demonstrates that she is chaste according to the definition that Mrs. Willis gives to the women of the sewing-circle in Contending Forces--"'[s]trength to do the right thing under all temptations"' (149). However, Winona would not recognize the significance of her action, a recognition that might well release her from her shame, because she has internalized white culture's definition of chastity.

If anything, Winona's acceptance of her father's legacy functions in the same way that her earlier reminder to Warren of her father's "'class'" (406) functions: it serves as a vehicle both of self-distraction from her shame and of self-persuasion of her worth. In other words, her acceptance of her father's legacy draws attention away from her mother's legacy or, more specifically, her own position as a slave and all things associated with it, and it focuses on her newly acquired material wealth as well as social status. Indeed, Winona's acceptance of her father's legacy--his "honor ..., ancient lands, and name" (433)--undoubtedly enables her to feel worthy of becoming Warren's wife in spite of the fact that she yet feels self-shame. ${ }^{10}$

Further, although I have argued that Dora's and Sappho's choices of marital partners are indications of their having replaced self-shame with self-love or selfacceptance, I cannot argue the same about Winona's choice of marital partner. First of all, 
I assume that Winona marries Warren. After the inheritance scene, the narrator relates that "[Winona and Warren] loved each other ... [and] would marry sooner or later, after they reached England" (435). Two paragraphs later, when Winona as well as Warren are "in England," the narrator says that "[Winona] is fortified against misfortune now ... by love" (435-36). Thus, it seems reasonable to assume that Winona marries Warren. Even though Winona marries a man whom she "love[s]," it is important to realize that whatever fondness she feels toward Warren is based upon an apparently unending sense of indebtedness for his having rescued her from slavery.

The morning following her rescue, Winona determines that she " $w[i][1]$ try to serve this man in some way ... [and that] nothing [i]s too great to render him in service for his noble generosity" (356). Indeed, at one point, when Judah expresses the desire for Winona to become his wife, she responds by saying, "'Do you forget all that Mr. Maxwell has done for us ... ?"' (378). Regardless of her feelings of gratitude to Warren, Winona may not be able to feel wifely love toward Judah because they have been raised together as siblings. However, it is significant that, in rejecting his romantic love, she refers not to their relationship but to what Warren "'has done for [them]."' When Winona participates in Warren's rescue, she helps save him from being hanged, but nothing in the novel indicates that she thinks she has "serve[d] this man" (356) enough.

Thus, Winona's marriage to Warren may well be a reflection of her "render[ing]" (356) herself to him toward payment of his "noble generosity" (356). Indeed, Winona undoubtedly has that sense of unending indebtedness because she feels inferior to him or, in other words, ashamed of herself. Unlike in the past, Winona does not have an older woman of color to give her a sense of her value that would allow her to see Warren for what he is.

From Winona's first indicated silences to her last indicated silences, Hopkins leads readers to Winona's final act of prostration, her marriage to Warren. During Winona's initial silences, she both questions the assumption of white and male supremacy and 
validates the sense of self that Nokomis instilled in her. Once Winona becomes separated from Nokomis, is enslaved, and then raped, she feels virtually nothing but self-shame in her silences, especially when she is in Warren's presence. When Winona has the opportunity to claim membership in a culture that, as Warren demonstrates, believes in white and male supremacy, she does, silently. Thus, in the next-to-last section of the last chapter, when the narrator, apparently referring to Winona's marriage to Warren, says that "[g]reater joy than hers, no woman, she believes, has ever known" (436), I think that Hopkins intended for "no [black] woman [especially]" to "believe" it.

\section{Conclusions}

Most specifically, I think that Hopkins used all three protagonists' indicated silences to make young black women readers, especially, aware of the self-shame that internalization of the subject position Other generates. However, I also think that she used Mrs. Smith's and the Mother Superior's indicated silences to show older black women readers, especially, a means by which they could help the younger women to rid themselves of the shame and to embrace their own sense of self. I further think that she used Dora's and Sappho's confidences in Mrs. Smith and the Mother Superior as well as Mrs. Smith's and the Mother Superior's responses to their confidences to show the value of speech as well as silence. I also think that Hopkins used Nokomis's speech for the same reason. When Winona could hear it, she thrived; when she could not hear it, she suffered.

Although Collins does not mention Hopkins in her book, Black Feminist Thought: Knowledge. Consciousness, and the Politics of Empowerment, she presents two related claims that apply to Dora's and Sappho's journey toward selfhood and to Winona's inability to make that journey. She says that the "everyday knowledge essential to survival as African-American women" with which "Black mothers [not necessarily in the strict familial sense] have empowered their daughters" (96) includes the ability to formulate "a worldview [that] markedly differ[s] from that advanced by the dominant group" (147). 
She also claims that "the process of rejecting externally defined controlling images of Black womanhood" is "the process of personal growth toward positive self-definitions" (84). In "empower[ing]" (96) Dora and Sappho to formulate "a worldview" (147) that excludes the "controlling images" (84) of them "advanced by the dominant group" (147), their "Black mothers" (96)--Mrs. Smith and the Mother Superior, respectively--also "empower" them to formulate their own "positive self-definitions" (84). Since Winona does not have Nokomis or, in other words, a "Black mother" (96) after she internalizes the "controlling images" (84), she cannot make that journey; and her journey would involve "rejecting" two sets of "controlling images": of Native-American womenhood as well as of "Black womanhood."

Those two claims as well as an additional claim that Collins makes also apply to my argument in the next chapter on Kay Boyle's novels. Neither Boyle nor her protagonists are black, but both of her protagonists need others to help them reject their subject positions and seek their own sense of self. On the other hand, and differences in race notwithstanding, Collins's additional claim that, in novels by contemporary black women authors, "[o]ther Black woman may assist a Black woman in this journey toward empowerment, but the ultimate responsibility for self-definitions . . . lies within the individual woman herself" (112) also applies to my argument in the next chapter. Like Chopin's and Hopkins's protagonists, Boyle's protagonists need "[o]ther[s]"--"a speech community" (Yaeger 215)--but, according to one of Boyle's novels, the "journey toward empowerment" (Collins 112) is becoming more driven by the "individual woman herself." In other words, the journey is becoming more silent. 


\section{CHAPTER 3}

\section{SILENCES IN PLAGUED BY THE NIGHTINGALE AND THE UNDERGROUND WOMAN: THE GRADUAL EMERGENCE OF A SPEECH COMMUNITY ${ }^{1}$}

\section{Introduction}

As becomes evident in the next section of this chapter, Boyle used rhetorical methods that distinguish many of the silences of her protagonists from most of the silences of Kate Chopin's and Pauline Hopkins's protagonists. Nonetheless, like the silences of the other authors' protagonists, the silences of Boyle's protagonists in Plagued by the Nightingale (1931), her first extant novel, ${ }^{2}$ and The Underground Woman (1975), her last novel, draw attention to oppositions inherent in women's subject positions. Because Boyle's protagonists, Bridget and Athena, are white women, the opposites that their silences manifest are more akin to those integral to the silences of Chopin's protagonists, Therese and Edna, than they are to those manifested in the silences of Hopkins's protagonists. Like Therese's and Edna's silences, Bridget's and Athena's silences reflect dominant culture's belief that white women of the middle and upper classes are either selfsacrificing caretakers, women who show deference to their men and children by silencing their own feelings, or selfish women, women who oppose their men and children by expressing their own feelings. During some of their silences, Bridget and Athena assume themselves to be responsible for the well-being of their loved ones. However, they are confronted by situations that make it virtually impossible for them to fulfill their role. Odd as it may seem, to help her husband, who has a degenerative hereditary disease, Bridget must conceive a child with someone other than with him. To help one of her three adult daughters, Athena must convince her to leave a commune whose members are brainwashed and sometimes drugged by its leader. Because they cannot fulfill their role as caretakers, during some of their silences, Bridget and Athena feel shame and, during other silences, 
without an identity. Like Hopkins's as well as Chopin's protagonists, then, Boyle's protagonists are "given to suffering in silence ..." (Scott 4).

More than forty years separates Plagued by the Nightingale and The Underground Woman, but Bridget and Athena face the same challenge: to free themselves from an identity driven by oppositional thought. While Bridget, like both of Chopin's protagonists and the protagonist of Hopkins's Winona: A Tale of Negro Life in the South and Southwest, does not free herself from the "either/or" attributes of her subject position, Athena, like both protagonists of Hopkins's Contending Forces: A Romance Illustrative of Negro Life North and South, helps herself to become free, in part by confiding in people who, in some way, enable her to challenge oppositional thinking. In fact, the importance of "a speech community" (Yaeger 215) that Hopkins establishes gradually emerges in Boyle's novels. Interestingly, unlike the people who help the protagonists of Contending Forces, a man as well as a woman helps Athena, and the man is black. With this man, Boyle establishes a new phenomenon, for white protagonists at least: it is possible for a person of a race as well as a gender different from the protagonist's to be a member of the protagonist's "speech community."

Yet, no matter the confidant's gender or race, the "reciprocal fashion" of silent thought and verbal expression about which George Kalamaras argues (8) and the "fellow speakers who ... encourage ... growth of ... thought" about which Patricia Yaeger argues (215) aid the protagonist's journey to selfhood. Compared with the protagonists' silent thoughts subsequent to their confidences in Contending Forces, however, Athena's subsequent silent thoughts are more extensive, which relates to the claim mentioned by Patricia Hill Collins about protagonists of contemporary black women authors. Collins notes, "Other . . women may assist a ... woman in this journey . . , but the ultimate responsibility for self-definitions ... lies within the individual woman herself" (112). Race of the author notwithstanding, the protagonist's "journey" seems increasingly solitary or silent. 


\section{Critical Response}

My argument about the significance of the protagonists' silences in Plagued by the Nightingale and The Underground Woman corresponds with Sandra Whipple Spanier's contention that Boyle's fiction concerns "a woman ... groping for an identity" (215), and a few critics do make reference to types of silences in Boyle's novels. However, neither Spanier nor any other critic has noted a connection between a protagonist's "groping for an identity" and an indicated silence. Within an essay exploring Boyle's use of narrative description, Suzanne Clark examines a type of implied silence that she perceives. She says that through narrative description "Boyle opens language to the pressure of the unspeakable ... of what cannot be said, but can be mutually felt" (331). That is, Clark argues that Boyle uses narrative description as a subtle means by which to show, not tell, relationships among characters. Boyle might well have agreed with Clark's analysis. In an interview occurring decades before Clark's essay was published, Boyle responds to a comment similar to Clark's that in Boyle's writing "it's often what the characters don't say that is most important" ("Kay Boyle," Talks 223). Boyle replies, "I think that in having silences, in making implications, I'm simply recording what I've observed in life" (223). In other words, through "silences" or, more accurately, "implications" rather than through explanations or direct statements, Boyle attempts to reproduce her perception that people tend not to express but to sense each other's feelings.

One of two types of silences to which Elizabeth Bell alludes within a chapter on Wedding Day and Other Stories, a collection of Boyle's short fiction published a year before Plagued by the Nightingale, relates to both the above-mentioned interviewer's comment and Boyle's response. The first, as well as the second, type of silence exists in the two novels that I examine. This first type concerns "what characters don't say," and it is "impli[ed]" (Boyle, "Kay Boyle," Talks 223). More specifically, it concerns "what [protagonists] don't say" to other characters but do say to themselves. In her analysis of "Theme," a story about "the departure of an adult son from his mother's home" that is told 
from "the mother's perspective," Bell refers first to "the mother['s] pretend[ed] conversation with her son" during one of his brief absences prior to his final leave-taking and then to the fact that upon the son's return "the mother remains silent, unable to communicate with him as she had in her fantasies" (Kay Boyle 11). Unfortunately, Bell fails to report the things that the mother "pretends" to say to her son, thus precluding the possibility of gleaning how the mother feels about her identity as a mother. However, Bell alludes to an implied silence when she notes that the mother is "unable to" say to her son what she says to him in "her fantasies," and this type of implied silence exists in both Plagued by the Nightingale and The Underground Wuman. Often in these novels, the protagonists imagine talking to other characters, and they usually do not actually say to them the things that they imagine saying.

In my examination of Boyle's novels, I make mention of the implied silence to which Bell alludes, but my examination focuses on the second type of silence that Bell's analysis of "Theme" also suggests. This second type makes it possible for readers to perceive the implied silence because, unlike the implied silence, it is made explicit. That is, an omniscient narrator gives directives, words indicating that as the protagonist begins to imagine saying to another character things she may not actually say at some later moment, she is being literally silent. Bell does not refer to narrative words that indicate the mother's literal silence as she imagines talking to her son, but they apparently are there. In saying that "the mother remains silent" (emphasis added) after her "pretend[ed] conversation" (Kay Boyle 11), Bell implies a distinct awareness that the mother is being silent as she has the "pretend[ed] conversation." Indeed, it is clear that the protagonists of the two novels are being literally silent as they imagine talking to other characters because the narrators indicate that they are being silent. ${ }^{3}$

Bell does not provide an in-depth discussion about Boyle's use of the imagined conversation, nor does she describe the specific manner in which Boyle presents the conversation. However, toward the conclusion of her chapter on Wedding Day and Other 
Stories, she makes a general comment about Boyle's early writing that relates to those rhetorical strategies as Boyle uses them in Plagued by the Nightingale and The Underground Woman, and it is those strategies that distinguish many of the silent thoughts of Boyle's protagonists from most of the silent thoughts of Chopin's and Hopkins's protagonists. Bell comments that Boyle "freely experimented with narrative form and with some of the conventions of punctuation, particularly of dialogue ..." (Kay Boyle 15). Like Chopin and Hopkins, Boyle uses an omniscient narrator in each of her two novels to indicate the protagonist's silences and, in some instances, to reveal their thoughts as well. However, in many instances, she "experiment[s] with narrative form" by using the omniscient narrator in combination with a type of first-person narrator. In these many instances, and as apparently occurs in "Theme," Boyle uses the omniscient narrator to indicate that the protagonist is being silent. During the silence, the protagonist narrates her own thoughts by "dialogu[ing]" or, most often in the novels, by "[mono]logu[ing]" with herself and/or other characters. In other words, the protagonist imagines herself to be speaking. There are two exceptions to this pattern in The Underground Woman. In one case, the protagonist imagines another character speaking back to her, and, in the other instance, she imagines not herself but another character to be speaking.

In these novels, Boyle also "experiment[s] ... with some of the conventions of punctuation" (Bell, Kay Boyle 15), and in two ways. Sometimes when the protagonist has an imagined monologue or dialogue, Boyle encloses these silent speeches within "punctuation," and, from the writing of Plagued by the Nightingale to the writing of The Underground Woman, Boyle further "experiment[s]" by changing the type of punctuation that she uses. When Bridget and Athena speak silently to themselves and/or to other characters who are not in their presence, Boyle does not use any punctuation to distinguish the silent speech from the surrounding text. However, with a couple of exceptions in Plagued by the Nightingale, which I discuss in my analysis, when Bridget and Athena speak silently to other characters who are in their presence, Boyle uses punctuation. For 
Bridget's silent speech, she uses double quotation marks. For Athena's silent speech, as well as for the omniscient narrator's indication of Athena's literal silence, she uses parentheses.

The silent thoughts of Boyle's protagonists are similar to those of Chopin's protagonists in that they concern the subject position of middle- and upper-class white women. However, unlike Chopin's handling of most of those thoughts, Boyle's "experiment[ation] with narrative form" (Bell, Kay Boyle 15) enables her protagonists to reveal many of their own thoughts during the moments that they have them, and her "experiment[ation] ... with some of the conventions of punctuation" enables her to emphasize those moments beyond the emphases provided by the omniscient narrators' indications of the silences. While I cannot know with certainty the original motivation behind Boyle's use of those "experiment[al]" rhetorical strategies, I can posit some ideas. Undoubtedly, "[h]er [early] literary friends[hips] and acquaintances[hips] . . [ [with authors who included] James Joyce, Ezra Pound, Gertrude Stein, William Carlos Williams, Robert McAlmon, and Emmanuel Carnevali" (Jackson 84) affected her approach to writing. However, as the list indicates, Boyle, no less than Chopin, had to find an identity as a female author in a predominantly male world. Regarding this point, differences in cultural moments must be considered. On the one hand, by the time that Boyle began her literary career, the Women's Movement had realized goals, such as enfranchisement, that it had been striving to achieve as Chopin wrote. These accomplishments may have allowed Boyle to feel more confidence in her authority as a female writer than Chopin might have felt. On the other hand, unlike the decade during which Chopin wrote her novels, when Boyle began her career, the Women's Movement was in the process of being firmly silenced. This silencing may have given Boyle greater motivation to try different rhetorical strategies to validate her protagonist's silent thoughts than Chopin might have had. 
One could assume that the change in punctuation from Boyle's first to last novel marking the protagonist's silent thoughts directed to someone present reflects a decreased motivation to validate them, but it could reflect the opposite. Since Boyle replaced the double quotation marks, punctuation conventionally used to indicate a character's spoken words, with parentheses, punctuation conventionally used to indicate text that "may be helpful or interesting but not essential to meaning" (Fowler 428), the change could reflect a feeling on Boyle's part that women's silent thoughts did not need to be validated as much as they did previously. Rights denied to women in the 1920 s, such as the legal right to birth control, were acceded to them by the 1970s, the time during which Boyle wrote The Underground Woman. However, in the 1970s, the Women's Movement was beginning to be silenced as it had been in the 1920s, which would provide Boyle with at least an equal degree of motivation to validate her later protagonist's silent thoughts. Rather than Boyle's use of parentheses reflecting a feeling that women's silent thoughts needed to be validated less, it could reflect a feeling that they needed to be validated unequivocally. The quotation marks enclosing Bridget's silent thoughts obscure the fact that she is not speaking; the parentheses enclosing Athena's silent thoughts do not. Keeping in mind that Boyle "experimented ... with some of the conventions of punctuation" (Bell, Kay Boyle 15), she could have used parentheses to enclose Athena's silent thoughts to make clear that these thoughts "[can] be helpful[,] interesting[,] [and] essential to meaning" (Fowler 428), for the protagonist as well as for readers. While I subscribe to the latter possibility, I do not include the parentheses when quoting from Athena's silent thoughts because doing so may cause a misreading of my text. I do not think my inclusion of quotation marks enclosing Bridget's silent thoughts would have the same effect, so I include them.

\section{Biographical Information and Historical Background for Plagued by the Nightingale}

Boyle probably would have denied that she manipulated punctuation in her first as well as in her last, novel to validate her protagonist's silent thoughts, for she vehemently 
denied being a feminist. Joan Mellen, her latest and most thorough biographer, relates that she reacted to the Feminist Party's recognition of her the year before publication of The Underground Woman by writing to a friend, "'I'm not a feminist!"' (489). Indeed, some personal choices that Boyle made lend credence to her exclamation. For example, when Ernest Walsh, a poet-editor whom she reverenced, asked her "'how [she]'d feel about taking [him] on [as a lover]'" (qtd. in McAlmon 201), she had "want[ed] to finish Plagued by the Nightingale" (200), but she stopped working on it to expend all of her time and energy on Walsh's or, as she called him, Michael's needs and desires. In her reminiscences, she says, "[N]othing mattered to me except Michael's beauty and his courage, and I wanted to pay homage to what he was for all my life" (201). She "took dictation ... , and answered letters, and returned rejected manuscripts; [she] shopped and cooked, and sang the songs Michael liked to hear as [she] hung the laundry out to dry" (201). Fortunately for her own literary career, Michael died (213), and she went on to complete Plagued by the Nightingale (240).

Despite Boyle's unfeminist behavior, her first, as well as her last, novel concerns feminist issues. As Mellen comments in reaction to an article that "examin[es] how women writers dealt with 'the heroine's entanglement with patriarchal norms," it fails "even [to] mention the author of Plagued by the Nightingale, although [that novel] deals with just that conflict" (489). Boyle began to write Plagued by the Nightingale after she had moved to France with her French husband, and her "rather unpleasant experiences with [his family] are ... fictionalized ... [in her] first novel" (Bell, "Kay Boyle" 35). However, (auto)biographical evidence suggests that Boyle would have written it from the perspective of a woman yet "'entangle[d] with patriarchal norms'" particular to the United States (Mellen 489). She began writing during the winter of 1923-24 (66-67), only about six months after leaving the United States (54-55). During those first six months, her thoughts drifted toward her homeland. According to her own account, she frequently asked her husband, "What time is it in New York now?" (McAlmon 76). In fact, based upon a letter 
that Boyle wrote to her sister, Mellen infers that "Boyle stayed on in Europe only for her husband's sake" (60). Given Boyle's very recent emigration from the United States and her apparent emotional connection to her homeland, the "unpleasant experiences ... [that she] fictionalized ... [in her] first novel" (Bell, "Kay Boyle" 35) and the protagonist's indicated silences that she included in it are best considered within the context of the sociopolitical situation of middle- and upper-class white women, especially, in the United States around the time that she wrote it.

By the early to mid 1920s, the Women's Movement in the United States had gained power, but dominant forces reacted against those gains, contributing to a silencing of the Movement. Of course, this type of reaction is not surprising. Using Michel Foucault's idea about "discursive field[s]," Chris Weedon explains that "discourses ... marginal to existing practice ... [are] dismissed by the hegemonic system ... as ... bad" (35). Two manifestations of a "discourse ... marginal to existing practice" or, phrased differently, two of the largest gains experienced by the Women's Movement were the passage of the Nineteenth Amendment in 1920, preventing the denial of voting rights on the basis of sex (Rosenberg 72), and the institution of reform legislation in several states during the early 1920s, providing protective labor and health-care laws for women and children (74).

Feminist advances such as these were countered by accusations such as those made against the National Council for Prevention of War (NCPW), an organization formed by several women's groups after the First World War. The groups had united "to campaign for disarmament, an end to conscription, and an investigation of the munitions industry" (76). However, one influential army general--a mouthpiece for the "hegemonic system" about which Weedon speaks (35)--created "a 'spider's web' chart . . . describ[ing] the interconnectedness of American women's organizations and alleg[ing] . . . these groups['] inten[tion] to ... promote a Bolshevik takeover" (Rosenberg 76). This "chart," whose creation occurred at the height of the Red Scare, prompted women's groups to withdraw 
their support of the NCPW as well as of other causes (76-77), and the protective legislation began to lose ground (75).

Concurrent with the dominant culture's reaction against feminist gains, the Women's Movement experienced internal conflict. Once the Nineteenth Amendment passed, women within the Movement began to disagree about which goals to pursue. When the National Woman's Party initiated the all-encompassing Equal Rights Amendment in 1923, other women's groups opposed it primarily because they feared that it would lead to the abolishment of the protective labor laws (Rosenberg 79-80), and few women from either camp supported Margaret Sanger's efforts to legalize birth control largely because they feared that it would draw attention away from, if not jeopardize, other causes (82). Indeed, "birth control's implied sexual license was contrary to the ... feminine moral superiority upon which many women's rights advocates staked their political authority" (McCann 26-27).

Undoubtedly, the Movement's own disassembly, as well as external condemnation of the Movement, significantly affected the next generation of women. Younger women shunned the label "feminist," equating it with "being lonely and unmarried" (Rosenberg 91). A new type of feminism that rejected the "[older] feminist idea ... [of] unity in gender ... [and adopted an] inward . . . focus" burgeoned (92). This changed perspective, first envisioned by Heterodoxy, a club created in 1912 by politically motivated women in Greenwich Village (63), included a "preoccupation with sexual freedom and economic independence ... [which] spread like wildfire in the years after the [First World] [W]ar ..." (92). Unfortunately, the popular version of this new feminism embraced heterosexuality to the point of encouraging homophobia, so women tended to devalue relationships with each other (93).

All of these feminist groups and causes--Heterodoxy, the National Council for the Prevention of War, the Nineteenth Amendment, the Equal Rights Amendment, reform legislation, and the Birth Control Movement--challenged the status quo. However, I think 
that the Birth Control Movement is most relevant to Plagued by the Nightingale--and, because its effects were long-lasting, to The Underground Woman as well--because mainstream society believed it to be a major threat to the very foundation of woman's subject position: wifehood and motherhood. This foundation was established long before the image of the Southern lady, but it was buttressed by that image, which has continued to inform the subject position of women in the United States. Anne Firor Scott defines "[t]his creation ... as a ... wife whose reason for being was to love, honor, [and] obey ... her husband [and] to bring up his children ..." (4). Since the dominant culture considered women not of the middle and upper classes and/or not white to have qualities opposite and inferior to the qualities of that image, turn-of-the-century alarm about birth control centered around class and race issues. Not only did the dominant culture "view ... birth control [as] represent[ing] a rebellion of women against their primary social duty--motherhood," but it also "fear[ed] that the Yankee 'stock' ... would be overwhelmed . . . by immigrants, non-whites, and the poor" (Gordon 137). It is true that "[c]ondoms . . . had been available for centuries, rubber condoms since the mid-nineteenth century" (205) and that "effective contraceptive practices were common in the middle and upper classes ..." (154). However, women of every class had abortions, and black women were bearing the fewest number of children (154). Nonetheless, the dominant culture objected to birth control because it feared not only that women would gain more self-control but also that it would lose dominance over other cultures.

According to Carole McCann, author of Birth Control Politics in the United States. 1916-1945, those fears were later lodged against the Birth Control Movement in general and Margaret Sanger in particular, and the Sangerists inadvertently helped to maintain the dominant culture's biases. McCann contends that while Sanger believed "contraception [to be] a woman's fundamental right" and diaphragms, a means by which women could control their own reproductive capabilities (1), she couched her belief in terms congruous with "the gender, race, and economic order inscribed in [dominant] institutions and 
discourses ..." (5). In particular, Sanger and her co-workers adopted the rhetorical terms "an 'economic ethic' of fertility" (13) and "the ideology of racial betterment" (14). The former term was adapted from English economist Thomas Malthus (13), and the latter term was adopted from the science of eugenics (14). While the former term concerns financial status, the latter term concerns racial, including ethnic, status; for "[e]ugenicists . . . argued that racial [including ethnic] improvement required controlled breeding" (14). In essence, the Sangerists' adaptation and adoption of these rhetorical terms encouraged the dominant culture's belief that middle- and upper-class women of Western-European descent should produce more children than should women of the lower classes and of other ethnicities. Sangerists also aided in the perpetuation of traditional gender roles. As McCann argues, "Sangerists [did not] contest the conventional division of labor within the nuclear family wherein men provided financial support and women provided nurturant care" (18).

Overall, Sangerists inadvertently created a niche for dominant forces to silence the advocates' intent to empower all women with reproductive choice or, more broadly, to silence all women's right to control their own bodies. Courts gave control over the dissemination of contraceptives to medical doctors (McCann 19)--primarily, white men. The Supreme Court went so far as to support eugenic-driven legislation that mandated "compulsory sterilization ... of the feebleminded, insane, and syphilitic" (114). Since eugenicists "[r]epresent[ed] social hierarchies as [being] reflections of biologically based incompetence" (113), one can imagine that the Court-approved "compulsory sterilization" could have been used to limit the number of children that women of color and/or of the lower classes had. Albeit in an inverse way, middle- and upper-class white women also failed to gain reproductive freedom. As McCann says, "[t]he distance between the assumption that some women are dependent upon the proper guidance of science and the assumption that all women are so dependent is short" (20). Decisions made by the legal system and carried out by the medical system compelled middle- and upper-class women of Western-European descent to fulfill their role as mother (and, implicitly, as wife), which 
suggests that the dominant culture must have greatly feared that women in that subject position would not fulfill their role voluntarily. As Weedon argues, "[w]here existing power relations are under threat . .. , initially consensual forms of discourse often employ coercion to govern the subjects in question ..." (100-101).

That the magnitude of the "threat" the "existing power relations" presumably felt from the Birth Control Movement was real, however, appears debatable. Not only did women's groups fail to support the Movement and the Movement itself fail to challenge woman's dual role as wife and mother, many young women assumed that they would become housewives and have babies. While the "general rightward turn in the society in the 1920 s" prompted members of the politically motivated Heterodoxy to "dr[a]w back after a few years ... to more moderate positions and sometimes all the way to traditionalism" (Gordon 196), the popularized version of Heterodoxy adopted by many post-war women, which "emphasize[d] ... [heterosexual] sex[,] did not ... challenge the idea of woman's place being in the home" (202). Indeed, "[t]he 1920s . . masses were being fed a ... new culture [of advertising]," including cars, which made "premarital sexual adventure" more possible, and "beauty products," intended to relieve the "tedium of housewifery ..." (201-02). Further, except for the small number of well-educated and professional women, "motherhood was in fact as well as in ideology the most ... enjoyable part of [women's] lives ..." (133). As Weedon contends, "subjectivity ... is an effect of discourse" (86). For middle- and upper-class Anglo-American women, the legal and medical systems reinforced the wife-mother discourse that advertisers sold and unfulfilling employment encouraged.

However, Weedon also argues that those of us who have "[k]nowledge of more than one discourse ... [have] a measure of choice" about our subjectivity (106), and that argument is applicable to Boyle. On the one hand, like many girls entering womanhood during the latter half of the 1910s, Boyle was a product of the dominant discourse. According to Mellen, Boyle "grew up in an America where being a woman meant marriage 
and children, first and foremost" (29), and she evidently absorbed the post-Heterodoxy brand of feminism, which prepared many young middle- and upper-class white women for the role of wife and mother. In her mid-teens, she "ma[de] what passed for love in the back seats of automobiles," and, when one suitor "vanished from the scene[,] . . . a legion of young men quickly took his place" (36). By her twentieth year, at least, she "generally preferred male company" (50). On the other hand, Boyle was exposed to discourses that competed with the dominant one. When she was only six, her mother "convinced [her] that she was a poet and a writer" (25), and, soon after she began to pursue a literary career in her late teens, she had as her employer Lola Ridge, a "revolutionary socialist and feminist poet" who "opened to [her] a world of progressive ideas[,] [including] the urgency of contraception as a means of liberating women ... [and] the insistence that women be acknowledged as writers rather than as 'women writers' ..." (49-50).

Borrowing Weedon's phraseology, I think that Boyle's "[k]nowledge of more than [the] one discourse" dictating that women in her subject position should marry and have children did give her "a measure of choice" (106). I also think that the "choice[s]" she made--many of them during the time that she wrote Plagued by the Nightingale-- indicate a conflicted sense of identity, especially in terms of her societally prescribed role as dutiful wife and devoted mother. She married in 1922, when she was twenty years old (Mellen 48), but she (illegally, of course) aborted the fetus that she and her husband had created within the first year of their marriage (53-54). She bore a child four years after this abortion, in 1927 (100-101), but that child resulted from her extramarital relationship with Ernest Walsh (90-91), the poet-editor whom she called Michael. Interestingly, despite her middle-class status, letters that she wrote during the pregnancy suggest that she had been negatively affected, to some extent at least, by the Eugenics Movement. To her mother, she wrote that the baby "'must be perfect'" (100), and, to her paternal grandfather on the eve of the delivery, she wrote, "'[U]nless it be a perfect baby[,] I shall turn my face to the wall and die"' (101). Apparently, she had not felt entirely "reassured [by medical 
personnel] that the baby could not inherit Walsh's disease [tuberculosis]" (100). A year after this birth, she aborted a fetus that resulted from one of a number of brief liaisons $(124,126)$. By 1943 , Boyle was into her third marriage and had borne a sixth child (274, 278).

\section{Silences in Plagued by the Nightingale}

During the historical moment that Boyle wrote Plagued by the Nightingale, various discourses encouraged middle- and upper-class women of Anglo-European descent to marry and bear children. During her writing of that novel, Boyle was married and became a mother. Not surprisingly, the novel abounds with silences relevant to that dual gender role. As though seeking retribution against the Birth Control Movement and the group to which it attached itself to gain credibility, the Eugenics Movement, for having influenced not only her desire to have a child but also her fear of producing an unhealthy one, Boyle turned the racist and classist ideology underlying both movements on its head. By the end of the first chapter, a major conflict about the white protagonist's bearing of her middleclass husband's children becomes clear: despite the probability that should Bridget's husband, Nicolas, father a son, the son would inherit the degenerative disease with which Nicolas and most male members of the family are afflicted, Nicolas's parents expect him and Bridget to produce several children, and he refuses to father any children. ${ }^{4}$ Bridget has little knowledge of the French language when she and Nicolas arrive at his family's home with the hope that he can recuperate enough to find gainful employment, so she understands neither Maman's implicit expectation nor Nicolas's implicit refusal. In fact, Maman's implication that she expects Bridget to bear children renders Bridget literally silent. When Maman redirects her effusion about Charlotte, her one married daughter, and the several children whom Charlotte has already borne, to Bridget, by saying "so meaningly" to her, "'[e]t vous,"' Bridget responds by "look[ing] away in confusion . . ." (10). Undoubtedly, she is just as "confus[ed]" when Nicolas intimates his refusal to sire a 
personnel] that the baby could not inherit Walsh's disease [tuberculosis]" (100). A year after this birth, she aborted a fetus that resulted from one of a number of brief liaisons $(124,126)$. By 1943 , Boyle was into her third marriage and had borne a sixth child (274, 278).

\section{Silences in Plagued by the Nightingale}

During the historical moment that Boyle wrote Plagued by the Nightingale, various discourses encouraged middle- and upper-class women of Anglo-European descent to marry and bear children. During her writing of that novel, Boyle was married and became a mother. Not surprisingly, the novel abounds with silences relevant to that dual gender role. As though seeking retribution against the Birth Control Movement and the group to which it attached itself to gain credibility, the Eugenics Movement, for having influenced not only her desire to have a child but also her fear of producing an unhealthy one, Boyle turned the racist and classist ideology underlying both movements on its head. By the end of the first chapter, a major conflict about the white protagonist's bearing of her middleclass husband's children becomes clear: despite the probability that should Bridget's husband, Nicolas, father a son, the son would inherit the degenerative disease with which Nicolas and most male members of the family are afflicted, Nicolas's parents expect him and Bridget to produce several children, and he refuses to father any children. ${ }^{4}$ Bridget has little knowledge of the French language when she and Nicolas arrive at his family's home with the hope that he can recuperate enough to find gainful employment, so she understands neither Maman's implicit expectation nor Nicolas's implicit refusal. In fact, Maman's implication that she expects Bridget to bear children renders Bridget literally silent. When Maman redirects her effusion about Charlotte, her one married daughter, and the several children whom Charlotte has already borne, to Bridget, by saying "so meaningly" to her, "'[e] tvous,"' Bridget responds by "look[ing] away in confusion ..." (10). Undoubtedly, she is just as "confus[ed]" when Nicolas intimates his refusal to sire a 
All of the above silences lend credence to my claim that, in Plagued by the Nightingale, Boyle does not support the "'cult of domesticity"' which Patricia Raub says "most [women] writers of the Twenties ... reaffirm ..." (xvii). Raub describes these authors as "presenting heroines who devote themselves to ... raising children, and comforting husbands in exchange for their spouses' financial support and protection" (xvii). Essentially, these "heroines" represent the image of the Southern lady that Scott analyzes. It is true that Boyle "present[s] [a] heroine" who wants to "comfort [her] husband" and "rais[e] [his] children." Like most middle- and upper-class women of the 1920s, Bridget believes that she needs a husband and, through him, children in order to have an identity. Certainly, socioeconomic factors discouraged most women from thinking otherwise, and, in Bridget's case, Nicolas's inability to work and Papa's bribe give her added incentive to have Nicolas's child. Whether she intrinsically wants to be a mother is no more possible to discern than whether she actually wanted to be a wife. One could just as well ask a question about wifehood that E. Ann Kaplan asks about motherhood: "How can a woman distinguish her desire ... from that imposed on her [by patriarchy]?" (4). Boyle's own marital, abortion, and childbirth histories suggest that her inability to "distinguish" led to inner turmoil. However, unlike Boyle, whose literary career enabled her not to depend entirely upon a husband and children for an identity, Bridget has no idea that she could have a sense of self other than through her husband and his children, at least not until Charlotte suggests that lifestyles somewhat different from the social norm exist. Unfortunately, Charlotte's death precludes Bridget from getting support, both emotional and financial, for pursuing an identity not solely dependent upon her husband, and she is stuck with needing to meet the standards of the wife-mother discourse.

Perhaps because Boyle understood the dependent position in which the "'cult of domesticity"' (Raub xvii) placed women, in Plagued by the Nightingale, she sets up a problem that makes it impossible for her protagonist to meet the standards of that wifemother discourse, and, as though she wanted to draw attention to the inner turmoil that 
else because she cannot meet the standards of the "'cult of domesticity"' (xvii) and, usually, she uses the silent monologues to blame herself or to deny her own feelings. Basically, these self-narrated silences or silent monologues occur in clusters, and the clusters, in the following sequence. Initially, Bridget speaks silently to Nicolas, then to Luc--a man whom Nicolas's family hopes will marry one of their three eligible daughters but who takes a fancy to Bridget--and, between her silent monologues to Luc, to herself. Bridget's silent monologues to Nicolas, which begin when he absents himself for several hours from her, as well as his family's, presence, reflect both her shame in being unable to fulfill her caretaking role and her fear of being abandoned by him. In fact, his moroseness, often manifested by silence, can be perceived as a form of emotional abuse; for, at least at times, he becomes silent intentionally. In succession, she silently blames herself for his having become withdrawn, him for having become withdrawn, herself for being angry with him for having become withdrawn, and herself for not seeking employment that would end his dependence upon his family. In a sense, then, Bridget ultimately blames herself for not fulfilling her role as Nicolas's caretaker by assuming his role as breadwinner.

From the perspective that Nicolas's moroseness is a form of emotional abuse, Bridget's silent monologues to Luc are a reflection of her having reached her threshold of tolerance for Nicolas's abuse and, related to that, of her becoming aware that not only he but also most members of his family value each other and others, including herself and Luc, according to their potential to propagate the family. Although motherhood is an aspect of the identity that Bridget wants to have, she resents Nicolas and most members of his family for viewing her, as well as others, as breeders. However, because she depends upon Nicolas for a sense of self and he depends upon his family for their financial support, she denies to herself her feelings of resentment toward him and them primarily by projecting her feelings onto Luc. Initially, she silently urges him to escape from the family; later, she silently tells him that he lacks the strength necessary to leave them. During her 
last silent monologue to Luc, when circumstances make it virtually impossible for her to project her feelings onto him, she deflects those feelings by using a more direct method of self-deception: she pretends that she feels the opposite way that she actually feels. This last time, Bridget silently implies to Luc that she can leave Nicolas and his family.

Significantly, between the silent moments that Bridget projects onto Luc her initial desire to escape from the family and her lack of strength to leave them, her submerged resentment toward her own family, Nicolas's family, the type of family whom she did not have, and Nicolas briefly erupts, and she speaks silently to herself about her resentments. As it is true, I believe, that resentments toward others are actually reflections of ill feelings toward oneself, when Bridget silently talks to herself about the people whom she resents, she blames herself both for not seeking an identity outside social norms and for not being able to fulfill the identity prescribed by social norms. In essence, then, Bridget's silent monologues to herself about her resentments lead her to feel without any identity at all. As a result of this feeling of nothingness, she silences herself, first, by resuming her projection of her feelings onto Luc during a silent monologue to him and, ultimately, by deluding herself into believing that she can take care of Nicolas by becoming the mother of his child or, in other words, by denying the reality that Nicolas will not father a child.

Bridget's first silent monologue to Nicolas occurs as a result of his absenting himself from her and his family for several hours. The third-person narrative preceding Bridget's silent speech reveals the extent to which she depends upon his actual presence for a sense of being, but her own narrative reveals her feeling blameful for his absence. As long as Bridget remains on Charlotte's veranda and she "c[an] see" Nicolas helping some local fishermen position a net (41), she remains calm. However, upon conceding to Charlotte's desire of a walk, Bridget eventually loses sight of Nicolas, and the farther away they walk, the more distraught she becomes. Ultimately, the physical surroundings feel "unreal to her," and she "[i]s numb with terror" (43). In other words, without Nicolas within her field of vision, Bridget experiences a psychotic episode. The episode abates, 
but, when Nicolas does not return for dinner, "a terrible fear ... grow[s] in Bridget's heart ..." (45). At some level, she knows that Nicolas's bitterness toward his family "turned his heart so cold" (46) or, in other words, compelled him to leave them for awhile, but, as only her silent monologue to him reveals, she internalizes his resentment toward them. Albeit that she "whispers" or actually utters her thought, she does not utter it in Nicolas's presence, so I consider it to be a type of silence. Wandering aimlessly inside Charlotte's house, she asks her absentee husband, "Nicolas, where are you, what have I done ... to drive you away?" (46). In that Bridget assumes a causal relationship to exist between "where" he is and "what [she] ha[s] ... donc," she blames herself for his absence.

Within the above silence, Bridget implies self-blame for Nicolas's absence, but, when Maman insensitively yet without malice tells about an uncle of Nicolas who made a practice of absenting himself from his wife, during Bridget's next silent monologue to Nicolas, she temporarily shifts the blame for his absence from herself to him. As she, Charlotte, and Maman take a walk to distract themselves from Nicolas's absence, Maman relates that Uncle Robert, "'[having] made up his mind never to be [his wife's] husband again, ... le[ft] her for days at a time'" and that his wife "'sued him for divorce to have her own way"' (48). Maman's saying that Robert's wife "'sued . . . to have her own way"' makes clear that she does not sympathize with the woman. However, Bridget evidently empathizes with the wife, for, as she "listen[s] .. . [to] the story" (49), she thinks about Nicolas's alienation from her. She realizes that "[u]ntil this moment she had thought of . . herself and Nicolas [as] . . one spirited high will[;] [n]ow she kn[o]w[s] that they [a]re not" (49). When Maman relates that, in divorce court, Robert "'plead[ed] ... against the demands of passion,"' she "hisse[s]" that "'[p]assion it was [the wife] had for him ..." (49). Given Maman's obvious animosity toward Robert's wife for wanting him to show "'passion"' for her rather than to withdraw from her, it is not surprising that Bridget does not confide in Maman her own anger toward Nicolas for withdrawing from 
her. Instead, she "whisper[s]" her feelings to Nicolas, saying silently to him, "Why did you turn from me too" (49). At this moment, Bridget blames Nicolas for "turn[ing] from [her]."

As angry as Bridget is with Nicolas for withdrawing himself from her as well as his family, when she, Charlotte, and Maman encounter him a few minutes later, she only silently articulates her anger because she becomes ashamed of it. More specifically, she becomes ashamed of having a feeling that she attributes to women in particular. Maman chides Nicolas for upsetting her, and Charlotte cries on his shoulder. However, Bridget considers the idea that "whenever a woman $\mathrm{sp}[\mathrm{ea}] \mathrm{k}[\mathrm{s}]$ out without reflection it [i]s really some complaint she [i]s making," and in that "[e]verything she could think of to say to Nicolas was no more than a complaint against him," she reinforces the idea (50). Not only does her thought-process reveal that she attributes her own "complaint against," or her anger with, Nicolas to the fact that she is "a woman," but it also indicates that she has been socialized to define women in terms of binary opposites: they are either selfish women, women who oppose men by expressing their own feelings, or, by implication, caretakers, women who show deference to men by silencing their own feelings. Since Bridget wants to be a caretaker and not a selfish woman, what she says in actuality to Nicolas, "'How's your bunch of miseries?'" (51), suggests nothing about her own feelings. What she initially "sa[ys] . . . in silence" to him, "'Am I nothing at all to you that you could abandon me'" (50), indicates that she feels anger toward him for having "'abandon[ed]"' her. As though to blame her sex and, so, herself for that feeling, she silently adds, "'The womanly heart of me ... has nothing to do with where you were or what you did with your bunch of miseries'" (50-51).

Of course, along with the shame that Bridget feels for being angry with Nicolas, she keeps her anger silent because she fears that should she express it, Nicolas would "'abandon'" her again (50). In that she internalizes his emotional distantness, it is a form of abuse, which begins long before the day that he literally absents himself from her. 
Although she thinks it is not "[u]ntil th[e] moment" she hears the story about Uncle Robert that she realizes Nicolas's alienation from her (49), she actually senses his distantness much earlier. During a scene in which he rails bitterly against his family and ends his rage by expressing disappointment with some trees near or on his family's property because they no longer seem as large as they did when he was a child, "she fe[e]l[s] that something [i]s taking place in him that she kn[o]w[s] nothing about" (34). In fact, "[s]he fe[e]l[s] he [i]s turning remote ..." (34). Bridget obtains a sense of self from Nicolas, so, when "something ... tak[es] place in him that she kn[o]w[s] nothing about," she becomes less certain of her identity. At this stage of her awareness that "he [i]s turning remote," she responds with words of encouragement about his health rather than with silence. However, as his "remote[ness]" builds, her self-doubt and fear of being forsaken increase to the extent that she silently blames herself not only for his literal absence and her anger with him for absenting himself but also for his impending financial destitution, as her final silent monologue to him reveals.

In the scenes leading up to Bridget's final silent monologue to Nicolas, he does not yet blame her for creating his financial dependence upon his family, nor does he yet suggest to her that she surreptitiously conceive a child with another man so that he can collect the large sum of money his father offers him for fathering a child. However, he makes clear his enormous frustration with being unable to work and his unwillingness to father a child, after which he becomes withdrawn and silent. During the scene in which he discloses his father's bribe, he says that he and Bridget "'haven't any money ... no money at all,"' and, to justify his unwillingness to reproduce as well as his inability to work, he refers to "'this thing in [his] legs,'" the debilitating disease (51). In the following scene, he disregards Bridget. When she walks toward him, he "turn[s] away ... [,] setting new silences between them" (57). Of course, "new" implies that Nicolas has already created "silences between them" or, as I argue above, that he has been emotionally distant from Bridget for some time. It also forecasts his increasing withdrawal from, and 
silence toward, her. In the next scene, when they are opposite each other in a car enroute to Uncle Robert's home, he "s[i]t[s] with his face averted ..." (59). During their visit with Uncle Robert, Nicolas "s[i]t[s] silent and arrogant ..." (61). With the assumption that Nicolas's various silences are a form of passive-aggressive behavior or, with regard to Bridget, an attempt to instill guilt in her for having failed to be a successful caretaker to him, her final silent monologue to him is an indication of the effectiveness of his efforts.

This silent monologue occurs as Bridget stares at her reflection in a mirror. Initially, she focuses her thoughts on herself. However, because she has difficulty conceptualizing herself as a discreet entity, she shifts them to herself in relation to Nicolas-specifically, to her shame in not seeking an employment that could resolve his financial destitution. Hauntingly like the scene in The Awakening when Edna, crying in silence, "could not have told why she was crying" (Chopin 886), Bridget asks herself, "[W]hy should I cry ... [w]hy in the world should I cry?" (Boyle, Plagued 90). Like Edna, Bridget does not understand that her husband's behavior contributes significantly to her feeling sad. She does not perceive her husband's behavior as abusive. Unlike Edna, however, Bridget seeks an answer to the reason for her sorrow by silently addressing her husband: "Nicolas, Nicolas, I could be a brave woman if I tried, she [i]s thinking ... [;] [i]f I were a brave woman I'd go out and make a fortune ..." (90). Since Nicolas has not yet suggested to her that she conceive a child with someone other than with him so that he can collect on his father's offer and since, when he does make the suggestion, she interprets it as being a perverse joke, I think it unlikely that her reference to "mak[ing] a fortune" is an indication that she has already thought about doing what he later suggests. Further, since she has no apparent training that would enable her to "make a fortune," she probably is alluding to prostitution, an occupation that not only can pay well but also requires one to "go out" as well as be "brave," whether it be in the courageous or in the showy sense, or both. In any case, as the "if" clause implies, she does not perceive herself to be "a brave woman." In fact, "[s]he notice[s] nothing but her own shameful face in the 
glass ..." (90). From Bridget's perspective, she cries and perceives herself to be "shameful" because she has failed to take care of Nicolas.

Bridget's silent monologues to Nicolas end when she reaches her threshold of tolerance for his abuse of her. However, she does not reach that point when he blames her for creating his financial dependence upon his family. Upon telling her that "'[i]t's mostly [her] fault ... [,] [i]t was [her] idea that [they] come to France"' (106), he "st[ands] in silence beside her" and "look[s] immovably off into the impersonal distance ..." (107). Because Bridget fears being abandoned by him, she responds to his blame and sudden "silence" by "fl[i]ng[ing] her arms around [his] neck and saying, "'Darling, darling, I love you ..." (107). As mentioned previously, she does not even respond angrily when he generally suggests that she conceive a child with someone other than with himself (105). However, when Nicolas specifically suggests a potential surrogate father, Bridget absorbs the fact that he is not joking, and she reacts suddenly and violently. Upon commenting that a man they recently met at a picnic "'rather liked [her],"' Nicolas asks her "'[w]hat would [she] think of [that man] as [being] a pater familias,'" and she, feeling "an instant of . . rancour and despise," retorts, "'Don't ever tell me you love me again ... [;] I am going away'" (109). Given Bridget's dependence upon Nicolas for an identity, she, of course, does not "'go away.'" However, given that that identity involves not only "comforting [one's] husband" but also "raising [his] children" (Raub xvii), when Bridget realizes that Nicolas actually wants her to "comfort" him by "raising [a] child" who is not his, her rage temporarily overwhelms her fear of being abandoned. In speaking out against him, she speaks out for that identity.

Subsequent to Bridget's speaking out against Nicolas, she has a conversation with his sister, Marthe, and that conversation plants a new seed of resentment in Bridget. These growing resentments are significant because they precipitate Bridget's silent monologues to Luc. During this conversation with Marthe, she discovers that, like Nicolas, Marthe has come to value her for her ability to bear a child. She already knows that Marthe determines 
the worth of herself and her sisters according to their reproductive potential. In an earlier conversation, Marthe implies that, between herself and her two sisters who are also unmarried, she is most worthy to become Luc's spouse because she is both willing and able to bear children. She discounts Annick as being a viable candidate because "'it is a convent [Annick] has always wanted'" (90) and, by implication, not motherhood. She determines that "'Julie should not marry anyone at all"' because, biologically, "'Julie could never be a mother"' (91). It is not until Marthe, in essence, begs Bridget to become pregnant that she knows Marthe assigns the same value system to her. Desperate to increase her dowry so that she may be particularly attractive to Luc, Marthe, "down upon her knees," points out that Bridget "'could . . . lend [her] ten thousand francs out of the money Papa has promised ... for [Bridget's] baby"' (112). Strictly speaking, Marthe values Bridget for her capacity to provide her with a monetary lure to attract Luc.

However, bearing a child is the means by which Bridget can acquire that lure for her, so Marthe does value her for her reproductive ability.

During this same conversation with Marthe, Bridget also discovers that, like Nicolas and Marthe, Papa and Maman expect her to bear a child to satisfy their individual interests. Bridget already knows that the family wants Luc to marry one of their three eligible daughters so that he can engender more children for them, but she had not realized that her in-laws value her for the same reason. Several scenes earlier, she hears Uncle Robert encourage Luc to marry one of his nieces because Luc "'[woul]d have such pretty children ..."' (96). Bridget apparently recognizes the selfish nature of the family's desire for Luc to marry into the family, for it is the one and only time that she advises him "'n[o]t [to] get married"' (96). Despite that recognition, prior to her conversation with Marthe, Bridget does not think that the impetus behind Nicolas's parents' feelings about Luc extend to her as well. She believes that "[t]he family ... ha[s] been motivated [to urge her to have a child] by the one thought of bringing [her and Nicolas] closer to each other as husband and wife ..." (106). However, during the conversation in which Marthe begs Bridget to 
become pregnant so that she can increase her dowry, Marthe expresses the assumption that Bridget "'would not wish to wound Papa [by not bearing a child]," and she relates that Maman recently said '"[i]t is such a joy ... that Bridget is so anxious to please [them] all [by having a child]'" (111). Of course, in saying these things, Marthe attempts to promote her own cause by implanting in Bridget a feeling of obligation toward Papa and Maman to bear a child, but she also implants in Bridget the idea that Papa and Maman expect her to bear a child for their own "'joy"" or "'pleas[ure]."'

Minutes after her conversation with Marthe, Bridget has the first of three silent monologues to Luc. Probably because she fears involuntarily shouting out to the family the intense resentment that she feels toward them, Bridget sublimates her feelings by projecting them onto Luc. Undoubtedly, however, a promise that she makes to Marthe at the culmination of their conversation exacerbates her resentment toward the family. She has agreed to do to Luc what they have done to her: coerce him into satisfying their desires or, more particularly, encourage him to marry Marthe. Although "the speech of all she [ha[s] to say to [Luc] spr[i]ng[s] to her lips"--that is, her urging him to marry Marthe-"there it falter[s]" (113). At the moment, Bridget cannot bring herself to speak that which she does not feel. At the same time, however, she cannot bring herself to speak that which she feels. Apparently, she cannot even acknowledge to herself that which she feels, for, rather than think about her own feelings, Bridget silently urges Luc to do, in essence, what she cannot. Specifically, "her disturbed heart sp[ea]k[s] clearly out[,] 'Oh, ... escape ... [,] save yourself from all [the family] would condemn you to!"' (113). However, moments after Bridget has this silent thought, Luc hints at his romantic interest in her, and, apparently because she thinks that virtually any response to his interest would encourage him and belie her responsibility to Nicolas, she ignores his intimation and acts on her promise to Marthe. As the narrator relates, "[b]ecause [Bridget] [i]s Nicolas'[s] wife[,] she $\mathrm{kn}[\mathrm{o}] \mathrm{w}[\mathrm{s}]$ she ha[s] no right to know [with certainty Luc's feelings toward her]" (116). So strongly does she identify with being "Nicolas'[s] wife" that she cannot even utter her 
silent admonitions about the family to Luc. Instead, she says to him, "I'm sure that Marthe would make you very happy"' and "'I am sure you would be very happy with Marthe ..."' (117).

In that Bridget silently projects her resentment toward the family onto Luc and then actually speaks that which she does not feel, she doubly sublimates her feelings, and the price that she pays for that double self-silencing is not only more self-blame but also more self-deception. Upon encouraging Luc to marry Marthe, Bridget's "blood ... kindl[es] with the shame of ... interfering in other people's lives," and "she [i]s angry that she ... lack[s] the courage to say out what [i]s in her mind to say" (117). Bridget's feeling "[a]shame[d] of ... interfering in other people's lives" or, more accurately, having acted in the way for which she resents the family reinforces her low opinion of herself. However, her feeling "angry" with herself for not "say[ing] ... what [i]s in her mind to say" draws attention to a more fundamental problem: she does not recognize her habitual cognitive pattern of self-deception. Without that recognition, Bridget lacks the opportunity to break the pattern. "[T]he words she c[an]not utter" but thinks silently to Luc, "'[W]hat are you doing ... with people who would wrench children from you?"' (117), are "the words" she would like to say to him. However, she does not recognize her avoidance of asking herself the same question--that is, "'[W]hat a[m] [I] doing ... with people who would wrench children from [me]?'" Bridget also deceives herself by fantasizing that she can elope with Luc or, in other words, leave Nicolas. Accurately, she "th[inks]" that were she "[t]o escape with [Luc]," she "would be ... abandoning Nicolas" (118). However, she does not recognize the fact that she fears being "abandon[ed]" by Nicolas. As much as Bridget "lack[s] the courage" to speak her thoughts (117), she "lack[s] the courage" to be honest with herself within them. Without self-honesty, Bridget cannot begin to deal constructively with her resentments and with her fears.

The next moment that Bridget speaks silently to Luc, her cognitive pattern of selfdeception continues. Rather than recognize the fact that she feels incapable of leaving the 
family, she silently projects her feeling onto Luc. As though to enable herself to make that projection, when she gazes at Luc during the funeral mass for Charlotte, she perceives him to be like an infant. She notices "the arch of his neck and relentless purpose of his jaw," but she imagines that "his wrists [a]re delicate enough to be snapped in two ... [,] [that] his hair ... [i]s no stronger than the finest silk ... [,] [and that the areas] [b]ehind his rosy ears [a]re the most vulnerable spots that ha[ve] ever been ..." (177). Having perceived these infantlike qualities, she "th[inks]" to him, "[H]ow can anybody save you, ... what can anybody do?" (177). In that Bridget doubts "anybody [can] save [him]," she apparently imagines that he lacks the ability to "save" himself. Further, since she then envisions the deceased "Charlotte smiling because she ha[s] evaded [the family] all so well" (177), Bridget apparently imagines that what Luc cannot "evade" or, in other words, what he cannot "save" himself from is the family. More specifically, since the fetus that Charlotte was carrying died along with her, Bridget imagines that what Luc cannot "evade" is the family's expectation that he will produce a child for them.

Because Bridget accepts the fact that Luc plans to leave France and because her resentment toward Nicolas and his family threatens to overwhelm her, in her last silent monologue to Luc, she does not continue to project onto him her inability to leave Nicolas and his family. Instead, she returns to an earlier self-deception: she fantasizes leaving them by eloping with Luc. On the eve of this last silent monologue, Marthe relates to her Luc's announcement to the family that he "'is going to Indo-China ..."' (185). Bridget often denies to herself things Nicolas tells her, but she apparently accepts the sincerity of Luc's announcement and wants to absorb the strength of character she thinks his decision reflects. The following day, while she and Nicolas, his family, and Luc are together on an outing, she perceives Luc to exude energy, and she imagines that he transmits it to her. When he looks at her and says that he wants her to "'come down with [him] . . . and dig for clams,"' she "fe[els] . . ignited by his . . radiance" (188). In actuality, she becomes enflamed by her resentment toward Nicolas and his family. When she "fe[e]l[s] . . every 
eye ... [upon] her face ... [and] the grim relentless smile ... hovering on Nicolas'[s] lips [to be] the severest judgment of them all," she wants to "flog them with [her] despise [and] let loose the torrents of [her] impotence" (188). Of course, were Bridget to "let loose" her "impotence," or her inability to confront Nicolas and his family, by "flog[ging] them with her despise," or her resentment, she would jeopardize her position within the family--specifically, Nicolas's caretaking wife--which she fears doing. Thus, to control her resentment, she gives herself a sense of power, albeit false, by silently telling Luc that she will flee from the family with him. More specifically, she "think[s]" to him, "By all means, Luc, let us escape them[;] .. [1]et us go at once while we are consumed with it" (188).

In that Bridget accompanies Luc to the shoreline, she temporarily flees from Nicolas and his family. However, when Luc makes clear his hope that she will go to the Far East with him, she cannot permanently flee from them--especially Nicolas, "the severest judg[e] of them all" (188)--as her silently expressed word "escape" (188) indicates that she will. Luc does not hide from the family his decision to move to Indo-China, so, when he asks Bridget to "'dig for clams'" with him (188), he probably means just that and not, as she interprets his request, to leave the family "at once" (188). However, she does not misinterpret his hope that she will be his traveling companion. As they stand near the shoreline, he tells her that she "'know[s she is] coming away with [him] ..." (189). At this point, Bridget reveals to the reader, if not to herself as well, that she cannot "'com[e] away with'" anyone but Nicolas because she depends upon him for a sense of self. In response to Luc's statement, not only does she say, "'I cannot do that"' (190), but also, and similar to her reaction when Luc first intimates his romantic interest in her, she reaffirms her connection to Nicolas. This time, Bridget does not merely think about the fact that "she [i]s Nicolas['s] wife" (116). In effect, she reinforces that identity when she proclaims to Luc, "'Nicolas and I are going to have a child"' (190). 
Because critical debate about Plagued by the Nightingale centers around Bridget's last words, they merit some consideration. According to Spanier's summary of proffered interpretations, Frank Gado argues that Bridget will have Luc impregnate her, and Richard Carpenter contends that she will elope with him (61). With regard to Gado's argument, it is true that, at one point, when Nicolas asks Bridget, "'What do you think of Luc as a father of the race?'" (Boyle, Plagued 114), he intimates to her the idea that Luc impregnate her. And I agree with Carpenter's implication that Bridget is physically attracted to Luc. Once, when Luc lifts her into a rowboat, she "hear[s] in her heart the ... thunder of his blood" (88). However, Gado and Carpenter apparently do not take into account Boyle's characterization of Bridget as a woman who cleaves to her husband. Thus, I find most credible Spanier's claim that "Bridget's final statement [should] be taken at face value, as an indication of her faith that she can redeem Nicolas's spirit and persuade him to have a child despite the biological consequences" (62). Unless Bridget is willing to face the reality that Nicolas's illness and his unwillingness to father a child preclude him from giving her the identity that she wants, she must delude herself into believing that "'Nicolas and [she] are going to have a child"' (Boyle, Plagued 190). ${ }^{6}$

More challenging to me than the meaning of Bridget's last words is the fact that, unlike all of the other silent monologues that Bridget has in the presence of the person to whom she imagines speaking, her last two silent speeches to Luc--at Charlotte's funeral and at the family outing--are not enclosed in quotation marks. Rather than it having been an editorial oversight, I think that these singular absences of quotation marks may have been an attempt, however subtle, on Boyle's part to represent the point that Bridget does not, after all, have her own inner voice because she does not have a sense of self separate from, or in addition to, the identity of wife and prospective mother that the dominant culture prescribed for women in her subject position. Significantly, these unpunctuated silent monologues follow two moments during which, in silent monologues to herself, Bridget experiences an identity crisis. As though to reflect the intensity of this inner 
turmoil, the omniscient narrator intimates nothing of Bridget's thoughts for several pages after her two self-revelatory moments, and it is not until several pages after the narrator indicates only that, at one point, "Bridget ... [is] thinking of Charlotte who [i]s dead now" (173) that Bridget resumes her silent monologues to Luc, which allow her to avoid dealing directly with her inner turmoil.

Bridget's identity crisis begins when her resentments temporarily overwhelm her. More specifically, during her initial silent monologue to herself, her resentment toward her own family, Nicolas's family, and an ideal family erupts and culminates in a form of selfresentment. As the family waits for the dying Charlotte to somehow heal herself, general ruminations that Bridget has about younger people needing role models lead her to envision an ideal family. She "th[inks]" to herself, "I should have liked ... to have had heroes behind me ... who gave up family [and] fortune ... to discover a new planet ... or to fly alone across the Atlantic ... when no one had flown across it" (159). In believing that "had [she such] heroes behind her," she could "have shamed [Nicolas's family]" (159), Bridget implies that her own family is no more "hero[ic]" than Nicolas's family is. Apparently, her own family did not "g[i]ve up" the social norms of "family [and] fortune," and, by accepting them, they taught her not "to discover ... or to fly alone"--that is, not to seek self-definition--but to accept the norms, just as Nicolas's family expects her to do. Despite the fact that Bridget resents her family for teaching her to accept social norms and Nicolas's family for expecting her to fulfill them by bearing Nicolas's child, she cannot admire the ideal that her imagined family of "heroes" represents. Although she initially tells herself that she "should have liked ... to have had" a family of "heroes," she concludes her silent monologue by "th[inking], .. . I resent the purpose of the good family, for I myself have no purpose at all" (159). Bridget "resents [their] purpose" or their determination to seek self-definition because she "ha[s] no" like determination. In other words, she perceives herself to be deficient, and she "resents" herself for it. 
Given Bridget's conclusion that she lacks the determination necessary to seek an identity outside social norms, it is quite natural that, in her silent monologue to herself the following day, she thinks about Nicolas. According to the norms, women who marry into middle- and upper-class families obtain identities from their husbands. However, in making an implicit comparison between Luc and Nicolas, Bridget convinces herself that she cannot obtain an identity from Nicolas, and she ultimately blames herself. As she observes Luc walking toward Nicolas's family's house, she "th[inks]" to herself, "[T]his stern grace ... merit[s] loyalty. To him ... could be given a devotion which more sensitive men d[o] not require" (165). Apparently, Bridget then compares Luc with Nicolas, for, "as Luc c[o]me[s] across the room," she "th[inks]" to herself, "Of what use am I to Nicolas, ... of what use?" (165). Because Luc exudes the masculine standard of "stern grace" or self-possession, Bridget believes that a woman "could be ... [his] devot[ee]." In questioning her "use" or value to Nicolas, she implies that he is one of those "more sensitive men" who "d[o] not require [a woman's devotion]." She also implies that his "sensitiv[ity]" does not "merit loyalty." As her latter implication especially suggests, Bridget resents Nicolas's lack of self-possession because it precludes her from garnering an identity from him that meets social norms. No matter which perspective she takes-Nicolas not needing her "devotion" or his not deserving her "loyalty"--the outcome remains the same: she cannot be his caretaker. However, as Bridget's question to herself indicates, she turns her resentment toward him against herself. Rather than ask herself "[o]f what use [Nicolas is] to [her]," she asks herself "[o]f what use [she is] to [him]," and in blaming herself for being of no value to him, Bridget essentially blames herself for lacking an identity.

That Bridget silently experiences an identity crisis as Charlotte lay dying and that, in the aftermath of the crisis, she spends time "thinking of Charlotte who [i]s dead now" (173) are not coincidental events. Charlotte was the only person in Bridget's milieu who loved her unconditionally and who gave her permission, in a manner of speaking, to think 
about an identity other than the identity dictated by social norms. In other words, she introduced Bridget to a discourse different from the dominant discourse, an awareness of which, as Weedon argues, gives one "a measure of choice" in terms of subjectivity (106). When Charlotte learned of her father's attempt to coerce Nicolas into engendering a child and, by implication, to coerce Bridget into becoming a mother, she spoke out against her father's bribe. She not only told Bridget that "'[i]t was so terrible a thing for Papa to say to Nicolas,"' but she also expressed her concern for Bridget by exclaiming, "'Darling, so terrible a thing to buy a little baby right out of your heart that way!"' (55). Unlike other members of the family, Charlotte did not expect Bridget to bear a child for whatever selfish reasons she, Charlotte, might have had, such as desiring to have a niece or nephew. Further, despite the fact that bearing children and being a caretaker to her husband was, as she said to Bridget, "'the life I want'" (56), she did not assume that everyone, including Bridget, should have a like identity. As Charlotte told Bridget, "'[T]here are people who live differently,"' and, using her own children as an example, she said that "'[they] may choose to live differently"' (56).

Concerned about Bridget's well-being, Charlotte may well have uttered her condemnation of Papa's bribe and her acceptance of lifestyles alternative to hers, and then paused after each utterance, to provide Bridget with an opportunity to discuss her thoughts and feelings about each of those issues. However, Bridget did not use Charlotte as a confidante. Whatever thoughts and feelings she had during the moments that Charlotte uttered hers remained unspoken. Although Charlotte's stopping at a pond to look at some ducks after she condemned Papa's action gave Bridget ample time to speak in turn, she apparently did not; and although Charlotte "walked slowly ..., watching ... her ... boots[,]" after revealing her receptivity to varieties of lifestyles, Bridget apparently did not respond (56). Unlike Dora and Sappho in Contending Forces who utter their thoughts and feelings when Mrs Smith and the Mother Superior become silent, Bridget did not speak during Charlotte's silences. In fact, "they ... talk[ed] together" only after Charlotte 
described her children's interest in music (57), a topic having no direct relevance to Bridget. It is possible that Bridget thought it inappropriate to speak about her father-in-law to one of his daughters, that she feared Charlotte might resent her for speaking about him, that she did not trust Charlotte to keep her confidences, or that, having reached her early twenties during the era of post-Heterodoxism, she discouraged relationships with other women. However, it is probable that she had been shocked into silence by Charlotte's frankness and openmindedness. Before Charlotte spoke about Papa's bribe, Bridget could not imagine "how [people aware of it would] look into each other's eyes" (51). And, other than perhaps having briefly contemplated prostitution as a means of freeing Nicolas from his financial straits, Bridget apparently had not thought about alternative lifestyles.

Despite Bridget's silences, Charlotte's utterances and her subsequent plan to enable Bridget to have an alternative lifestyle probably initiated Bridget's desire to seek an identity on the fringes of, if not outside, the boundary created by social norms. Determined to give Bridget as well as Nicolas an opportunity "'to live differently'" (56), Charlotte told them of her plan to convince her husband to offer Nicolas a managerial post on one of his ranches in North Africa, a position that would not require physical exertion (126-27). Presumably, in North Africa, Bridget would continue to be Nicolas's wife, but since he would be gainfully employed and, so, probably happier, she would be unburdened of the idea that she should bear his child to make him financially solvent and, in general, less burdened with being his caretaker. In turn, she would be freer to pursue interests that could give her a degree of self-definition. Although Bridget initially feared a life of new and unknown possibilities, she began to want and to will herself to seek that life. At first, she wondered "what it would mean ... [t]o go so far away" (128). However, her anxiety lessened, and "the thought of winter on the [ranch] ... made shivers of delight pierce [her] heart" (147). She had even decided to paint during her remaining time in France (148). Despite the fact that "[i]n this determination her mind was like a stranger to her," it was an "agreeable" one (148). The combination of Bridget's felt "delight" (147) and her mental 
"determination" (148) probably would have enabled her to seek an identity at least somewhat different from the norm. Further, because she had begun to reciprocate Charlotte's love, as suggested by her addressing Charlotte as "'Darling'" (150), were her resolve to have faltered, she probably would have confided in Charlotte and been strengthened by Charlotte's love.

Without Charlotte, though, Bridget's fragile resolve to seek an identity on the fringes of the boundary defined by social norms collapses, and understandably. The more obvious and immediate cause of its collapse concerns the fact that both of the people, other than Papa, who can afford to finance Bridget and Nicolas's plan to establish a new life for themselves will not help them and, in fact, silence Nicolas's hope that they will. Jean, Charlotte's husband, does not honor his wife's wish that he offer Nicolas a position in North Africa. While Charlotte could yet speak, she indicated her wish to Jean (138-139), but when Nicolas, on the eve of Charlotte's death, intimates his hope that Jean will make the offer, Jean feigns ignorance (163). A short time after Charlotte's death, Nicolas explains to Uncle Robert that he needs money to seek employment in Paris, a city which would certainly allow Bridget opportunities for personal growth. Uncle Robert responds only by reminding Nicolas that he can get money by engendering a child (181). Following this scene, the narrator alludes to the dissipation of Bridget's fragile resolve to seek an identity at least somewhat different from the norm by revealing that "[a]t this moment [she] decide[s] what it [i]s that she w[i]][1] do" (184). Of course, at the end of the novel, she tells Luc "'what [she is] going to do ... [;] Nicolas and [she] are going to have a child"" (190). In other words, Bridget falls back upon the delusion that she can fulfill dominant culture's expectations of women in her subject position.

Without the financial means, Bridget's ability to maintain her resolve is severely limited, but there is a less definitive, and more pervasive, reason for its collapse. Like Therese, the protagonist of Kate Chopin's At Fault, Bridget is isolated, or silenced, from speaking with, people who might think differently from the people in her immediate 
surroundings. However, Therese, living in the vast backcountry of northwest Louisiana, is physically isolated from people outside that area. Bridget, living with Nicolas's family just outside a town, is socially isolated from the townspeople. Primarily influenced by Papa, a retired army colonel whose "ancestors in the salon" had apparently been members of the upper class (19), the family keep themselves separate from the working-class townspeople. As a result, they depend on each other to the extent that, if one or more of them is absent for any length of time, the remaining ones become "unreal, suspended in a mechanical dream" (17). Since Bridget, upon Charlotte's death, is restricted to the company of women who unequivocally accept traditional gender roles, it is virtually impossible for her to maintain her resolve to seek an even slightly different identity and highly unlikely that she would ever express to them her fleeting desires. Maman, "the hard centre ... around which fluttered ... [her] three [unmarried daughters]" (8), apparently taught them to seek an identity through a man. To them, "Luc . . . [i]s . . . a . . career that they ... had learned to bow before, ... [a] man who ... mean[s] a lifetime crowned or doomed forever ..." (45). Indeed, when Luc's departure for Indo-China is imminent, "there [a]re ... signs of mourning upon the faces of Maman and the three girls" (185). "Maman and the three girls" are in "mourning" because they all believe that, without a "man" to define them, they have no "career," no meaningful "lifetime" (45).

As for the men in the family and Luc, they view women as being their subordinates in general and their childbearers in particular. They certainly would not encourage Bridget to seek an even slightly different identity. Papa's bribe neatly conveys his attitude toward women. He does not consider Bridget's feelings when he offers money to Nicolas for engendering a child; he simply expects her to become pregnant. He even expects women to be silent during their pregnancies. At one point during Charlotte's sixth and last pregnancy, as the family wrangles about the best diet for her, she heaves into a container and then asks them to "'[1]et [her] have peace ..."' (135). Rather than apologize for the part he played in upsetting her, Papa "retreat[s] [in] agitat[ion] ..." (135). Like Papa, 
Uncle Robert does not especially consider Bridget's feelings when he tells Nicolas "'to permit things to flow naturally ... on'" (182) or, in other words, to engender a child. Despite the fact that Bridget is standing next to them, Uncle Robert directs his comment primarily to Nicolas. When Jean, Charlotte's husband, first meets Bridget, he "smile[s] and smile[s]" at Maman's assumption that Bridget will soon be pregnant, and, only then, does he turn toward Bridget to kiss her (30).

Most suggestive of the men's attitudes toward the women, however, is Bridget's nightmarish daydream about Nicolas's brother, Pierre. She envisions him treating women as receptacles for babies. Interestingly, although Luc is not the focus of Bridget's daydream, he is included in it and, through his association with Pierre, holds the same perspective about women. Undoubtedly, because Luc and Pierre actually operate a medical clinic together and because they both delay paying a medical visit to Charlotte when she first shows signs of being abnormally ill during her final pregnancy (151), Bridget has this daydream. In it, Pierre "ha[s] just concluded a successful operation ... , seconded by Luc" (155). The operation entails temporarily removing the uterus of a woman pregnant with twins in order to extract a cyst so that she will deliver her babies vaginally. Bridget imagines Pierre discussing the procedure as though the woman were an insignificant party. Describing the first step of the procedure, he refers to "'[t]he twins on the operating table labouring in the womb of the unconscious woman'" (155). From Pierre's perspective, the "'twins'" are active; they are "'labouring.'" To him, the woman is passive or, more exactly, "'unconscious," and probably inconsequential because, at that moment, her "'womb"' is outside her. Even when he refers to the woman's delivery of the twins, he does not include her. He says, "'[T]hree hours later the normal birth took place'" (155). In effect, Pierre silences the woman.

Since Bridget depends upon Nicolas for an identity, it is understandable that she keeps silent both thoughts about her inability to take care of him and, with the exception of her one outburst against him, feelings of resentment toward him and his family. However, 
as her silent monologues reveal, she suffers psychologically. During the majority of her silent monologues to Nicolas, she blames herself for his actions, her feelings about his actions, or his problems. Her silent self-blame emanates from her thinking of herself from an either/or, caretaking wife/selfish woman perspective, and it is exacerbated by her fear that the increasingly withdrawn Nicolas will abandon her and leave her without an identity. Given her fear of abandonment, when she becomes aware that he and most of his family value her almost solely for her reproductive potential and her resentment toward them threatens to manifest itself, she denies to herself her feelings through silent monologues to Luc. Within those monologues, she projects onto him her resentment toward Nicolas and his family and her inability to leave them, or she deludes herself into believing that she will leave them.

At one point, Charlotte's expressed frankness about her father's selfishness and her openmindedness about alternative lifestyles as well as her proclaimed intention to help Bridget achieve one of those lifestyles enable Bridget to believe that she need not think of herself as being either a caretaking wife or a selfish woman but, rather, someone whose identity could fall somewhere between those opposites. However, as Bridget's silent monologues to herself reveal, when she loses Charlotte, she loses that perspective. Ultimately, Bridget returns to blaming herself silently, but, this time, she blames herself not only for being unable to fulfill society's definition of her but also for being unable to seek self-definition. From her limited perspective, Bridge has little choice but to delude herself into believing that she can convince Nicolas to father their child, for it is only through her relationship with him that she can imagine any feeling of well-being.

\section{Biographical Information and Historical Background for The Underground Woman}

Boyle almost always had a man in her life. However, except for the time that she temporarily stopped completion of Plagued by the Nightingale to take care of Emest 
Walsh's needs and desires, she did not rely solely upon any of her relationships with men for an identity. From 1928 through 1942, the years during which she began a relationship with and married Laurence Vail, she wrote prodigiously and garnered recognition for her writing. As Bell notes, it was "[d]uring the 1930s [that] Boyle entered a period of immense literary activity, publishing ... six ... novels as well as several novellas and collections of short stories" ("Kay Boyle" 37). One of her stories "was republished in the Edgar J. O'Brien anthology Best Short Stories of 1931" (38), and another one "appeared in the Q. Henry Memorial Award Prize Stories of 1932" (39). In 1935, a third "story won the O. Henry Memorial Award first prize" (39), and "[i]n 1941, Boyle again won the O. Henry Memorial Prize Award ..." (41). From 1943 through 1963, the years of her third marriage, her popularity with critics waned. According to Byron Jackson, "many observers regret that in the 1940s the inner agonies of her main characters began to correlate with public issues, instead of arising from such oppressions as interfering families ..." (90). Despite this decrease in popularity, Boyle continued to write and publish; she did not become silent. During her third marriage, six novels, a collection of novellas, many short stories and essays, individual poems, and a collection of poetry were published. ${ }^{7}$ When blacklisted during the McCarthy Era, Boyle "was dismissed [as a foreign correspondent] from the New Yorker" but "wrote regularly ... for the Nation" (Bell, "Kay Boyle" 42); and "[i]n 1961 [she] was granted her second Guggenheim Fellowship ..." (42).

From her relationships with Vail and her third husband, Boyle bore five children, but her successful literary career during those years of childbearing suggests that she did not rely solely upon mothering to define her any more than she relied upon housekeeping for an identity. In fact, her children eventually felt abandoned, and she later felt guilty. By the 1930s, "there were now always a maid and a cook [in the Boyle-Vail household]," and "hired ... girls ... t [oo]k care of the children ..." (Mellen 149). During the early 1940s, Boyle "made [her fifth child's] formula and took [her fourth child] to school ... [,] [but] 
[t]here her duties ended" (274). With one hired woman, Boyle "work[ed] ten hours a day" (274). According to Mellen, "none of [Boyle's] children were happy" during the latter 1940s because, as Mellen implies, they no longer all lived together and Boyle resisted their emotional dependence upon her (308-09). In 1958, when Boyle's second eldest child, Apple, had a nervous breakdown, Boyle apparently felt much guilt for having pursued both her love interests and her career. Sometimes she "fled any consideration of the consequences of her actions," and sometimes she "believed she had harmed her older daughters greatly both by ... [divorcing her second husband] and by giving so much of her time to her work" (406-407). Undoubtedly, Apple's psychiatrist increased Boyle's guilt when he told her "Apple had been [emotionally] abandoned as a child" (407) and he "forbade her from ... see[ing] Apple ..." (408). About The Underground Woman, a fictionalization of Boyle's sentiments concerning her daughter Faith's membership in a Charlie Manson-like commune during the 1960s, Mellen argues, "Boyle defends herself against the charge that she was not a sufficiently nurturing mother ..." (485). Rather than "defends herself," I would argue that Boyle expresses guilt and that she does so, in part, through the protagonist's silent monologues.

In general, parents who devote more time to their outside careers than to their children might feel some degree of culpability when their children have psychological disorders or choose lifestyles that are self-destructive. However, Boyle's guilt can be more fully understood within the context of white middle-class women's subject position in the United States--particularly, within the discourses of work and motherhood during the 1930s and 1940s, the decades during which Boyle concurrently pursued her literary career and bore several children, and the 1950s and 1960s, the decades during which, respectively, Apple had a breakdown and Faith decided to live in the commune. Since Athena, the protoganist of The Underground Woman, is younger than her creator was, the latter 1940s through the 1960s are most relevant to her feelings of maternal guilt. 
There are reasons why a woman, especially, might feel responsible for whatever her adult children's experiences and/or decisions are. The basis for those reasons harks back at least to the mid-nineteenth century when the image of the Southern lady was at its apex. Of this image, Scott says that "one of the most persistent threads ... was the glorification of motherhood, with its great possibilities for beneficent influence on the coming generation" (37). In the 1930s, women like Boyle were expected to "glorif[y] ... motherhood." During that decade, as McCann explains, "in the context of declining population growth ... white, middle-class women were encouraged [by the medical profession] to have children ..." (96). Further, they were expected to raise them according to exact standards or, in other words, to be an especially "beneficent influence on the coming generation" (Scott 37). Rosalind Rosenberg notes that "[b]y the 1920 s ... mothers ... scrupulously watch[ed] their children's diets, ... attend[ed] child-study meetings, ... [and] read . . a about child-rearing ..." (99). Scott wryly comments that "[i]n the past when children turned out badly, it could be seen as the will of God . . . or ... human nature; now it ... [was] the failure of the mother ..." (221).

During the 1920s, gainfully employed women, like Boyle, undoubtedly felt both conflicted about not devoting themselves to their husbands and children and alone. By that decade, "[m]iddle-class white wives enjoyed greater job opportunities" (Rosenberg 98). However, because social expectations about mothering increased significantly, "[w]omen who tried both to work and meet these new standards were often driven to exhaustion" (99). That may explain why Boyle hired housekeepers and nannies as she pursued her literary career. Further, women, like Boyle, who had outside careers and did not adhere to the "new standards" for mothering probably kept silent whatever guilt they might have felt about their chosen lifestyle. The Women's Movement, after its success in gaining women the right to vote, did not begin to coalesce and to challenge traditional gender roles until the latter 1960s. As Rosenberg explains, "[b]y the end of the 1920s feminism as an organized movement was in retreat" (91), and "a privatized form" replaced it (92). In analyzing the 
ramifications of this change in relation to job discrimination, Rosenberg says that "[t]he cost of the privatizing ... was that women bore their defeats individually, believing ... they ... [were] [under]qualified" (98). I would think that working mothers might also have silently blamed themselves for any and all problems their children had.

During the 1930s, as the economy plummeted, society reacted more strongly against working wives, and women reacted against themselves as well as against each other. Some "[w]omen's groups . . campaigned to repeal" a portion of the 1932 Federal Economy Act "aimed at [eliminating] wives" from federal jobs, and some "[w]omen activists defeated [state] measures" intended "to prohihit the hiring of married women in any job" (Rosenberg 103). However, there was "widespread ... opposition to the working wife" (103). Unmarried women feared for their own salaries, wives not gainfully employed feared for their husband's incomes, and working wives felt themselves to be less deserving than men of paid employment.

Popular culture's desire to maintain traditional gender roles did not lessen during World War II, when Boyle was into her third marriage and had her sixth child, and when Athena married and had her first child. Because of a "critical labor shortage" during the war, "government officials, employers, and union leaders" encouraged women to work outside the home (Rosenberg 126), and "[f]or the first time in U.S. history married women outnumbered single women in the labor force ..." (130). Apparently, though, neither "government officials, employers, and union leaders" nor the "married women" and the "single women" envisioned an egalitarian society. In war industries, "[male] union leaders" insisted upon gender-specific seniority lists, "with the implicit understanding that [women] would be eliminated when the men returned from war" (133-34). In turn, "[m]ost women . . . accepted the [male] view that their jobs were temporary and ... [male] veterans had a prior claim to high-paying jobs" (134), and "many young women," dreading a single life, quickly married men remaining stateside, became pregnant, and left their jobs (131). The National Woman's Party "campaigned hard" for the Equal Rights Amendment 
during the war (136). However, as before, concerns about protective labor laws kept women divided, and the amendment was again defeated (136-37).

Following the war and throughout the 1950s, marriage and motherhood dominated most women's thoughts and actions. Undoubtedly, "fifteen years of privation and war" influenced them (Rosenberg 147). So, too, did popular psychoanalysts who "urged ... women ... to accept their femininity through subordination to their husbands and the joyful acceptance of motherhood" (154), medical professionals who "encouraged [middleclass white women in particular] to have more children to fulfill their renewed domestic roles" (McCann 96), and child experts who stressed that "the good mother ... was always there for her children" (Rosenberg 151).

Using the term made famous by Betty Friedan in her 1963 publication, The Feminine Mystique, which explores post-war, middle-to-upper-class white women's elusive discontent with the subject position described above, Linda Gordon argues that this "feminine-mystique propaganda campaign eventually failed ... [because] the two-income family increasingly [became] a necessity" (386-87). However, she adds a qualification particularly relevant to Boyle and to her creation, Athena: "[t]he campaign succeeded ... in making many ... middle-class women feel . . guilty" (387). These women had been taught by such discourses as "the psychiatric and medical establishments," as mentioned above, that "a true woman ... [c]ould ... make an important ... contribution to civilization through ... her edifying influence on her children" and that "defiance of [her gender role] . . . lead[s] to ... failure" (360). Were any of their progeny to have chosen a lifestyle outside mainstream culture and within a particularly aberrant subculture, these women probably would have "fe[lt] ... guilty" (387).

Further, these women probably would have been reluctant to discuss, if not have had difficulty articulating, their feelings, especially with other women. Reminiscent of the post-Heterodoxy attitude about relationships among women, "[t]he feminine mystique spurned forms of collective support--particularly among women--outside ... heterosexual 
relationships" (Gordon 389). As a means of describing the limited extent to which "[m]iddle-class women" involved themselves in groups outside the home, Rosenberg says that they "often served as volunteers and joined the PTA ..." (152). Of course, both of those activities reinforced aspects of women's traditional gender roles. Given the antifeminist climate of the 1950s, it is not surprising that "[i]n 1950, the Women's Trade Union League [established in 1903 (41)] disbanded ... [a]nd by 1960, the League of Women Voters had shrunk to half the size it had been in the 1920s" (153).

However, it is important to note that "[middle-class] [w]omen remained active ... in the movement against nuclear armament" (Rosenberg 153). Boyle's anti-Vietnam War activism, some of which is recreated in The Underground Woman, followed from her participation in that "movement" and led her to meet more women than she might otherwise have met. Mellen remarks that "[b]y the early sixties [Boyle] was active in ... Women Strike for Peace" (403), a group that, as Sara Evans explains, "proclaimed their concern for peace in the name of mother love" (Born for Liberty 264). Evans points out that the group's "politicized femininity ... was not the source of the new feminism"--its emphasis on "mother love" reinforced woman's maternal role--but she contends that "it helped create an environment in which ... the feminine mystique could be challenged" (264).

As is true of women who wrote during this moment when the feminist movement was being silenced, women who joined together and spoke out were "challeng[ing]" the "mystique" (Evans, Born for Liberty 264). 8 When Boyle took part in one anti-nuclear demonstration, she and women from an acting company "s[a]ng" as they marched (Mellen 403). On one of two occasions in 1967, when she, the elder Joan Baez, and the "folksinger Joanie" Baez, as well as others, were arrested for "blocking the entrance" to an induction center, Boyle spoke to the press (451). When women united, they became for each other the "speech community" about which Yaeger speaks: "[people] who ... encourage the growth of ... thought and its translation into praxis" (215). That Boyle and Joan Baez became "close ... friends" (Mellen 486) is significant because the fictional 
characterization of Joan in The Underground Woman "encourage[s]" Athena to speak her "thought[s] and ... translat[e] [them] into praxis" (Yaeger 215), a "praxis" both silent and verbal. So, too, do younger women, including the fictional characterization of Joanie, help Athena to develop a sense of self separate from social norms, and through silence as well as speech.

Indeed, through Boyle's experiences as an anti-war activist, and as a teacher at San Francisco State College from 1963 until 1973 (Mellen 425, 489), she was exposed to the generation of young women who, through consciousness-raising groups and the political activism that emerged from them, initiated the Women's Liberation Movement. However, Boyle's response to their influence was mixed. Some aspects of The Underground Woman, which I discuss in my analysis, suggest that Boyle understood the relationship between the personal and the political or, as Weedon explains it, "difficulties, problems and inadequacies not as [being] the effect of individual, personal failings, but . . . the result of socially produced structures ..." (85). Yet, as Mellen flatly states, "[t]here was one cause of which [Boyle] wanted no part[;] [t]hat was feminism" (486). In fact, Boyle "vehemently opposed the Women's Caucus" formed at San Francisco State to protest the lack of "a full-time tenured woman full professor" in Creative Writing, and she "set herself against [the likely candidate's] advancement" to that position (489).

Attempting to make sense of Boyle's attitude, Mellen argues that she was "a victim of the social era into which she had been born" (490), and I agree. I think it important to emphasize Evans's point that "it was ... [y]oung women ... [who] . . tor [e] away with intrepid zeal and directness the shrouds of ... mystification surrounding women's roles" (Personal Politics 212). For middle-class white women generations older than those "[y]oung women," it was probably difficult to "t[ea]r away with . . . zeal and directness" the lie they had been coerced into believing, especially when, in the early-to-mid 1970s, anti-feminist leader Phyllis Schlafly, younger than Boyle but Athena's age, "contributed the influence of her Stop ERA campaign to the [anti-]abortion fight" (Rosenberg 228). Maybe 
the best that Boyle could do was explore her feelings through Athena--that is, "[i]ndirect[ly]" (Evans, Personal Politics 212).

\section{Silences in The Underground Woman}

Boyle's attempt to balance her mothering role with her literary career occurred during the strongly anti-feminist decades of the 1930s-1950s. That period of time was followed, first, by a decade of increasing revolt among primarily white middle-class young women against their socially prescribed gender roles and, then, by a decade of public debate about those roles. Thus, it is not surprising that when Boyle wrote The Underground Woman during the early 1970s (Mellen 483-84), the timeframe of the novel, her protagonist, a white, forty-two-year-old, middle-class, working widow of three adult children, experiences angst about her role as mother. Indeed, in this last novel, Boyle's treatment of issues relevant to motherhood apparently coincides with sentiments expressed by many of her contemporaries. Kaplan claims that while "[a] summary glance at popular materials from 1970 [and onward] reveals a plethora of heterogeneous and contradictory motherhood discourses[,] . . .

[s]omething that all [of them] have in common is anxiety" (181). Kaplan further argues that "[a]nxiety emerges ... because there is now [within society] the 'question' of whether or not to mother, and of what sort of context for mothering one wants or deems essential" (182). Of course, because Athena, unlike Bridget, already has children, she does not experience "[a]nxiety" about "whether or not to [become a] mother." However, when one of her children becomes a member of a commune whose members idolize their fanatical leader at the expense of their own well- being, Athena is filled with "anxiety" about "what sort of ... mothering" she gave, or "deem[ed] essential." Athena's career as an English professor depends upon verbal communication skills, but, undoubtedly because she married and became a mother toward the end of World War II, she keeps her maternal angst silent for quite a while. 
Overall, Athena's marital role was traditional for its time, and its effects were apparently long-lasting. Upon marrying Rory, stationed in California during World War II, Athena bore their first child "five months after" $(38,40)$. Following the war, when he "bec[a]me a Foreign Service Officer," she traveled with him to France, where she bore their second child, and then to Germany, where she bore their third child (39). Apparently, these years of childbearing consumed Athena. When the omniscient narrator relates the facts about them from Athena's perspective, what she did, other than bear children, is not mentioned. One way or another, she must have been responsible for the children's care because Rory "had committed himself to eight or ten hours of work a day, six days of the week" (39). Indirectly, Rory reinforced the idea that Athena should devote herself to their children. One time, having brought home piglets left by hunters in woods that he patrolled, in Athena's presence, "[h]e told them their mother had ... defended them ... until she dropped ..." (40). He ended the story by noting that "[s]he did not abandon [them] ..." (40). Athena and Rory's children--all daughters--had probably also listened to the story and, thus, received a lesson from their father about one of their future roles, for "after supper, he would turn ... [details about animals he encountered in the woods] into stories for Sybil, and Paula, and Melanie ..." (40). Given Rory's reinforcement of Athena's maternal role, it makes sense that, years later, when she became a widow and, thus, lost her identification as wife, she would cling to her identification as mother, despite the fact that she had become a college professor and her daughters had moved away. As Kaplan explains, "patriarchal culture has ... fixed the concept 'Mother' . . . instead of permitting it to be a mobile part of [a woman's] being that comes and goes depending on whether [she is] in relation or not to the child" (41).

In The Underground Woman, various institutions in "patriarchal culture" (Kaplan 41)--courts, prisons, and the church--reinforce that "culture['s]" expectations of women, including the expectation that women not challenge them. When women characters speak out, representatives of those institutions remain silent to them or silence them. The day that 
Athena and other women demonstrators are arraigned for blocking an induction center, the judge allows a few of them to speak. However, their words matter not to him. As one woman talks, he "ha[s] a weary look in his eye," and while another woman speaks, "nor d[oes] he tremble ..." (35). When Athena talks, "[t]he judge g[i]ve[s] short shrift to [her] statement ..." (35). As though to mimic the judge's silence toward the women, before relating their speeches, the narrator reveals that "their fate ha[s] been decided and the sentence already entered in the register" (34-35). In the prison, women guards become instruments of women's oppression. Indirectly or directly, they silence women prisoners. When a fight between two long-term inmates interrupts the daily agenda, the upset "this generate[s] in the figures of authority silence[s] the speech on every tongue" (71). Interestingly, that agenda includes duties traditional to women--"mak[ing] . . beds, . . . [doing] laundry, ... scraping and waxing ... halls, and ... sewing and ironing" (72). The imprisoned male demonstrators, as one of them explains, "'ha[ve] a great time ... h[o]ld[ing] seminars . . . every day'" (165)--in other words, talking. Sometimes, the women guards literally silence their prisoners. One guard puts a demonstrator in solitary confinement after the woman says she will "'work in the garden ... or ... not work at all'" (154-55). Even the woman minister who visits the prison silences women. During a service, when one young demonstrator questions the godliness of the minister's ornate attire, the minister retorts, "'No one is authorized to speak . . . !" (124).

On the other hand, sometimes the women demonstrators advocate silence as a means of seeking inner peace, or they perceive it to be a type of freedom. When Lydia, the woman mentioned above, is put in solitary confinement, Callisto, the fictional characterization of Joanie Baez, attempts to meet with the woman lieutenant. After Callisto's first unsuccessful attempt, she returns to her sister demonstrators, and, as though desiring to comfort them as well as, perhaps, herself, she talks aloud to Jesus. However, upon her return from a second unsuccessful attempt, she does not resume talking to the religious patriarch. Instead, she suggests to the women that silence can calm their 
thoughts. Perhaps she had heard them describe Lydia as being "all they had not ... dared to do or say" (156), and she wishes to end that form of self-criticism. In any case, she tells them about "'[a]n Indian philosopher . . [ [who] . . says . . . that if you have . . . enough desire for stillness, then you will find ... it"' (156). However, as though she becomes irritated with his assumption that inner peace depends only upon "desire" and not, for example, upon the assuredness that one may speak without being put in solitary confinement, she quickly adds, "'Sometimes I think it is enough to say that if we don't ... shut up once in a while, then we'll lose our minds ...'" (156). In essence, she encourages the women to seek tranquility by not fulfilling the stereotype of women as being chatty. Upon returning from her third unsuccessful attempt, she models for them by "not speak[ing]" (157). Perhaps because of Callisto's silence as well as her speech, Athena perceives silence as sometimes being a personal preference. After her release from prison, along with thinking about the "free[dom] to move without explanation ... [and] to look up at the sky without [seeing] . . barbed wire," she appreciates the "free[dom] to be alone, in silence, if that [i]s what one cho[o]se[s]" (180-81).

Like some of Bridget's silences, some of Athena's silences reveal guilt about her inability to fulfill the caretaking role--in her case, to rescue her daughter Melanie from the commune. However, as a whole, Athena's silences help her to achieve a shift in subjectivity. In silence, she begins to think in ways different from the patriarchally derived binary perspective that women in her subject position are either self-sacrificing caretakers, women who show deference to their loved ones by silencing themselves, or selfish women, women who oppose their loved ones by expressing themselves. Athena's silent monologues and one silent dialogue both mark this process of shifting subjectivity and contribute to its occurrence. Early in the novel, a cluster of three silent monologues, augmented by narrative disclosures following the first two, reveal Athena to be experiencing an identity crisis because the role by which she has been identifying herself, mother, is one that she cannot completely fulfill. These silent monologues, addressed to 
people with whom she is incarcerated, help her to begin accepting not only the loss of Melanie and, concurrently, her identity as Melanie's caretaker but also the need to find an identity separate from Melanie. They also serve as rehearsals for the moment when she actually tells some of her thoughts to a friend, including the fact that Melanie has rejected letters from her. A later cluster of silent monologues, some addressed to people not in her presence and one "spoken" by someone other than herself, as well as an imagined dialogue between herself and a friend, help her to begin thinking of herself as a woman who can express her feelings, confront reality, and release herself from her caretaking role; and they serve as rehearsals for the moment when she actually does all of these things. Her last silent monologue, addressed to a personification of actuality, helps her to maintain her resolve.

However, as my reference to Athena's actually confiding in a friend intimates, her ability to shift her subjectivity involves silence and speech, other people's as well as hers. Unlike Bridget, Chopin's protagonists, and Hopkins's Winona, Athena is among several people who stimulate her to think in ways different from the binary perspective. Unlike the people who help Hopkins's Dora and Sappho, two--one of whom is a man--are Athena's contemporaries, and some of the women are a generation younger than she. Calliope, the fictional representation of Joan Baez and the friend mentioned above, listens to Athena's confidences and says things that help her to deal silently with the loss of Melanie. The younger women--Callisto, college students, and a long-term inmate--use speech and silence to combat various oppressions. After Calliope's responses and the younger women's modeling, Athena desires to define herself and imagines doing it. In the later cluster of silent monologues mentioned above, she mentally composes letters that, albeit indirectly, express her feelings about particular people, and she imagines Lou, one of the college students, telling the women demonstrators to face reality. Once home, Athena silently faces the reality, as she perceives it, that she, and her husband, failed to prepare Melanie for adulthood. However, she then imagines a dialogue in which Calliope essentially tells 
her to stop holding herself as responsible for Melanie as she has been, and when a delegation from the commune commandeers her home and Lucky, the commune leader's lackey, tells her Melanie will soon join them, she nonetheless tells him she wants them to leave. When Lucky's browbeating silences her, Luchies, a neighbor and contemporary, urges her to talk about herself. Although Luchies's further help inadvertently compromises Athena's ability to act, she eventually evicts the delegation, fully releasing herself from the role of Melanie's caretaker. Later, with Calliope's words of encouragement, Athena commits herself to activism, and she silently embraces what is, rather than regrets what is not.

The first in a cluster of three silent monologues that serve as rehearsals for the moment when Athena actually tells some of her silent thoughts to a friend reveals Athena to be experiencing an identity crisis at the same time that she is identifying strongly with motherhood, as well as with widowhood. It occurs at the opening of the novel when, enroute to the city jail, she observes the other anti-war demonstrators in the paddy wagon. As she observes them, she becomes self-conscious about her own appearance or, more specifically, about the loss of her youthful looks, and she silently talks to them about it. At first, she cannot make sense of it. She thinks, "What ... happened to the rounded throat and the ... brillian[t] . . eyes, I cannot tell you" (11). After this initial puzzlement, she links her appearance with being a mother--"Perhaps [my defined neckline and sparkling eyes] were presented as gifts to my daughters ... in an unguarded moment of helpless love" (11)--as well as with being a widow--"The belly is no longer concave [because the physical activities that I did with my husband] are things you do not do alone" (11). Struggling to understand the significance of the physical changes, Athena wonders how she would act were she to regain her youthful looks. She asks, "[W]ould I be able to take action without suffering this inner drama of division? Would I . . cease asking ... why the outside describes so badly what the inside has always sought to be?" (11-12). In silently thinking that her "outside," or appearance, manifests her role as a mother, as well 
as her position as a widow, and that it is at odds with her "inside," or psyche, which "has always sought to be" one who "take[s] action," Athena reveals not only that she feels "divid[ed]," or conflicted, but also that she feels as she does because she perceives motherhood, as well as widowhood, to concern passivity, a quality opposite to that which she has aspired.

Athena ends this silent monologue without answering her questions. However, the narrator continues her train of thought, revealing what, even in silent words, she may be too angry to admit, cannot fathom, or wants to forget: who she "has always sought to be" (12) is who her father defined her as being and who she felt she was not. As she "look[s] at the young people in the van ... [,] [she] remember[s] the exact words she had written her father when she had left home ..." (12). The letter said, "'[Y]ou named me Athena in the expectation of shaping me ... [,] [but] I was not the protectress ... and ... the goddess of war'" (12). In her youth, then, Athena felt herself to be neither a "'protectress"' nor a "'goddess of war"' or, in other words, not a woman who "take[s] action" (12). However, since she "always sought to be" that woman, she "always sought to be" who her father "'expect[ed]"' her to be; and, since trying to be who she felt she "'was not" has resulted in her feeling conflicted, she may be too angry to admit her father's influence on her. Or, she may be unable to fathom a seeming contradiction. Athena thinks of motherhood, a primary role that patriarchy assigns women of her subject position, as a passive role. Having one's youthful looks "presented" to one's children "in an unguarded moment of helpless love" (11) is a type of passivity. Passivity seems contrary to the role her father assigned her. At some level, Athena may understand that while patriarchy presupposes women to be passive, it sometimes demands that they be active. It "'expect[s]"' (12) women to "'protect'" (12) their children by "'war[ring]"' (12) against anyone threatening the children. In any case, Athena probably recalls her letter while "look[ing] at the young people" (12) because they remind her of Melanie. As the next two silent monologues reveal, respectively, Melanie needed "'protect[ion]"' from the 
commune leader, but Athena could not "'war"' against him. That would account for Athena's desire to forget the seeming contradiction.

Athena's second silent monologue occurs not as she silently observes the other demonstrators but while she actually talks with some of them. In fact, her explanation of another's words and her own words lead her to become silent, probably because they evoke feelings of guilt. The first night in jail, Athena apparently tells the demonstrators that she is a professor, for one of them asks her about readings for one of her courses. Indicating that she varies the readings to suit current interests, she refers, as an example, to an author whose subject is communes. When Athena says, "'He's written about people who are panic-stricken, frantic, stumbling this way and that ... and who cling together under a common roof[,]' . . the strange, faltering thing happen[s] to her voice, ... as it ... d [oes] whenever she th[inks] of Melanie" (28). Clearly, Athena is "th[inking] of Melanie," and, probably, her "voice" is "faltering" because her explanation of the author's text suggests to her that Melanie chose to live "'under a common roof,"' or in a commune, because she had been "'panic-stricken, frantic, [and] stumbling,"' or without direction. Melanie's choice is something about which, in a much later silent monologue, Athena reveals profound guilt. At the moment, she tries to silence her feelings by continuing the academic conversation. However, the next text that she mentions silences her because it raises a related point about which she also feels guilty. When Athena says, "'Or I might ask [students] to read 'The Grand Inquisitor,' . . . for a long moment she d[oes]n't say any more" (28). Athena probably "d[oes]n't say any more" because, as she reveals in the last silent monologue of this initial cluster, when she learned that the commune leader convinces his followers to submit to LSD trips and then brainwashes them, she had perceived him to be "'the Grand Inquisitor'" whom she could not challenge.

During the "moment [Athena] d[oes]n't say any more" (28), she silently relates to the demonstrators her recollection of the commune leader's claim to phallic supremacy. Perhaps because Athena cannot face her feelings of guilt about Melanie's dependence upon 
him for direction and her submission to him, and perhaps because Athena has some inkling that she is at least not entirely responsible for Melanie's dependence and submission, she prefaces her recollection by making a connection between Melanie and herself that suggests another explanation for Melanie's attraction to him. She silently says, "Melanie is [almost] twenty years old ... and already [has] two babies, which is just one of the ways that the lives of daughters transcribe their mothers' lives" (28). Athena's reference to early motherhood as being "just one of the ways" indicates her awareness of other "ways." Since her thought is on motherhood, she may be alluding to the idea that because Melanie, like she, had been defined by men and along the lines of motherhood, Melanie would tend to seek direction from, and to submit to, a man, including having his babies should he wish. Just as the name that Athena's father gave her, which represents the safeguarding quality expected of mothers, defined her, Melanie's father's stories, at least one of which-the pig story--extols the virtues of motherhood, probably defined Melanie. And, just as Athena's husband, through storytelling, reinforced her father's definition of her, the commune leader, through self-assertion, reinforced Melanie's father's definition of her. Following the maternal connection she makes between Melanie and herself, Athena recalls that the leader had "declared ... he was the great erection come to fecundate a world ... in the throes of impotency ..." (28). Indeed, as she can acknowledge only much later and silently, this "great erection," or supreme phallus, "fecundate[d]" Melanie. By him, Melanie became the mother of the "two babies" to whom Athena refers above.

If Athena has some idea that patriarchal influence led to Melanie's dependence upon and submission to the commune leader, she cannot sustain it. The third-person narrative continuing Athena's train of thought suggests she would rather think that Melanie pretends to be powerless against him than that she actually is powerless against him, which, of course, is also a thought that would assuage Athena's feelings of guilt. Significantly, the above silent monologue ends with her recollection of the leader's "declar[ation] ... to fecundate a world ... in the throes of impotency ..." (28). More exactly, the phrase, 
"'[t]he throes of impotency[,]' evoke[s] the spectacle of a dance so convoluted that Athena c[an] scarcely bear the writhing vision of it" (28). Since the leader had said he would "fecundate" people who are "in the throes of impotency," Athena probably "c[an] scarcely bear the writhing vision" of the "dance" that is "convoluted" because the mental image concerns his sexual manipulation of Melanie or, more largely, Melanie's "impotency" against him. Rather than stay with that image, which undoubtedly raises her level of guilt, Athena thinks about two moments when Melanie had looked guileless but, in one case, had been pretending. In the first moment, Melanie is reading one of the leader's speeches. In it, he proclaims his authority by virtue of his gender, as well as his nationality. Instead of focusing on his manipulative words, Athena focuses on Melanie's virginal look. Upon "see[ing] [Melanie's] face, fresh as a jonquil," she moves "back . . . in time to see Melanie ... ripp[ing] off [items] from [store] counters ... and no one suspecting ... because of ... the ... innocence of her face" (29). Apparently, Athena would like to believe that Melanie's adult "fresh[ness]" is as pretentious as her childhood "innocence" was, but she cannot. In her next silent monologue, she begins to accept Melanie's powerlessness against the commune leader.

During Athena's third silent monologue, addressed to the demonstrators the second night, she begins to accept the reality that Melanie has been drugged and brainwashed by the commune leader. In doing so, Athena begins to accept not only Melanie's powerlessness but also her own felt loss of Melanie, the loss of her identity as Melanie's caretaker, and the need of an identity separate from Melanie. Unlike the previous silent monologue, which results from Athena's own speech, this one is precipitated by Callisto's speech. As the demonstrators are about to be housed with long-term inmates, Callisto warns them against "'counting on words'" to get along with the other inmates (49). When Athena hears Callisto utter the word "'words,"' she recalls "hearing a voice on a tape ..., hearing the fearful, delirious words repeated," and she challenges herself to "face the meaning of them" (49). The "tape," which Athena had "hear[d]" during a visit to the 
commune, is a recording of the leader, as well as his lackey, manipulating a young woman under the influence of LSD into believing she had died. Apparently, Athena had not recognized the young woman's "voice." She silently remembers asking Melanie, "'That girl on the tape, whatever became of her?"' (54). When Melanie had responded not only by claiming the voice but also by anticipating another LSD trip, understandably, Athena felt bereft. In a sense, "'[t]hat girl on the tape'" had died. Athena silently explains, "I wanted ... [an] answer ..., not knowing that once ... answered, the room ... would become ... a ... darkness in which I would ... grop[e] to find my way" (54). Then, Athena could only feel the "darkness," or loss of Melanie and her identity as Melanie's caretaker, and the need to "grop[e] to find [her] way," or to struggle for an identity of her own. Now, as her silent articulation of those feelings indicates, she is beginning to accept them, and she can begin to accept them because she is beginning to accept the reality underlying the recorded "words" (53).

That Athena is just beginning to accept the reality underlying her feelings and, thus, the feelings as well, is suggested by another revelation within the same silent monologue: she still thinks that she could have saved Melanie from the commune leader. When Melanie told her that "'Pete says everyone has to have three [LSD] trips in a lifetime . . . if . . . she ... want[s] to know who ... she really is'" (53), Athena had spoken out against him, but only indirectly. She recalls having asked, "'You don't believe that, do you?'" (53). Athena had questioned rather than objected, and she had focused on his assertion rather than on him. And when Melanie retorted by regurgitating more of his assertions, Athena had not responded at all. In silence, she explains, "I couldn't say anything, I couldn't speak" (53). Essentially, Athena "couldn't speak" out against Pete's recommendation of additional trips for resistant subjects, his belief in administering larger dosages of LSD than Timothy Leary did, and his apparent claim to "'keep[ing] it under perfect control"' (53). When Melanie had made the latter point, she undoubtedly meant that Pete retains "'perfect control'" over the trip. However, as Athena's silent explanation of what she had "wanted 
to say" (53) indicates, she believes that he retains mastery over his followers. She had "wanted to say [that Melanie's retort] is the Grand Inquisitor's definition of the three powers that ... conquer the impotent rebels: miracle, mystery, and authority" (53). In other words, Athena thinks of Pete as a "Grand Inquisitor"; he "defin[es]" the LSD trip as being a "miracle," his ability to administer LSD effectively as being a "mystery," and himself as being the "authority." Athena's silent obsession with what she "couldn't speak," or what she had "wanted to say," suggests that she thinks she could have saved Melanie from Pete by arguing against him. Thus, she has not fully accepted the reality that his drugging and brainwashing of Melanie took away Melanie's power of choice.

Because the first cluster of silent monologues does not enable Athena to accept fully the reality that Pete's drugging and brainwashing of Melanie rendered Melanie powerless, it does not enable Athena to accept fully her felt loss of Melanie and her identity as Melanie's caretaker, as well as her felt need to create an identity of her own. Further, and as I discuss below, it does not help her to stop feeling abandoned by Melanie, nor does it instill in her a desire to have an identity of her own. Nonetheless, this cluster, addressed to the demonstrators in general, serves as a rehearsal for the moment when Athena actually confides some of her silent thoughts to one demonstrator in particular, Calliope. While Athena neither confides her feelings to Calliope nor mentions the tape recording of Melanie's LSD-induced brainwashing session, and speaks only half-truths at one point, she tells Calliope of Melanie's whereabouts, another commune member's background, and Melanie's rejection of her letters. Despite these limited, and, in one instance, only partially honest, disclosures, because Athena makes them, Calliope has the opportunity to respond to them. Albeit indirectly, as a result of Calliope's responses, Athena comes to accept the reality underlying her feelings of abandonment, loss, and need--in other words, that Melanie is under Pete's control; and, although she feels guilty about Melanie's having gone to the commune in the first place, she realizes that she could not have saved Melanie from 
Pete by the time that she heard the tape. With this acceptance and realization, along with words of encouragement from Calliope, Athena begins to desire an identity of her own.

One day, as Athena and Calliope walk together on the grounds of the prison, she confides in Calliope for the first time, but Athena does not speak with ease because she is ashamed of the feelings that prompt her. She says, "'She's been over two years in a commune, my youngest daughter, Melanie'" (91). Since this disclosure begins a new chapter that does not continue the scene with which the previous chapter ends, it seems abrupt, as though Athena speaks involuntarily. Indeed, this disclosure that "Athena ha[s] wanted to say for a long time to Calliope [because] there were things about women and their daughters that she wanted to talk about with her" she only realizes "she must have said ... aloud [because] Calliope [i]s asking ... [about her visits to the commune]" (91). Significantly, Athena has been reluctant to disclose Melanie's whereabouts for the same reason that Bridget does not speak immediately to Nicolas upon his return from a prolonged absence. From Athena's perspective, "it [i]s not easy to find the words that would make the questions [about mother-daughter relationships] free of any murmur of complaint" (91). Like Bridget, Athena has a "complaint" to make against her loved one, and their grievances are probably quite similar. Later in this conversation, Athena tells Calliope that Melanie has rejected letters from her, so I assume that Athena, like Bridget, feels abandoned by her loved one. Given my assumption, Athena probably wants to ask Calliope the same "question" that Bridget wants to ask Nicolas: how could you/Melanie have abandoned me? However, Athena, like Bridget, has been socialized to think of herself as being either a caretaking woman who shows deference to her loved ones by silencing her feelings or a selfish woman who opposes her loved ones by expressing her feelings. Since both Athena and Bridget identify with being caretakers, both of them silence their "complaints." In Athena's case, she neither asks Calliope "questions" nor divulges her own feelings. 
As if Athena wants to justify her feeling of abandonment by Melanie without having to divulge it to Calliope, she alludes to the idea that Melanie had the capacity to abandon her by telling Calliope a story about Lucky, Pete's lackey, that illustrates his having had the ability to act voluntarily. Although Athena masks her feelings about Melanie by telling a story about Lucky, her storytelling gives Calliope something to which she can respond; and, although Calliope's responses do not compel Athena to divulge her feelings, they lead her to say more than she might have said, which, I think, leads her realize that her feeling of abandonment by Melanie is not based upon reality. During Athena's narrative, Calliope asks a question not relevant to her motive for narrating, but the question leads Athena to reveal the point of her narrative in relation to Melanie. Initially, she only says, "'[T]his is why I'm telling you ... --Lucky ... was so new to the commune [at the time of the story] that he had not yet given his will'" (97). Soon after, she adds, "'[H]e was a questioning ... kind of person, and Melanie was once that, too'" (99). With that information, Calliope asks how people can be forced into submission. Athena's exclamation, "'I don't know how it is done!"' (99), suggests her refusal to accept the fact that Pete's drugging and brainwashing of Melanie rendered Melanie powerless. However, a foreshortened comment that she makes suggests otherwise. Immediately after telling Calliope she is narrating Lucky's story to show that, at the time, "'he had not yet given his will"' (97), Athena says, "'That was . . . before,' . . . but she d[oes] not finish the sentence. She d[oes] not say: before the tape about the girl ..." (97). I think "she d[oes] not finish" her comment, or "d[oes] not say" anything about "the tape," because she is confronted with the reality that the recording represents: Melanie lost the ability to act voluntarily, so she could not have abandoned anyone.

Assuming that Athena accepts the fact that Pete's drugging and brainwashing of Melanie took away Melanie's power of choice, Athena probably now realizes that she could not have saved Melanie by arguing against him, so she probably does not tell Calliope about the tape even when asked how people can be forced to submit because she feels 
guilty about Melanie's having gone to the commune at all. Upon claiming ignorance of people's forced submission, Athena says, "'That's why I threw the frying pan one night ... across Melanie's kitchen ...'" (99). Until asked, Athena does not reveal that this "'night"' was the last time she saw Melanie or, in other words, was some time after she heard the tape. With that knowledge, it is clear that her further explanations about "'why [she] threw the ... pan'" are also only half-truths. First, she says she hurled it upon overhearing one member imply that they could indulge in drugs because she was tending their children and another one imply that she should pay their phone bill. Then, she says she hurled it "'at the evil magic of [Pete's] power"' (99). Finally, she says, "'I threw it at myself for being so weak as to allow [the two members'] voices to take over'" (99-100). Since one of Athena's silent monologues suggests that shortly after hearing the tape, she began to accept the reality that Pete's LSD-enhanced brainwashing of the members took away their free will, she would not have been provoked by the members' implications but by the awareness that they were Pete's desires; and she would not have hurled the pan at "'the evil magic of his power"' but at his giving LSD to the members. Further, since Athena apparently thinks Melanie joined the commune from lack of direction and, as she reveals in a later silent monologue, she thinks she did not prepare Melanie for adulthood, she would not have hurled the pan "'at [her]self for ... allow[ing] [the members'] voices to take over"' but for having failed to enable Melanie "'to [dis]allow [Pete's] voice'" from luring her to the commune.

Calliope's final question compels Athena to reveal that since the pan-hurling incident, she has not seen Melanie and Melanie has rejected her letters, both of which realities lead her to self-pity and fantasy. However, one of Calliope's prior questions apparently has led Athena both to accept the fact that Melanie lost the power of choice and to realize she could not have saved Melanie by arguing against Pete, and part of Calliope's response to Athena's revelation about not having seen or been able to communicate with Melanie suggests that Athena has the power of choice. Thus, Athena yields only briefly to 
self-pity and fantasy. When Calliope asks what happened after she hurled the pan, Athena says, "'[S]ince then[,] nothing. . . . For a while I went on writing . . , but my letters came back, the envelopes marked in that ... schoolgirl hand "Return to Sender"'" (100). Melanie, the apparent owner of the "'schoolgirl hand,"' wrote the directive, but Athena knows she did not do it of her own free will. However, probably because Athena cannot yet admit her thought that she failed to prepare Melanie for adulthood, she rounds out her explanation by adding details that suggest self-pity at the same time that they deflect attention from her only. She adds, "'Paula [another daughter] tried telephoning, ... but Melanie [i]s finished with both of us'" (100). The first half of Calliope's response--"'this isn't the end'" (100)--leads Athena to fantasize that her relationship with Melanie "'[has]n't ... end[ed]." Later that day, she "indulge[s] herself with the fancy of a letter ... addressed in the ... schoolgirl hand ..." (100). Yet, the words "indulge" and "fancy" indicate Athena's awareness that Melanie will not write to her. Further, the latter half of Calliope's response--"'[t]here are things that we can do'" (100)--apparently suggests to Athena one of the "'things,"' or choices, she "'can do,"' or make, for she begins to desire an identity of her own.

As a result of talking with Calliope, Athena begins to want that which, during her third silent monologue to the demonstrators, she begins to know she needs. That is, she moves from realizing she must have an identity separate from Melanie to desiring an identity different from that which culture dictates, and she discovers that this shift in subjectivity will be difficult. As Athena performs breakfast duty the day following her conversation with Calliope, it becomes apparent that she has thought more about Calliope's comment, "'this isn't the end"' (100), but from an obverse perspective. Rather than continue fantasizing that her relationship with Melanie "'[has]n't . . . ended,"' she begins hoping that her dependence upon cultural norms has "'ended." She "[i]s seeking . . to believe that she ha[s] come to the end of quotations from other people's books . . . and ... speech, and even ... mythology" (103). She "seek[s] . . to believe" in this "end" 
because "now she want[s] to function out of her own experience, her own history, and to speak with a vocabulary that [i]s her own" (103). Rather than be defined by "other people's" stories and words--including, perhaps, that author's theory about why people join communes--Athena "want[s] ... her own experience" and "history," or stories, and "vocabulary," or words, that she "speak[s]" to define her. However, when she finds herself imagining a prison guard to be Dryope, "that woman of myth" who turns into a tree upon picking "blossoms" for her child, "she s[ees] ... this [subjective shift] c[an]not be done so quickly ..." (103). Apparently, Dryope's story has led Athena to imagine not only, as she does in her first silent monologue, that her body aged, or became woody, because she gave her youthful looks, or "blossoms," to her children but also that the guard, about whom she knows little, is a self-sacrificing mother. Thus, Athena "sees," or discovers, she "c[an]not ... quickly" shed "that woman[-]of[-]myth" definition which culture taught her.

If Athena's conversation with Calliope results in Athena's desire to shift her subjectivity from cultural definition to self-definition, then her observation of ways, both silent and vocal, in which the young women rebel with some success against oppressions that reinforce cultural definitions of them results in her beginning to make that difficult shift. Callisto, the young woman who, later in the novel, deals with a guard's threatening behavior by practicing oral prayer and inner contemplation, is one of the rebels. Just after Athena attempts to assuage her upset over Melanie's return of her letters by fantasizing that she receives a letter from Melanie, a guard rejects a letter that Callisto had written to an incarcerated male demonstrator. Callisto rebels against the guard's silencing of her by singing, after silent deliberation, a modern version of a spiritual. When the guard states that "'[m]ail between inmates cannot be delivered[,]' . . . Callisto walk[s] back to her cot[,] ... sit[s] on [it], ... [and] beg[i]n[s] to sing ..." (100). During the moment that she "walk[s]" and "sit[s]," Callisto probably remains silent to keep her composure and to decide how to respond to the guard's silencing. Her decision does not make the guard 
deliver her letter any more than Athena's fantasizing makes Melanie send her one, but a wonderful event results. Both "the black and the Chicano [long-term] prisoners and the [white] demonstrators ... s[i]ng with [her], ... and the words ... they shout stamp into oblivion the deputies standing there" (101). Since the "deputies," as I argue, reinforce patriarchal culture's expectations of women--including women's acceptance of them--"the words ... [the inmates] shout stamp into oblivion" the expectations as much as the guards. Thus, through silence and song, Callisto not only lessens her frustration but also enables two disparate groups of women to unite, albeit temporarily, against cultural definitions of them.

On other occasions when the guards expect compliance, Athena witnesses the college students rebel by harmonizing, debating, masking their physical appearances and being silent, altering their physical appearances and speaking duplicitously, and even expressing anger overtly. Perhaps because roll call highlights the fact that each inmate is an individual but is not treated as such, the students rebel most often against that practice. Once. when a guard reads a name, "three or four voices . . . answer simultaneously in different keys ..." (102). By "answer[ing] simultaneously," the students feign sameness, but, by using "different keys," they assert difference. A subsequent morning, they pretend confusion about their respective individualities by "argu[ing] ... among themselves ... which name belong[s] to whom ..." (102). Yet another morning, by "st[an]d[ing] ... silent ... with their pillowcases . . over their heads" (102), they mask aspects of themselves--their voices and their faces--that mark individual difference. Perhaps because "kitchen detail" (102) reminds them of slavery, a practice that denies humanness, never mind individuality, they rebel against it by "braid[ing] one another's hair into ... little plaits" (102), a style associated with African-American slaves. When a guard expresses disapproval, one of them responds in a way that a rebellious slave might: she represents their defiance as compliance. She says they wove their hair "'out of respect for the pure food laws ..."' (102). However, one student responds with anger. Shouting, "'[I]t's a 
crime to laugh in this place?[,]' ... she fl[i]ng[s] her ladle down" (103). Indeed, either "'in this place"' or outside prison, "'it's a crime'" for women "'to laugh'" at, or to oppose in any way, expectations of them. Nonetheless, if the outcome of the students' rebellion against roll call is uncertain, their rebellion against breakfast duty is effective. The guard dismisses them from doing it.

Athena also observes a young long-term inmate combat an oppression similar to, yet different from, that which Callisto and the college students combat--denial of individuality on the basis of skin color, not sex--and she does it in a way similar to, yet different from, Callisto's way--by being silent and then speaking, not singing. Further, the young woman's silence, like Calliope's, demonstrates its power to maintain composure, but it also demonstrates its power to project composure. Upon urging the demonstrators to forgo their visitation time so that inmates not to be released as soon as they will have maximum visitation time, the young woman indicates her unselfish motivation by saying, "'I shall be leaving [the prison soon]"' (106). In response, a demonstrator asks the length of her incarceration thus far. While it might make sense to ask when she will be released, the question asked is irrelevant to the situation. Since the demonstrator asks with "timid[ity]" (106), her question lacks malice. Nonetheless, racism underlies it, for she assumes the right to know. Undoubtedly, the young woman remains silent to keep her composure as well as to consider her response, and her audience perceives that composure. Following the "moment it seem[s] there w[ill] be no answer,... [she] appear[s] to stand even more erect ... and her ... words ... [to] c[0]me with even greater efficiency" (106). Since "[p]erhaps half the demonstrators wr[i]te 'No Visitors' on the slips" (106), her plain "words" satisfy many. However, one refuses to forgo her time, "'swear[ing] [she] do[es]n't see [the young woman] as black'" (107). Again, the young woman pauses before speaking. At least in part because the demonstrator perceives the composure, her own "underlip tremble[s]" as the young woman "look[s] at her ... [i]n total silence" (107). With the aid of "silence," the young woman's response, "I choose ... to be 
black'" (107), not only invalidates the assumption of superiority underlying the demonstrator's refusal; it also validates the young woman.

Both as a whole and in a particular way, the young women's rebellions affect Athena. Around the time she witnesses them, she begins to challenge the culturally influenced denial of self by writing imaginary letters to, or concerning, people in her life that indirectly express feelings she has kept silent, probably from herself as well as from them. Although Athena does not actually write the letters and imagines expressing her feelings only as indirectly as most of the young women express theirs, this form of silent monologue begins the second cluster of silent moments that lead her to become selfassertive. That is, just as the initial cluster of silent monologues functions, this cluster, which includes a silent dialogue, serves as a rehearsal for the time when Athena actually does things similar to those that she imagines doing. Before going to sleep, she "write[s] ... letters in her mind" (107). The contents of those "[s]he wr[i]te[s] to her three daughters, and to her dead mother" (107) are not disclosed, but the contents of those she writes to other people are. Given Athena's reticence, probably all of her letters contain a form of duplicity the disclosed ones contain. Similar to the young woman who claims concern about health standards when she confines her hair in a style associated with slaves, Athena "wr[i]t[e]s ... recommendations" (107) for students in which she alters their names and describes their attributes to reflect her disgust with them. For example, she writes, "'It is a tribute to Mr. Egocent's tenacity of purpose that he was never ... touched by the plight of Prometheus ..." (108). Basically, she "recommend[s]" his selfcenteredness. Similarly, in a letter "asking [a smoke shop] to stop sending [her husband] [its] catalogue" (110), Athena expresses her anger by thanking it for having encouraged his death. She writes, "'I appreciate your ... sending . . . suggestions for "The Man Who Has Everything," . . . cancer of the lung, . . . death . . ."'" (110).

While the young women who rebel by expressing their feelings indirectly undoubtedly fear that direct expression will lead to punishment, as it does for Lydia, the 
woman put in solitary for speaking out, Athena has no reason for such fear because she is rebelling silently. She probably imagines expressing her feelings only indirectly because she cannot accept them. In the next silent monologue, Athena begins to realize that to accept them and, thus, to express them directly, she must face the reality underlying them. She begins to make that realization by imagining what Lou, a demonstrator out on bail, would say to the woman who deflects her upset over the silencing that prisons impose and Lydia's confinement makes obvious by babbling about birds. Later in the day that Lydia is put in solitary, the woman describes in great detail her pet hummingbird and its valiant resistance to having its claws trimmed. She probably talks excessively about the tenacious but fragile bird because it reminds her of Lydia, a courageous but frail woman. However, "whether ... Lydia [is] in her mind there [i]s no way to know" (158) because she does not express "her mind" or, more accurately, her feelings directly. During the woman's incarceration, "her gray curls ha[ve] turned into the wisps of a witch's hair, and her once rollicking laughter ha[s] come to have a cackling, hollow sound" (157). These changes suggest that being imprisoned, or silenced, has upset her greatly. Athena begins to realize the woman needs to face the fact underlying her feelings, for she imagines the absent Lou screaming at the woman, "'[W]e're in jail! What's the matter with that for reality? Can't we talk about where we are . . . instead of . . . about hummingbirds?'" (159). Indeed, Lou had insisted upon facing "'reality."' The first night, when the demonstrators learn a prostitute died on a bunk one of them will use (19), Lou says, "'She died . . over there[,]' [and] ... jerk[s] her chin toward the bed that nobody want[s] to see" (20-21).

Apparently trying to emulate Lou, Athena silently faces the reality, as she perceives it, underlying her remaining feeling of guilt toward Melanie. It is the reality Athena had silenced herself from thinking about when she explained to some of the demonstrators one author's theory that people join communes because they lack direction: she, and her husband, failed to prepare Melanie for adulthood. A couple of days after the demonstrators' release from prison, Athena gets a letter from Calliope, detailing the "'quick 
visit to the commune'" she had offered to make (114). When Athena reads that "Charles Manson's picture [i]s still hanging there" (218), her mind moves quickly from one thought to another. Upon recalling that Manson had written to Pete that they were mirror images of each other, Athena regards "Melanie [as] their garbled reflection ..., or what she was once" (218). Athena's thinking about "what [Melanie] was once" translates into images of moments in Melanie's life from childhood to adulthood, a mental panorama that ends with an image of a pregnant Melanie holding her other baby. Probably because the baby and the second pregnancy, both apparently fathered by Pete, make obvious Melanie's attraction to him, Athena thinks about its causes. While she silently asks Pete, "What was it that you ... gave [Melanie?" (219), she thinks she knows, for, then, "she ask[s] . . questions of those who had not heard Melanie, year after year, inquiring about which way to go" (220). Evidently, Athena thinks Pete "gave [Melanie]" that which she believes "those"--she, as well as her husband--did not: a response to Melanie's "inquir[y] about which way to go." In telling herself, "Rory had not wanted them to grow up . . . and I . . asked too much in asking them to grow up immediately" (220), Athena reveals her belief that while "Rory" failed to prepare Melanie (and their other daughters) for adulthood by denying Melanie the right to define herself, she failed by not giving Melanie the time as well as guidance for doing it.

Athena's silent self-confrontation, initiated when she imagines Lou reinforcing the importance of facing reality and furthered when she reads Calliope's actual words, does not make Athena express actually or directly her remaining feeling of guilt about Melanie. However, it enables her to imagine confiding in Calliope part of the reality, as she perceives it, underlying her feeling, and her ability to imagine saying part of it enables her to imagine Calliope responding in a way that questions whether she should blame herself as much as she does. Perhaps because Athena has difficulty maintaining her silent, implied belief that fathers, as well as mothers, are responsible for their children's upbringing, or, phrased differently, perhaps because she has difficulty making the subjective shift from 
acceptance of cultural expectations to embracement of her own experiences, even "[i]n silence to Calliope," she can imagine saying only, "I asked too much of [Melanie]" (222)-"in asking [her and her sisters] to grow up immediately" (220). Athena imagines saying nothing about her husband's responsibility. However, she imagines Calliope responding, "[P]erhaps that's better than asking too little" (222), which is essentially what Athena perceives her husband did. In "not wanting them to grow up" (220), or denying their responsibility as well as right to define themselves, he "ask[ed] too little" (222). Thus, the response Athena imagines Calliope making suggests that "perhaps" she should not blame only herself. Interestingly, the ending of Calliope's letter, to which Athena returns following this imagined dialogue, literally underscores the futility of her continuing to blame herself. Callipoe's "last sentence" reads, "'Melanie is not ... in solitary ...., although . . is . . . being detained ..." (222). Inadvertently, Calliope's words make the point that Athena's continued self-blame will not erase the past any more than it will erase the present.

Having acknowledged the reality, as she perceives it, in a silent monologue and having dealt with it in a silent dialogue, Athena becomes able to maintain her focus on reality and, in doing so, to express her feelings actually and directly. From another perspective, Athena's silent monologue and her silent dialogue, together, enable her to begin to forgive herself and, in doing so, to speak on her own behalf, even when speaking on her own behalf lessens the possibility of being reunited, at least physically, with Melanie. In her letter to Athena, Calliope had written that the commune was "'working on ... starting a West Coast branch ... [but that] [w]hich city it will be in hasn't yet been determined ..." (217). Athena could not have known that "two nights later,... [she would be] awakened by the sound of voices ... on the first floor" (222). Upon discovering that a contingent from the commune has just infiltrated her home, Athena approaches Lucky, Pete's emissary, with a basic question. She asks, "'How did you get in?,"' because she "need[s] the simple details of the maneuver to give it reality" (223), and 
she continues to focus on "reality." When he tells her that Melanie and the children will soon be joining them and that "'the whole world is going to be [Pete's] community,'" she asks another reality-grounding question: "'How many of you have come?'" (224).

Apparently, Athena's questions stabilize her, for, when Lucky tells her the commune "'wants to include her in the family's life [and] [she]'ll have to accept that"' (225), she is able to express her feelings loudly, as well as actually and directly. "[A]bove the ... voices in the kitchen," she replies, "'No, I do not accept it"' (225). Even when he alludes to Melanie's imminent arrival and says "'that [is] what [Athena has] been waiting for'" (225), Athena asserts her own feelings. She says, "'No. . . I want her to be set free'" (225). Before leaving the room, she adds, "'[A]s soon as . . it's light . . . I want you all to go'" (226).

This first time, Athena does not assert her feelings with ease. However, even when Lucky browbeats her, she continues to reassert them. She becomes silent only when he literally beats her. Seconds after telling Lucky that she "'want[s]"' the entire contingent out by daybreak. "[s]he st[an]d[s] on the first step [of the staircase to her bedroom] and looks back at Lucky, and a sudden feeling ... swe[e]p[s] over her, a ... longing for all that [i]s lost" (226). A few hours later, "she f[i]nd[s] herself descending in unnatural rigidity ..." (229). Athena probably feels an "unnatural rigidity," or an artificial steadfastness, because she is in the process of "f[i]nd[ing] herself." Because that emerging, assertive self is unfamiliar, she "long[s] for all that [i]s lost" (226), including her old, reticent self. To her credit, rather than reach back for that "lost" self, Athena holds on to her "[new]found" (229) self. When she awakens Lucky and he intimates the contingent's intention of staying, she reasserts herself, saying, "'I made it clear three hours ago... [Y]ou and the others ... have to ... move on'" (233). When he implies that her life will stagnate if she does not receive the commune into her heart, as well as her house, "[h]er eyes $d[o]$ not move from his as she sa[ys]: 'I want you to wake the others up and go'" (233). When he suggests a plan different from her remaining with them once her house becomes the 
commune, she replies, "'[T]here isn't any way to work it out ..."' (233-34). When he screams that she is "'slam[ming] the door in [Melanie's] face"' and adds that "'[t]his is the end of [her, Athena's] life if [she] put[s] [the contingent] out,"' she says, "'Then it will have to be the end"' (234). When he tells her, in essense, that unless she obeys Pete, she has no identity, she responds, "'A thousand times, no"' (234-35). Only after Lucky "str[i]k[es] her twice" does Luchies, her neighbor, happen by, and, "either s[eeing] ... the tears on her face, or the ... rage in Lucky's," he guides her outside (235-36).

Athena stops reasserting her feelings only after Lucky literally assaults her, but one of his verbal threats has permeated her new and, thus, vulnerable, sense of self. Fortunately, Luchies gets Athena to talk about herself, and, in doing so, she gains enough strength to expel a desire to silence herself. When he guides her outside, she asks "'[w]here [they] are ... going,"' but "the words [are] like ashes in her mouth" (236). When he tells her they are going "'to [his upholstery] store, ... [because they] can talk there,"' she replies, "'Maybe there's nothing to talk about . . . . . . not adding . . . now that my life has come to an end" (236). Apparently, Athena's "words [are] like ashes" for the same reason that she thinks "'there's nothing to talk about"': she has begun to believe Lucky's above-mentioned threat that "'[t]his is the end of [her] life if [she] put[s] [the contingent] out"' (234). In other words, Athena has begun to believe not only that "[her] life has come to an end" (236) but also that she has caused it by asserting her feelings. Indeed, had Luchies not said to her, "'[B]egin by telling me the story of your . . . life,"' or, more significantly, had he not added, "'[Lucky] told me you weren't letting your ... daughter come home'" (237), Athena might not have asserted her feelings again. Clearly, her new sense of self is shaken, for "[s]he begins speaking ... in uncertain ... sentences" (237) and relates the same story about Lucky that she had told Calliope. However, as she speaks, she regains some possession of herself. Not only does she finally say, "'I cried this morning out of pity for myself, because I had lost my daughter"' (237), but also, when "a new wave of despair" leads her to "want ... a life that would annihilate all that ha[s] 
gone before" (238), she expels that desire to erase her own history, or herself.

Undoubtedly because Luchies had encouraged Athena to speak, "the moment of [self-] surrender passe[s] . . quickly ..." (238).

Luchies is the first male character in this study who both tries and succeeds in helping the protagonist to express herself. For that reason, his character merits consideration. One might think that this innovation in male characterization reflects a change in gender dynamics from the end of the nineteenth century to the 1970s and 1980s. However, Luchies possesses feminine as well as masculine qualities, so the innovation does not simply and necessarily reflect a change in gender dynamics. Luchies's feminine qualities are apparent before Athena confides in him, so she may confide in him because he possesses those qualities. As his drawing her out in the above scene suggests, one of those qualities concerns his desire to help her. Days before the scene between Lucky and Athena, on the day following her release from prison, Luchies makes clear his regard for her well-being. Upon telling her, "'I am disturbed . . . about you,' . . . his . . . eyes [become] sw[o]lle[n] . . with his concern" (204). That "concern" emanates from his belief that she "'work[s her]self too ... hard'" (204), but it turns into frustration with her neglect of living things. Referring to her intentional arrest, he wonders at her "'leaving everything ... to die!,"' and "his voice go[es] high," or womanlike, when he exclaims (206). During her "'leav[e],"' he assumed woman's caretaker role. He "'water[ed] [her] ivy, and . . . the tree ..."' (206). And, womanlike, he values not the abstract but the material, literally: "[t]he materials he work[s] with in his business, he sa[ys], .. . [a]re what mattered" (206).

However, physically as well as in one behavioral way, Luchies is very much a man, and that masculine behavior impedes Athena's ability to regain full possession of herself. That is, it leads her to feel silenced, which suggests that Luchies's prior success in getting Athena to express herself does not reflect a major change in gender dynamics from the earlier novels. Along with having a "Vandyke beard" and wearing "trousers" (204), 
Luchies does not encourage Athena to make her own decisions; he makes them for her and speaks for her. When he articulates his assumption that she will have the police evict the commune members, "she s[i]t[s] .. . [,] not knowing which act to turn to" (240).

Probably, Athena does "not know" what to do because she has just fought off "the moment of [self-]surrender" after which she feels "a kind of agony she ha[s] not known before" (238). However fleeting, that "moment" apparently causes her "a kind of agony" that compromises her ability to think. She says, "'There has to be another way [to evict the members]'" (241), but she does not think of it. Given Athena's emotional pain and the resultant inability to think, when Luchies implies his intention to seek the advice of an attorney, it is no wonder she defers to his decision and awaits his return. Probably because Luchies decides not only to consult the lawyer but also to engage him without requesting Athena's consent, she feels silenced, or rendered powerless. He and the lawyer return with pseudo documents transferring ownership of her house to Luchies so Lucky will believe that the members can be evicted immediately. Upon signing the papers, "she look[s] in helplessness from one to the other of the two men ..." (245). Since Athena feels "helpless," when Luchies intimates that she should get ready to confront Lucky, it is not surprising that she begs, "'[L]et me stay here[,]' .. . [and] hear[s] the words coming ... as if from ... a subjected woman ..." (245).

Perhaps because Athena "hear[s]" herself speak like "a subjected woman" (245), she does not capitulate to that, her old, identity. Not only does she go with Luchies and the lawyer to her house, but she also regains full possession of herself. She evicts Lucky, physically as well as verbally. One may argue that Luchies's insistence upon his and the lawyer's being "'just ... witnesses [to the eviction]"' (246) motivates Athena to speak and act. However, she neither talks nor moves during the first several minutes of being in Lucky's presence. In fact, despite Luchies's spoken intention to be a "'witness"' only, he unlocks the entrance to her house and tells Lucky, "'You got half an hour to pack up and go'" (247). Further, when it becomes apparent that Lucky and his group will not leave so 
easily, the lawyer presents him with the pseudo bill of sale and deed, and, despite Lucky's continued bravado, "the spirit [i]s quailing ..." (252). If anything, then, Luchies's, as well as the lawyer's, behavior and words, however inadvertently, undermine Athena's motivation to speak and act. It is a visible reminder of Lucky's human frailty, or his vulnerability to control by others, that motivates her. When Lucky "tremble[s] in his skin, Athena fe[e]][s] the surge of her returning will ..." (252). Perhaps because she "s[ees] him as man defeated by other men" (252), or as in a position not unlike that in which she has been until very recently, she does not misuse her "will." When "the power of choice come[s] alive in her again[,] [a]nger and outrage and cven grief [a]re replaced by the ability to act" (252), but she does not use her "power" in a way that will further humiliate him. She says firmly yet gently, "'Please go now, Lucky ..."' (252). When he does not move, she repeats her words in a "voice quiet as breathing ..." (252). Athena's "voice [is] quiet," or calm, because she has regained full possession of herself. As a result, she can "act" on her words: "[s]he beg[i]n[s] carrying [the group's gear outside] . . ." (253).

As Luchies's interactions with Athena illustrate, the extent to which people help her to define herself and to maintain that identity varies. Nonetheless, her final action and, as I discuss in a subsequent paragraph, her final silent monologue reinforce the idea that her involvement with others, especially women, is important to that process of self-growth. In the opening scene of the novel, when Athena overhears some experienced demonstrators reveal their low socioeconomic status and their related personal motive for blocking the induction center, she "th[inks] . . only [they] ... w[ill] travel [in the police van] again after the genteel ha[ve] returned to their gentility" (14). However, in the concluding scene of the novel, she, as well as some of the other "genteel" demonstrators, having blocked the induction center a second time, "travel [in the police van] again." It is Athena's friendship with Calliope that enables Athena to define herself by repetition of action as an anti-war activist. A couple of weeks after the eviction and while spending an afternoon with Calliope, Athena considers a quality they share that nullifies differences between them. 
Upon envisioning a boating catastrophe, she imagines they "would, as one woman, gather the . . . children in their arms ... [and] buckle preservers around the aged, . . [and] [,] as they took action, ... the veil . . between them [would] be dispelled . . ." (259). Through her friendship with Calliope, Athena realizes she likes to "t[a]k[e] action" with others to "preserve" others, and Calliope suggests an outlet for that aspect of Athena. As they ponder what may have happened to one of the long-term inmate's children whom Athena had promised to contact but could not find, Calliope says, "'We must go back. . . ! We've forgotten about the others ..."' (262). The "'others'" to whom Calliope refers is vague, but I assume that she at least means the "'other'" activists because the final scene shows Athena and her as having "'go[ne] back'" to demonstrate against the war.

Athena's vision of Calliope and herself "gather[ing] children ... and buckl[ing] preservers around the aged" (259), Calliope's concern "'about the others'" (262), and their demonstration against the conscription of young men and, thus, the killing of "children" and "the aged" (259) may seem synonymous with the role of maternal protector that both of them have been culturally taught. However, Athena's vision, Calliope's concern, and their shared activism are significantly different from that cultural expectation. During the 1960s (and today), American culture did not expect women to perform acts of heroism for people who were not members of their own family. For that matter, it seldom considered women to be heroes. When it did, it praised maternal passivity and condemned activity separate from motherhood. In 1963, after President Kennedy's assassination, the public admired Jacqueline Kennedy's stoicism when she stood between her children as the casket passed them. A few years later, when she had been seen traveling abroad and without her children, public admiration turned into criticism. To understand the way in which women activists tended to be perceived, one need only recall Stokely Carmichael's response at a 1964 conference of the Student Non-violent Coordinating Committee (SNCC) to a written complaint submitted by women about men's treatment of them as subordinates: "The only position for women in SNCC is prone"' (Evans, Personal Politics 87). In demonstrating 
against the involvement of the United States in Vietnam and its policy of conscription, Athena protests against aggression, a behavior expected of men, and the enforcement of that behavior. In other words, she challenges a cultural expectation of men. In demonstrating at all, she challenges the cultural expectation that women be passive, even when she does it by sitting in, or by being silent, because she chooses to be silent.

If Athena's friendship with Calliope enables Athena to define herself as an anti-war activist, then, as her final silent monologue suggests, her reacquaintanceship with Lou helps her to maintain that identity. Even if Athena were not sitting opposite Lou the second time in a police van, she would be aware of Lou's presence. Lou, always grounding herself and others in factual details, in a "voice as loud as ... a cheerleader's shouting[,] [announces][,] "'There're a thousand people, fifteen hundred maybe . . . [at the sit-in]!"' (263). Significantly, during her first encounter with Lou, Athena cannot tolerate Lou's "voice." When Lou, indicating the bed on which an inmate had died, says to another demonstrator, "'You've had quite a lot of exposure to reality so far today, haven't you, Ann[,]' . . Athena quickly interrupt[s] the sound of [Lou's voice]" (21). Ostensibly, she "interrupt[s]" Lou's voice because she feels protective of "'Ann,"' a "delicate-boned girl" (20). However, she may also silence Lou's voice because she has difficulty "'expos[ing] [herself] to reality'" (21). However, just as when she imagines the absent Lou screaming at another demonstrator to recognize their imprisonment, when Lou really and "loud[ly]" announces not only the number of participants at the second sit-in but also her intention to "'be in [prison] ... with the rest of [the demonstrators]"' (263), Athena does not respond negatively to Lou. In effect, she embraces Lou's belief in dealing with actualities. As Athena walks into the city jail, she "t[ells] herself that ... Melanie and Rory a[re] gone forever," and, "ask[ing] in silence of the ... walls," she says, "[즐eality, hold me close ..." (264). Thus, Lou's "voice" (263) at the end of the novel helps Athena to remember "silent[ly]" that, to maintain her new identity, she must continue to face the loss of 
"Melanie[,] [as well as] Rory, as being as much an actuality as the "walls" are a "reality" (264), for that actuality underlies her need and desire for her new identity.

As Athena's silent monologues indicate, her journey to selfhood is primarily a solitary one. In the initial cluster of silent monologues, those to the demonstrators, she struggles with a major conflict: her feeling of being without an identity contradicts the social expectation that, as a widow, she accept the singular identity of mother. As the last silent monologue in this cluster reveals, this conflict results from her inability to fulfill all aspects of motherhood--in particular, her inability to take care of Melanie. Once Athena accepts her need and desire for an identity different from social norms, she has a second series of silent monologues in which she struggles to create her own sense of self. In one of them, she imagines expressing her feelings in letters, but she can express her feelings only indirectly. When she imagines Lou suggesting that the reality underlying one's feelings must be faced, she applies that idea to her own history, but, in doing so, she blames herself, primarily, for having failed to teach Melanie how to be an adult, how to take care of herself. Once she imagines a dialogue in which Calliope suggests to her that she did not raise Melanie as badly as she thinks, she begins to speak her feelings, but, because that assertive self is so new, when Lucky vigorously challenges her, she silences herself. Eventually, Athena reiterates her feelings and acts upon them. In doing so, she releases herself from her caretaker role and becomes able to focus on herself separate from that role. At the end, and in silence, she buttresses her new sense of self by reinforcing the reality that the identity which social norms expect her to assume is not one that she can fulfill. Without a doubt, all of the people whom Athena observes--Lou, as well as other students, Callisto, and the long-term inmate--and the people in whom she confides-Luchies as well as Calliope--are essential to her journey to selfhood. Nonetheless, since so much of Athena's journey occurs in silence, it is primarily a solitary one. 


\section{Conclusions}

Comments that Boyle makes in interviews, when analyzed and applied to The Underground Woman as well as to Plagued by the Nightingale, suggest that, despite her self-proclaimed anti-feminism, she might have used indicated silences to expose the gender oppression to which women have been subject in order to effect change. In a 1964 interview, Boyle says that "women ... should try not to write like women ... [by] presenting the woman's instead of the human point of view" ("Kay Boyle," Talks 235). However, in both novels, her protagonists are women, so she "present[ed] the woman's ... point of view," and, to a significant degree, through the protagonists' silent monologues. In another interview conducted sometime between 1972 and 1975, the latter year being the year in which The Underground Woman was published, Boyle says that one of her motives for writing is "to ... speak of injustices that are being done ..." ("Kay Boyle," Fiction! 20). While The Underground Woman obviously critiques the involvement of the United States in Vietnam, both it and Plagued by the Nightingale show the "injustices" suffered silently by women as a consequence of dominant culture's expectation that they identify themselves solely according to their gender roles as wives and mothers. Importantly, in that latter interview, Boyle responds to the question about whether "fiction has the power to change men's minds" by saying, "[I]t can have the power to reveal each person to himself" (24). Not many years after that interview, Chris Weedon expresses a similar sentiment, but from a feminist perspective: "literature has long been a powerful source in the sexual-political education of women, offering alternative ways of seeing gender ... and of recognizing forms of patriarchal power" (144). In her two novels, Boyle "offer[s]" that "education." Through her indication and exploration of Bridget's and Athena's silences, she invites women readers to give themselves the opportunity "to reveal [themselves] to [them]sel[ves]" ("Kay Boyle," Fiction! 24).

Bridget's and Athena's early silent monologues reveal that both protagonists blame themselves for being unable to meet the standards of the image of the Southern lady to 
which white patriarchal culture expects women of their race and class to conform. Eventually, however, each woman uses silence in her own way, and the difference between their uses accounts significantly for Bridget's remaining mired in that subject position and Athena's extricating herself from it. In her early silent monologues, Bridget essentially blames herself for her inability to be "a ... wife whose reason for being [i]s to love ... [and] obey ... her husband, [and] to bring up his children ..." (Scott 4). To "obey ... her husband," Bridget would have "to bring up . . . children" not "his," and, to "bring up . . children" not "his," she would have "to love" a man not "her husband." In her early silent monologues, Athena essentially blames herself for her inability to be "the glorification of motherhood, with its great possibilities for beneficent influence on the coming generation" (37). In that she bears three children, Athena is "the glorification of motherhood," but, for her "motherhood" to be an entirely "beneficent influence on the coming generation," she would have to persuade her drugged and brainwashed daughter to forsake the evildoer. Along with silently blaming themselves, both protagonists silently acknowledge their lack of an identity, and that is the point at which their similar uses of silence end. Bridget deals with her feelings about identity by silently projecting them onto others and, ultimately, by resuming her earlier denial of the reality underlying them: her husband will not father a child. Athena deals with her feelings about identity by silently confronting issues directly related to them and, ultimately, by silently reinforcing the reality underlying them: Melanie will not forsake Pete. In facing the reality underlying her feelings, Athena becomes able to create and to keep an identity different from patriarchal expectations.

Apparently, a particular comment made sometime between 1923 and 1924 by a poet-friend of Boyle's influenced the content of both Plagued by the Nightingale and The Underground Woman. Boyle paraphrases this friend as having written to her, "[E]very lie, every denial, ... makes a man a little less than he was, or what he was intended to be, so, finally, ... he is diminished ..." (McAlmon 141). Bridget "deni[es]" the "lie" that the 
image of the Southern lady represents, so "[s]he is diminished." Unlike Bridget, Athena, like Dora and Sappho before her, stops "den[ying]" the "lie" that the image represents, so, like them, she is able to become the "[wo]man [who] ... [s]he [i]s" rather than the woman whom patriarchal culture "intended [her] to be." Like them, "[s]he is [not] diminished." Unlike Dora and Sappho, however, Athena begins to accept the reality of the "lie" in silence, and she reaffirms that reality in silence. Early in the novel, she silently begins to acknowledge the reality that she could not save Melanie from Pete, and, by the end of the novel, she silently reminds herself that Melanie is beyond her reach. Essentially, and in silence, Athena faces the dual "lie" that mothers can always protect their children from harm and that women can only derive their identity from their maternal, as well as their marital, status. Largely, Lou's speaking about things that are real encourages Athena to deal with truths, and she does that, silently.

Indeed, Boyle understood the need for speech as well as silence, and distinctions she makes between Bridget and Athena reflect that understanding. During the 1964 interview mentioned earlier, Boyle says, "Language goes . . . almost more deeply than we realize," and she refers to "psychologists [who] would tell you that the lack of an adequate means of verbal expression plays a great part ... in the tragedies of ... all the lost" ("Kay Boyle," Talks 217). Along with Bridget's tending not to use silence to deal directly with her feelings as Athena eventually does, Bridget does not use "verbal expression" to disclose to others issues related to her feelings and the feelings themselves as Athena eventually does. These differences between the protagonists lead Bridget to remain "lost" and Athena to find herself. Since most people in Bridget's milieu essentially believe in the image of the Southern lady, one might argue that Bridget "lack[s] ... an adequate means of verbal expression" of her feelings surrounding the image, but that argument does not take into account Charlotte's desire to help Bridget explore her feelings and create an identity at least somewhat different from the image. A more cogent argument would be that once Charlotte dies, Bridget "lack[s] an adequate means of verbal expression." 
Fortunately, Athena confides in Calliope issues related to her feelings surrounding the image, and, when Luchies encourages her to talk, she articulates some of her feelings. Her confiding in Calliope helps Athena to explore her feelings further in silence, to speak on her own behalf, and, eventually, to act for herself. Her articulating her feelings to Luchies enables her to hold on to her newfound self, painful memories and all. And, prior to Athena's becoming able to assert her own feelings, Callisto's, the college students', and the young long-term inmate's uses of speech as well as silence help Athena to imagine speaking on her own behalf.

Not surprisingly, both silence and speech reflect and affect the protagonists' identities in Paule Marshall's novels, the last novels considered in this study. As is the case with their literary predecessors and the people in the predecessors' social milieu, the ways in which Selina, the protagonist of Brown Girl. Brownstones, Avey, the protagonist of Praisesong for the Widow, and the people with whom they have relations use silence and speech influence the extent to which Selina and Avey extricate themselves from the image of the Southern lady. 


\section{CONCLUSION}

\section{Confirmations and Predictions}

In the introduction, I explained that my study is informed by Chris Weedon's argument that "a theory is useful if it is able to address the questions of how social power is exercised and how social relations of gender, class and race might be transformed" (20). I also agreed with George Kalamaras and King-Kok Cheung that "silence and language," as Kalamaras says, "act in a reciprocal fashion in the construction of knowledge" (8) as well as with Weedon that "knowledge brings with it the possibility of power and control" (14). In chapters 1 through 3, I have shown that these "theor[ies] [are] useful" (20) to an examination of indicated silences, or "silence" indicated through the "language" (Kalamaras 8) of the narrator and/or the author specifically, as in authorial manipulation of punctuation. Many of these silences of Kate Chopin's, Pauline Hopkins's, and Kay Boyle's protagonists show "how social power is exercised" (Weedon 20), and these silences of other women in Hopkins's Contending Forces: A Romance Illustrative of Negro Life North and South and Boyle's The Underground Woman show "how social relations of gender, class and race might be transformed" (20). The silences of these other women lead the protagonists to acquire "knowledge [that] brings with it the possibility of [selfem]power[ment] and[,] [thus, some] control" (14) over their subjectivity, and both the protagonists' and the other women's indicated silences give readers that "possibility."

In other words, the authors are to readers what the other women characters are to the protagonists: "a speech community" that Patricia Yaeger describes as "fellow speakers who ... encourage the growth of ... thought and its translation into praxis" (215). When this "community" is absent--as in Chopin's At Fault and The Awakening--or when it is lost--as in Hopkins's Winona: A Tale of Negro Life in the South and Southwest and Boyle's Plagued by the Nightingale--the protagonist's "thought" does not "grow"; so, neither does she. However, with this awareness, readers still can. 
I also explained in the introduction that I would discern trends emerging from the one historical moment to another historical moment and being confirmed in a later historical moment. Beginning with Boyle's Plagued by the Nightingale, written during the 1920s, and continuing with her novel written fifty years later, The Underground Woman, I discerned a gradual emergence of the "speech community" (Yaeger 215) that Hopkins's turn-of-the-century Contending Forces established. In The Underground Woman, I also discovered in the protagonist's "speech community" a person whose gender and race is different from her own, which suggests the beginning of a new trend. With a few differences, these trends as well as additional ones are confirmed in Paule Marshall's Brown Girl. Brownstones (1959) and Praisesong for the Widow (1983). ${ }^{1}$

On the one hand, like the female characters in Chopin's novels and, with the exception of Charlotte, in Boyle's Plagued by the Nightingale, most of the female characters in Brown Girl, Brownstones and in Praisesong for the Widow do not encourage the protagonists to define themselves. To varying degrees, most of the female characters in Selina Boyce's and in Avey Johnson's life--some older, some contemporaries, and, in Avey's case, one younger--essentially tell the protagonists who they are not or who they should or should not be. Depending on the degree to which these characters insist, Selina and Avey become silent to them because they feel alienated from them or because they are resisting them. At least to some extent, then, Marshall's protagonists, like the protagonists before them, are "given to suffering in silence ..." (Scott 4). 2

On the other hand, similar to Dora and Sappho in Hopkins's Contending Forces and Athena in Boyle's The Underground Woman who, respectively, have Mrs. Smith, the Mother Superior, and Calliope as well as the younger women in their "speech community" (Yaeger 215), Selina and Avey each have a woman in their "community." However, unlike the closeness between the "communit[ies]" of Hopkins's protagonists and the protagonists, some type of distance exists between Selina and Avey and their 
"communit[ies]," and that quality is reminiscent of Athena's relationship with Calliope, as well as others in her "community."

Of the six female characters in Selina's life--her sister, Ina; her childhood friend, Beryl; her older neighbor, Suggie; her elderly neighbor, Mrs. Thompson; her mother, Silla; and her college friend, Rachel--Selina often becomes silent to all but one of them. Selina becomes silent to Ina and Beryl because she feels alienated from them. Unlike Selina, they act ladylike and are lighter skinned. In other words, they better conform to the image of the Southern lady than Selina does. When they make clear to Selina that she is not like them and, thus, not like the image, she becomes silent. ${ }^{3}$ Suggie, Mrs. Thompson, and Silla essentially tell Selina who she should not be or who she should be. Suggie tells Selina not to become part of the Barbadian Association whose goals for their children include not only a college education but also home ownership--in other words, a middle-class and materialistic lifestyle that can be viewed as an outgrowth of the lifestyle that the image of the Southern lady represents. Mrs. Thompson and Silla essentially tell Selina that she should be who Suggie tells her not to be. At one time or another, Selina resists all three women's less-than-subtle guidance by becoming silent. ${ }^{4}$

Selina does not usually become silent to Rachel, the one female character who unequivocally encourages Selina to seek self-definition. That is, Rachel is virtually the only woman--indeed, virtually the only person--who comprises Selina's "speech community" (Yaeger 215). Unlike the rest of the girls and women in Selina's life, Rachel not only encourages Selina to further her own interests, such as dance, but she also accepts Selina's desire to move away from home and provides Selina with a way of doing it. 5

In a couple of ways, Rachel is like Calliope in Boyle's The Underground Woman, but there is one significant difference between them that affects their relationship with the respective protagonists. Like Calliope, Rachel is the protagonist's contemporary, and she encourages the protagonist to develop her own sense of self. Yet, unlike Calliope, Rachel is of a race different from the protagonist, and that difference causes a particular type of 
distance to exist between Rachel and Selina that does not exist between Calliope and Athena. Because Athena's friendship with Calliope is based primarily upon only one common interest, their relationship is limited, but Athena never doubts Calliope's perception of, and respect for, her as an individual. Selina maintains her friendship with Rachel, and she accepts Rachel's help in moving away. However, at one point, she feels that Rachel denies her individuality. ${ }^{6}$ Thus, some type of distance exists between Athena and Selina and their womenfriends, but the reason for the distance is different.

In one form or another, there are four women in Avey's life--her two friends, Thomasina and Clarice; her daughter, Marion; and her deceased Great-aunt Cuney--and, to all of them, Avey becomes or is silent. Thomasina and Clarice (Thomasina especially) expect Avey to embrace the middle-class status that they all share and that necessitates their denying their blackness and, in that sense, their conforming to the image of the Southern lady. Marion and Great-aunt Cuney, the latter through Avey's dream about time spent with her during childhood, expect Avey to reject middle-class materialism and embrace her blackness, of which a sense of communal spiritualism is integral. No matter in which direction Avey is pulled, she resists by becoming or being silent. ${ }^{7}$

However, Avey's dream about the annual summer visits that she used to make with Great-aunt Cuney to Ibo Landing, a former point of debarkation for slaves, eventually helps Avey. This dream is significant in three particular ways: it shows that Great-aunt Cuney influences Avey in a positive way; it shows that Avey uses silence, as in the act of dreaming, to (re)claim her own sense of self; and, related to those two points, it links these women with women in earlier novels. Within the dream, Great-aunt Cuney essentially tells Avey that, to cope as a black person in a white society, she must maintain her sense of African spirituality. Unlike Mrs. Smith and the Mother Superior, Great-aunt Cuney is dead, so a very real distance exists between her and Avey. However, as Mrs. Smith and the Mother Superior, respectively, help Dora and Sappho, she helps Avey not to be 
ashamed of her ethnicity. And the silence of Avey's dreaming is like some of Athena's silences because it helps her to define herself.

While Marshall's two novels are similar to each other in that some type of distance exists between the protagonists and the women who help them, there is a significant difference between the two novels in terms of the protagonists' interactions with men. In that regard, the earlier of the two novels, Brown Girl, Brownstones, closely matches the majority of the novels in this study, while Praisesong for the Widow is similar to Boyle's The Underground Woman.

As is the case in the majority of the novels, neither of the two men in Brown Girl, Brownstones encourages the protagonist to define herself, and, with one significant difference, Selina, like most of her predecessors, shows deference toward, and concern for, the men in her life through silence. Especially as David in Chopin's At Fault, Warren in Hopkins's Winona, and Nicolas in Boyle's Plagued by the Nightingale, respectively, focus on their own concerns and desires and, in that way, discourage Therese, Winona, and Bridget from developing a sense of self, so, too, do Selina's father, Deighton, and her boyfriend, Clive, discourage Selina. ${ }^{8}$ As much as Therese, Winona, and Bridget do, when Selina is with the men in her life, she uses silence to show deference toward them and to try to help them in some way. In that sense, then, Selina, like Therese, Winona, and Bridget, acts according to the standards of the image of the Southern lady. Yet, unlike the other protagonists, Selina uses silence to try to help the men in her life because some act of racism has scarred them. ${ }^{9}$

As is the case in Boyle's The Underground Woman, in Praisesong for the Widow, a man plays a positive role in the protagonist's quest for selfhood, but significant differences exist between the men in these novels and the extent to which they help the protagonists. Lebert Joseph is for Avey as Luchies is for Athena: a member of her "speech community" (Yaeger 215). Unlike Luchies, however, Lebert is older than, and of the same race that, the protagonist is; and he possesses qualities more obviously androgynous than 
Luchies possesses. ${ }^{10}$ Most importantly, Lebert remains silent more often than Luchies does. In other words, Lebert gives Avey more space in which to think as well as to speak than Luchies gives Athena. Indeed, the willingness to give a woman that kind of space may be considered a feminine quality. Through that willingness, Lebert is particularly like both Mrs. Smith and the Mother Superior--and Charlotte, for that matter. Luchies's encouragement of Athena to speak helps her to regain her hold upon her new sense of self. However, like the initial silence of each of the two older women in Contending Forces, Lebert's initial silence--in his case, an additional silence as well--propels the protagonist toward her own sense of self. ${ }^{11}$

These trends that continue in some form in Marshall's novels allow me to predict their direction for the foreseeable future in novels by women when the protagonists are girls and/or women. ${ }^{12}$ In every novel in this study, the extent to which the protagonist becomes able to define herself depends upon whether she has a relationship that is ongoing in some way with a woman who, through silence and/or speech, encourages her to develop a sense of self different from the image of the Southern lady or its inferior opposite. Thus, I think that protagonists' "speech communit[ies]" (Yaeger 215) will continue to include women. Further, since the majority of the women who help the protagonists help them at least in part by being silent at some point, I think that women authors will continue to indicate these silences to stress their importance.

Based upon the two most recent novels in this study, Boyle's The Underground Woman and Marshall's Praisesong for the Widow, I think that men who have androgynous qualities will continue to play a role in helping protagonists to define themselves. When the men in Boyle's and Marshall's novels are compared, it becomes evident that the man who more manifests feminine qualities, especially the willingness to be silent so that the protagonist can think as well as speak, better helps the protagonist to define herself. Thus, I think it likely that women novelists will continue to include in the protagonists' "speech 
communit[ies]" (Yaeger 215) men who have feminine qualities and that they will indicate the men's silences to stress their importance.

The significance of the "speech community" (Yaeger 215) to the protagonist's selfdevelopment notwithstanding, the relationships between two recent protagonists, Selina and Avey, and the people who help them suggest a continuing distance in those relationships, as well as a change in the "communit[ies]" themselves, in novels by black women. Because Selina is identified by the dominant society as Other, she feels an emotional distance from her white friend. Perhaps for that reason, Marshall does not include in Avey's, her more recent protagonist's, "community" anyone who is not black. Thus, I think that black women novelists will exclude people who are not black from their protagonists' "communit[ies]." Nonetheless, some type of distance exists between Avey and her "community," so I think that black women novelists will include black people in them to whom, for one reason or another, the protagonists are not close.

The relative newness of the white protagonist's "speech community" (Yaeger 215) makes predictions about the relationship between it and the protagonist particularly tentative. However, as I predict about the foreseeable future of that relationship in novels by black women, in novels by white women, I think that it will include some type of distance. From her first novel to her last novel, Boyle lessens the emotional distance between the protagonist and the protagonist's "community," but, in her last novel, Boyle maintains some degree of distance between her protagonist and the protagonist's "community." At one point, Athena and Luchies kiss, but, ultimately, they do not become romantically involved. ${ }^{13}$ As I have argued, because Athena's friendship with Calliope is based only upon one common interest, it is limited. And Athena does not have a close relationship with any of the younger women. Thus, I think that a distance between the white protagonist and the members of her "community" will probably continue.

These trends I perceive to have gradually emerged in Boyle's novels and to have been confirmed, with some differences, in Marshall's novels suggest a number of things to 
me about the foreseeable future of novels by women with female protagonists. Despite some form of distance between the protagonists and their "speech communit[ies]" (Yaeger 215), these "communit[ies]" will continue to be important for the protagonists' development of self, they will sometimes be silent, and the authors will continue to indicate their silences. Some of the protagonists' silences will reflect their subject positions, while other silences of theirs will help them to define themselves. In both instances, the authors will continue to indicate these silences. Indeed, I would argue that some of these predictions are borne out in very recent novels, such as in Louise Erdrich's Tales of Burning Love (1996), which is material for another study.

These predictions mean a number of things for women readers in particular. With the assumption that women novelists will continue to stress silences by indicating them, women readers will be given the opportunity to reflect upon the importance not only of having their own "speech communit[ies]" (Yaeger 215) but also of expecting that such "communit[ies]" will sometimes be silent so that they can think and/or speak. Further, women readers will be given the opportunity to reflect upon ways in which subject positions assigned them by the dominant culture influence their sense of self, including the fact that those positions silence them. And, that type of reflection will give women readers the opportunity to use their own silences to create their own subjectivity. In other words, the continued use of indicated silences by women novelists will help women readers continue to define themselves. 


\section{NOTES}

\section{Introduction}

${ }^{1}$ In her thought-provoking essay, "Interrogating 'Whiteness,' (De)Constructing 'Race,"' AnnLouise Keating explores problems with using the word "race" and words related to it. However, a particular point that she makes provides a reason for my using that word as well as for my identifying authors and characters in this study primarily by race rather than by ethnicity. She says, "Racial divisions were developed to create a hierarchy that grants privilege and power to specific groups of people while simultaneously oppressing and excluding others" (916). Since I had wanted to consider how racism--the "privileg[ing]"/"oppressing" and "[em]power[ing]"/"excluding" of such "groups"/"others" on the basis of race--in particular may influence authors' uses of silence, I found it necessary to identify the authors and their characters according to race. This study should be read with the understanding that my intention is not to validate the word "race" and words related to it.

2 For a brief discussion of speech communication studies which indicate that men use various conversational strategies to silence women, see Thorne, Kramarae, and Henley, 17.

3 A very recent collection of essays similarly argues that women authors use narrative strategies to represent that which cannot be verbalized; see Lashgari.

${ }^{4}$ Of course, white critics may have abstained from even acknowledging the existence of Contending Forces simply because its author was a black woman, and, had they reviewed it, they probably would not have looked favorably upon it. For an essay which compellingly argues that works by African Americans receive favorable commentary only when they can be interpreted as reflecting dominant ideologies, see Hogue, 34.

5 There is at least one contemporary of Kalamaras and Cheung, Andrew Vogel Ettin, who also explores the complementary nature of silence and language; for that reason, his text, Speaking Silences: Stillness and Voice in Modern Thought and Jewish Tradition, deserves recognition. Further, there are at least two additional contemporaries who argue against viewing silence as a necessarily negative condition, but, because they do not perceive or do not discuss the complementary nature of silence and language, I do not mention them in the introduction proper. They are Susan Gal and Patricia Laurence.

\section{Chapter 1}

${ }^{1}$ In describing people "who will encourage the growth of ... thought and its translation into praxis," Yaeger uses the terms "[s]peech community" and "group of fellow speakers" interchangeably; see 215 . Thus, I use these terms interchangeably. For example, in the introduction, I refer to feminist scholars who challenge hierarchical binaries as a "group of fellow speakers." 
2 Chopin completed a second novel shortly after At Fault, but she threw it away. See Seyersted, 25.

${ }^{3}$ Skaggs notes two other scenes during which Edna becomes silent--once with Robert Lebrun, once with Mademoiselle Reisz--and, in both instances, she quotes the narrative directives. See Skaggs, 101 and 105. Yaeger mentions two scenes in addition to the ones noted by Skaggs during which Edna becomes silent--once with her husband, once with Dr. Mandelet. While, in the first instance, Yaeger does not quote the narrative directive, in the second instance, she does. See Yaeger, 208 and 219.

4 In 1993, after participating in a Kate Chopin Conference in Natchitoches, I rode with a friend to New Orleans, and, despite the fact that she maintained a speed of eighty miles per hour on Routes 49 and 10, which, together, provide as direct a route as possible, we did not arrive in New Orleans until about seven hours after leaving Natchitoches. During the journey, I noticed that, except for Alexandria and Baton Rouge, through which, respectively, we passed after about one hour and four hours, the area between Natchitoches and New Orleans is still very sparsely populated.

5 Several critics have pointed out, but do not say as succinctly as Ruth Sullivan and Stewart Smith do, that "Edna acts ... by emotion." Along with Sullivan and Smith, 68, see S. Jones, 114; Elfenbein, 308; Solomon, 119; and Bauer and Lakritz, 50.

\section{Chapter 2}

${ }^{1}$ As Yaeger refers to it, the "speech community" includes people "who will encourage the growth of ... thought and its translation into praxis" (215).

2 In addition to Contending Forces and Winona, Hopkins wrote Hagar's Daughter: A Story of Southern Caste Prejudice, her second novel, and Of One Blood. Or. The Hidden Self, her fourth and last novel. All four novels were published within three years, and Contending Forces is the only one that was not serialized in the Colored American. See Campbell, 182. Although Of One Blood was Hopkins's last novel, I did not choose it for my study because it diverges radically from the literary conventions of the time and is not representative of her work.

${ }^{3}$ For a reference to support by some English subjects of the abolitionist cause, see, for example, former slave Elizabeth Keckley's comment from her autobiographical Behind the Scenes that, in 1862, "[f]rom England a large quantity of stores was received" for use by the Contraband Relief Association (qtd. in Sterling 250). As for evidence that some English subjects supported the anti-lynching campaign, one need only consider the fact that, in 1893, Ida B. Wells, the initial organizer of the campaign, upon "invitation[,] ... went on a lecture tour through [Great Britain]" (Giddings 90).

${ }^{4}$ For additional critics who argue that pre-1940s black women authors attempted to debunk stereotypes of black women by creating protagonists who strive to meet the standards exacted of white women, see Carby, Reconstructing Womanhood, 174, and McDowell, 95.

5 Dr. Sharon H. Strom, Professor of History at the University of Rhode Island, suggested to me that "Hopkins's choice of a Seneca 'foremother' is fascinating ...., 
especially since the Seneca had a matrifocal and matrilineal kin lineage." Dr. Strom further suggested that Hopkins might be "posing the 'love' of Seneca women as an alternative to 'white' knowledge." A closer reading of Nokomis would enhance the depth of my discussion, but it would also complicate it. Thus, for this study, I am primarily considering Nokomis as an older woman of color. With gratitude, I will apply Dr. Strom's suggestions to later work on Winona.

${ }^{6}$ For additional information about the particular sexual vulnerability of women house slaves, see J. Jones, 27.

7 Allusions to white-looking black women house slaves being sexually assaulted by their owners are common in both fiction and nonfiction. See, for example, Cassie commenting about her and Emmeline's treatment by Simon Legree, in Stowe, 385, or the earlier-mentioned Harriet Jacobs commenting about Dr. Norcom's (Dr. Flint's) expectations of her, 18.

8 It is worth noting that Warren's white paternalism is often contrasted with his seeming egalitarianism. For example, at the same time that he says the newly orphaned Winona and Judah merit attention because they are "'human beings'" (303), he also refers to them as "'my island proteges'" (314). In a later scene, when he prepares to fight alongside John Brown--an historical figure whom Hopkins, like many other African Americans, admired--he says to another white man that he wants to fight because "'we owe the poor girl [Winona] something'" (401). In actuality, he wants to fight because "he [i]s devoured by anxiety to be among the busy people of the world once more" (401)-"busy people" referring not to the fugitive slaves and the people who help them but to his fellow Englishmen. For evidence indicating Hopkins's admiration of Brown, see the narrator of Winona referring to him as "pastor, guide and counsellor" to fugitive slaves (374). For examples of Hopkins's contemporaries lauding Brown, see Frances Ellen Watkins Harper dubbing him "the hero of the nineteenth century" (qtd. in Sterling 163) and teacher Charlotte Forten referring to him as one "of the great and good men" (qtd. in Sterling 281). A recent biographer of Frederick Douglass claims that several black leaders, including Douglass, "spoke of Brown as one white person who took black people into account" (McFeely 194).

9 That Winona's owner might not have allowed her to be taught to read but that Winona may have taught herself is entirely possible. Despite laws in several states forbidding slaves to be taught to read, many of them nonetheless learned. See, for example, Note 5, which explains the forced closing of a black church (Yellin 270).

10 Winona's acceptance of her father's legacy, material as well as cultural, undoubtedly does make her particularly attractive to Warren. It not only relegates her mother's cultural legacy to a dark corner but also promises improvement in Warren's financial, if not social, status. As the narrator reveals at the outset of Warren's appearance in the novel, even though he is the son of a "baronet," being the youngest of four sons, "his ... share in the family estate w[i]l[1] amount to an annuity scarcely enough to defray his tailor's bill" (298). Even though his having accidentally become acquainted with Winona will earn him "a full partner[ship]" (299) in the law firm that had sent him to the United States to find Winona's father, "the heir of Carlingford of Carlingford" (298), it is unlikely that "all the emoluments of the position" (299) equal Winona's inheritance. Indeed, when Warren hears the witness to Winona's father's murder call her "'the heiress'" (428), he "preserve[s] his impassiveness by a struggle" and "[i]s filled with a hope that agitate[s] him almost beyond control" (429). 
Chapter 3

1 This term, a "speech community," that has been so valuable to me is, of course, from Patricia Yaeger's essay; see 215.

2 The manuscript of Boyle's first novel was lost by one of its readers; see Mellen 125-26.

3 Other works by Boyle, including poems and essays, have characters or personae who, in their silent thoughts, talk to others, but an exploration of those imagined conversations is beyond the scope of my study. An analysis of such conversations could be done, for example, with the short stories "Episode in the Life of an Ancestor" (1930), "The First Lover" (1933), "I Can't Get Drunk" (1933); with the poem "Testament for My Students, 1968-1969" (1969); and with the essays "No One Can Be All Things to All People" (1970) and "Report from Lock-Up" (1977).

4 My study primarily concerns women, so I do not explore, in depth, the ill Nicolas's refusal to engender children. However, Boyle's characterization of him is an interesting reversal of the nineteenth-century female hysteric. Because textual evidence indicates that he inherited the illness, one could begin an in-depth exploration by reading "On the Borderland: Henry Maudsley and Psychiatric Darwinism," Chap. 4 in Elaine Showalter's The Female Malady: Women, Madness, and English Culture, 1830-1980. Further, because Nicolas served in the First World War--see Boyle, Plagued 33, 142Chap. 7, "Male Hysteria: W. H. R. Rivers and the Lessons of Shell Shock," might be helpful as well.

5 As an interesting aside and a point worth probing within a study grounded in Marxism, Nicolas's earnest suggestion that Bridget conceive another man's child parallels Claude Levi-Strauss's idea put forth in "The Principle of Reciprocity," chapter 5 of his The Elementary Structures of Kinship. According to Levi-Strauss, in the game of "[e]xchange" between men, women are the "most precious category of goods" (61), and "[g]oods are not only economic commodities, but vehicles for . . . such [things] as ... . status ..." (54). Were Bridget to act on Nicolas's suggestion that she conceive a child with someone other than with him and were his father to be ignorant of the deception, not only would Nicolas's "economic" condition be improved because he would receive the large sum of money Papa offers in "exchange" for a grandchild, but also, from Papa's perspective, Nicolas's "status" would be elevated because he satisfies his father's expectation.

6 Apparently, critics have not considered the idea that Bridget's final words allude to an intention to conceive Nicolas's child without his consent, but that interpretation lacks credibility anyway. Because Boyle, like most authors writing during the 1920s, did not include in her text explicit references to sex or, in other words, remained silent about it, any interpretation that concerns Bridget and Nicolas's shared sex life must be based upon assumptions. Along with assuming that they have intercourse and that she is fertile and he, virile, I assume that they use a contraceptive and that its use or nonuse is determined by him, not her. Whether they brought it with them from the United States or obtained it in France, the contraceptive is likely to be a condom and not a diaphragm, and, of those two devices, only the latter, as Sanger well understood, allows the female partner reproductive control. For an essay concerning silence on sexual matters, see Henke. For the common usage of condoms following the First World War, see Gordon, 
206; for the unavailability of diaphragms during the 1920s in the United States and probably in France as well, see 263 and 172.

7 The eight-page Works by Kay Boyle section of Mellen's biography on her is itself a testimony to Boyle's productivity as an author; see 643-50.

8 For a compelling firsthand account of the difficulty that young women writing during the 1950s had in valuing their own work, see Joyce Johnson's Minor Characters. Also valuable in this memoir is Johnson's portrayal of her mother, a woman of Boyle's generation.

\section{Conclusion}

${ }^{1}$ The indicated silences in Marshall's novels, just as in Chopin's, Hopkins's, and Boyle's novels, merit an in-depth examination and within an historical context. In other words, the silences in Marshall's novels are material for future study.

2 I think it valid to assume that, to some extent, both of Marshall's protagonists have been influenced by the image of the Southern lady. Marshall, their creator, identifies herself as "'Afro-Caribbean and Afro-American'" (qtd. in Pettis 32). Further, she "'embrace[s] both these cultures and ... hope[s] that [her] work reflects what [she] sees as a common bond'" (32). Both of Selina's parents are from Barbados, and, although Avey's parents' origins are less definitive, she identifies with her African ancestry while visiting a Caribbean island. Certainly, "'Afro-American[s]'" have been affected by that image, and, according to people of the Dominican Republic with whom I spoke during my visit in 1996, a number of "'Caribbean[s]'" are descendants of slaves who fled the United States. It would seem, then, that, by association with such descendants, "'AfroCaribbean[s],"' including those who emigrate to the United States, have also been affected by that image. In other words, no matter how one considers Selina's and Avey's ethnic background, these protagonists must be influenced, to some extent, by the image of the Southern lady.

3 When Ina, comparing her recollection of Selina as an infant to her current and anticipated perception of Selina, tells Selina, "'You were ugly then, you're uglier now and you'll get worse[,]' ... [o]utrage clog[s] Selina's throat" (7). Selina does not become silent when Beryl tells her, "'My mother says I'm getting black running around with you in the sun'" (58). However, when Beryl refers to a mutual acquaintance who "'[i]s light and has good hair and all the boys like her[,]' . . . a hesitant silence" and then an "ample silence" soon follow (60).

4 Selina literally "turn[s] away" from Suggie when Suggie warns her a second time against the Barbadian Association (207). Seconds after Mrs. Thompson implies to Selina that Selina may become able to identify with Silla for making home ownership a priority, Selina as well as Mrs. Thompson "[a]re silent" (215). At one point, Silla threatens Selina with death if Selina divulges Silla's scheme for buying the brownstone that they rent (76), and "Selina sa[ys] nothing" (77).

5 At the end of a dance class that Selina and Rachel both attend, Rachel, whose "face ... [i]s ... pale," introduces herself and says to Selina, "'I wondered if you might like to join the Modern Dance Club. ... I'm president [of it]"' (250). Selina becomes a member, and, during a rehearsal for an upcoming performance, she reveals to Rachel her 
intention of moving away. In response, Rachel simply asks, "'Where're you going? When?"' and, when Selina indicates that any destination will suffice, Rachel offers to speak with an aunt whose employment in the travel industry may enable her to hire Selina for work on a cruise ship (279). About one week later, Selina follows up on Rachel's offer, and Rachel says, "'Okay.... We'll go see my aunt tomorrow" (308). The novel ends before that "'tomorrow." However, no evidence suggests that they will not "'see [Rachel's] aunt."'

${ }^{6}$ Following Selina's starring role in a dance performance, she and Rachel attend a party at which she is the only person of color. The host's mother, who has "pale ... skin" (285), insidiously reinforces Selina's position as Other. During the moment that the woman's possessive hand deters Selina from leaving, Selina thinks that "this woman, the [host] ..., those others ... , even Rachel [emphasis added], all, everywhere, s[eek] to rob her of ... her self" (289).

${ }^{7}$ At the outset of the novel, Avey suddenly decides to abandon the third cruise that she has taken with Thomasina and Clarice. As she repacks, she recalls that when she had been packing to go on her first cruise, Marion asked her "'[w] hy [she was] go[ing] on some meaningless cruise with a bunch of white folks "' (13) and that she, "ha[ving] developed a special silence to deal with anyone the likes of Marion[,] simply acted as if nothing unpleasant was being said ..." (14). Avey is pulled from her reverie by Thomasina's demand to know "'[w] hat's going on"' (19), but she "doesn't turn to [Thomasina] immediately" (19). When Clarice asks, "'What's happened,"' Avey is "enveloped in that special ... silence of hers ..." (21). In part, Avey abandons the cruise because her dream about being with Great-aunt Cuney unsettles her. When people dream, they are often silent, but, within her dream, Avey engages with her great-aunt in a "silent tug-of-war ..." (43). Great-aunt Cuney pulls toward a former slave landing; Avey pulls toward her suburban and mostly white neighborhood.

8 When Selina expresses upset because her mother has forbade her going to a movie theater without her sister, Deighton does not encourage her to talk further. Instead, he launches into a recollection of activities he and friends did "'when we was boys coming up'" (9). The first time that Selina wears her dance leotards in Clive's presence, "he ... throw[s] back his head [and] laugh[s] ..." (251).

${ }^{9}$ On a day that Deighton plans to seek employment, Selina hears Silla ask him "'[h]ow [he] can be putting [him]self up in these white people face [sic] asking for some big job ..."' (82). Upon his return from the job search, Selina "s[ees] him--lying . . . on the cot as though he ha[s] been severely beaten," and "[s]he wait[s] . . for him to speak first" (83). During a scene in which Selina and Clive sit on a jetty, he gives reasons for his and other black men's failure to realize their dreams, including that "'[w]e were born the wrong color"' (265). When he rises and almost falls into the water, she is "afraid to speak ..." (266). During Selina's silence, "a thought grip[s] her" (266). She plans to win a college scholarship from the Barbadian Association but use the money to move Clive, as well as herself, to a place where he can do his artwork.

10 When Lebert sings, "his voice ... take[s] on a noticeably feminine tone" (179); when he dances, "[o]ut of his . . . body . . . come[s] the illusion of ... femininity ..." (243). Avey's "fe[e]l[ing] as if he ... take[s] her ... firmly . . . by the wrist" (183) is reminiscent of Avey's dreaming that Great-aunt Cuney's "hand . . . close[s] around her wrist ..." (43). 
11 During Avey's first encounter with Lebert, "[h]e f[a]ll[s] silent ..." (168). Feeling "unable to leave without some sign from him," Avey "beg[i]n[s]" (169). Although she "beg[i]n[s]" by making an inane comment, she soon tells him of events surrounding her decision to abandon the cruise, including her dream about Great-aunt Cuney. When Avey finishes speaking, Lebert tells her "'not to leave yet"' (172). He encourages her to visit an island peopled by descendants of Africans, and, when he "sa[ys] nothing," she decides to visit the island (184). On that island, Avey connects with her African self.

12 These predictions, like the indicated silences in Marshall's novels, merit an indepth examination and within an historical context. In other words, they, too, are material for future study.

13 Apparently, when Athena and Luchies kiss, the desire is mutual, for "she $\mathrm{h}[\mathrm{o}] \mathrm{ld}[\mathrm{s}]$ him close in her arms as he fiercely kisse[s] her mouth" (239). Why they do not become romantically involved is unclear, but what does not seem to be an issue is their differing races. On the one hand, Athena thinks "she c[an]not find the way to begin with love again ..." (257). On the other hand, she tells Calliope that "'Luchies ... has a wife and four children'" and that "'he wouldn't take the duplicate key to the new lock'" she had had installed after evicting the contingent from the commune (257). 


\section{BIBLIOGRAPHY}

Bakhtin, M. M. The Dialogic Imagination. Trans. Caryl Emerson and Michael Holquist. Ed. Michael Holquist. U of Texas P Slavic Ser. 1. Austin: U of Texas P, 1981.

---. Speech Genres and Other Late Essays. Trans. Vern W. McGee. Ed. Caryl Emerson and Michael Holquist. U of Texas P Slavic Ser. 8. Austin: U of Texas P, 1986.

Bauer, Dale Marie, and Andrew M. Lakritz. "The Awakening and the Woman Question." Koloski 47-52.

Belenky, Mary Field, et al. Women's Ways of Knowing: The Development of Self, Voice, and Mind. New York: Basic, 1986.

Bell, Elizabeth S. "Kay Boyle." DLB: American Short-Story Writers, 1910-1945. 1989 ed.

--- Kay Boyle: A Study of the Short Fiction. Twayne's Studies in Short Fiction Ser. 34. New York: Twayne, 1992.

Boyle, Kay. "Episode in the Life of an Ancestor." 1930. Fifty Stories. Introd. David Daiches. Garden City: Doubleday, 1980. 17-24.

---. "The First Lover." 1933. Life Being the Best and Other Stories. Ed. and introd. Sandra Whipple Spanier. New York: New Directions, 1988. 103-10.

---. "I Can't Get Drunk." 1933. Life Being the Best and Other Stories. Ed. and introd. Sandra Whipple Spanier. New York: New Directions, 1988. 35-41.

---. "Kay Boyle." Fiction! Interviews with Northern California Novelists. By Dan Tooker. New York: Harcourt, 1976. 15-35.

.... "Kay Boyle." Talks with Authors. Ed. Charles F. Madden. Carbondale: Southern Illinois UP, 1968. 215-36.

---. "No One Can Be All Things to All People." Evergreen Review Aug. 1970: 63-66.

---. Plagued by the Nightingale. 1931. Pref. Kay Boyle. N.p.: Virago, 1981. New York: Penguin, 1990.

---. "Report from Lock-Up." Four Visions of America. Santa Barbara: Capra, 1977. N. pag. Rpt. in Words that Must Somehow Be Said: The Selected Essays of Kay Boyle, 1927-1984. Ed. and introd. Elizabeth S. Bell. San Francisco: North Point, 1985. 118-51.

---. "Testament for My Students, 1968-1969." Southern Review n.d.: n. pag. Rpt. in Testament for My Students and Other Poems. Garden City: Doubleday, 1970. 13-18.

---. The Underground Woman. Garden City: Doubleday, 1975.

---. Wedding Day and Other Stories. New York: Cape, 1930. 
Burns, Edward McNall. Western Civilizations: Their History and Their Culture. 8th ed. Vol. 2. New York: Norton, 1973. 2 vols.

Busia, Abena P. B. "Words Whispered over Voids: A Context for Black Women's Rebellious Voices in the Novel of the African Diaspora." Black Feminist Criticism and Critical Theory. Greenwood: Penkevill, 1988. 1-41. Vol. 3 of Studies in Black American Literature.

Campbell, Jane. "Pauline Elizabeth Hopkins." DLB: Afro-American Writers Before the Harlem Renaissance. 1986 ed.

Carby, Hazel V. Introduction. The Magazine Novels of Pauline Hopkins. Schomburg Library of Nineteenth-Century Black Women Writers. New York: Oxford UP, 1988. xxix-1.

---. Reconstructing Womanhood: The Emergence of the Afro-American Woman Novelist. New York: Oxford UP, 1987.

Cheung, King-Kok. Articulate Silences: Hisaye Yamamoto, Maxine Hong Kingston, Joy Kogawa. Reading Women Writing. Ithaca: Cornell UP, 1993.

Chopin, Kate. At Fault. 1890. Seyersted 739-877.

---. The Awakening. 1899. Seyersted 879-1000.

Christian, Barbara. Black Feminist Criticism: Perspectives on Black Women Writers. Athene Series. New York: Pergamon, 1985.

---. "Trajectories of Self-Definition: Placing Contemporary Afro-American Women's Fiction." Conjuring: Black Women, Fiction, and Literary Tradition. Ed. Marjorie Pryse and Hortense J. Spillers. Everywoman: Studies in History, Literature, and Culture. Bloomington: Indiana UP, 1985. 233-48.

Christian, Barbara T. "Response to 'Black Women's Texts."' National Women's Studies Association Journal 1 (1988): 32-36.

Clark, Suzanne. "Revolution, the Woman, and the Word: Kay Boyle." TwentiethCentury Literature 34 (1988): 322-33.

Cleveland, Grover. "Woman's Mission and Woman's Clubs." Ladies' Home Journal May 1905: 2-4.

Collins, Patricia Hill. Black Feminist Thought: Knowledge, Consciousness, and the Politics of Empowerment. Perspectives on Gender 2. Boston: Hyman, 1990.

Cuddy, Lois. Note to the author. N.d.

Donovan, Josephine. "Silence or Capitulation: Prepatriarchal 'Mothers' Gardens' in Jewett and Freeman." Studies in Short Fiction 23 (1986): 42-48.

DuBois, Ellen Carol. "Outgrowing the Compact of the Fathers: Equal Rights, Woman Suffrage, and the United States Constitution, 1820-1878." Journal of American History 74 (1987): 836-62. 
DuBois, W. E. B. The Souls of Black Folk. 1903. Three Negro Classics. Introd. John Hope Franklin. New York: Avon, 1965. 207-389.

Elfenbein, Anna Shannon. "Kate Chopin's The Awakening: An Assault on American Racial and Sexual Mythology." Southern Studies 26 (1987): 304-12.

Erdrich, Louise. Tales of Burning Love. New York: Harper, 1996.

Ettin, Andrew Vogel. Speaking Silences: Stillness and Voice in Modern Thought and Jewish Tradition. Charlottesville: UP of Virginia, 1994.

Evans, Sara M. Born for Liberty: A History of Women in America. 1989. New York: Free, 1991.

Evans, Sara M. Personal Politics: The Roots of Women's Liberation in the Civil Rights Movement and the New Left. New York: Knopf, 1979.

Fowler, H. Ramsey, and Jane E. Aaron. The Little, Brown Handbook. 4th ed. Glenview: Scott, 1989.

Friedan, Betty. The Feminine Mystique. New York: Norton, 1963.

Gal, Susan. "Between Speech and Silence: The Problematics of Research on Language and Gender." Gender at the Crossroads of Knowledge: Feminist Anthropology in the Postmodern Era. Ed. and introd. Micaela di Leonardo. Berkeley: U of California P, 1991. 175-203.

Gates, Henry Louis, Jr. Foreword. Contending Forces: A Romance Illustrative of Negro Life North and South. By Pauline E. Hopkins. 1900. Introd. Richard Yarborough. Schomburg Library of Nineteenth-Century Black Women Writers. New York: Oxford UP, 1988. vii-xxii.

Giddings, Paula. When and Where I Enter: The Impact of Black Women on Race and Sex in America. New York: Morrow, 1984.

Gilbert, Sandra M., and Susan Gubar. The Madwoman in the Attic: The Woman Writer and the Nineteenth-Century Literary Imagination. New Haven: Yale UP, 1984.

Gordon, Linda. Woman's Body, Woman's Right: A Social History of Birth Control in America. 1976. Middlesex, Eng.: Penguin, 1977.

Gwin, Minrose. "A Theory of Black Women's Texts and White Women's Readings, or ... The Necessity of Being Other." National Women's Studies Association Journal 1 (1988): 21-31.

Hall, Jacquelyn Dowd. Revolt Against Chivalry: Jessie Daniel Ames and the Women's Campaign Against Lynching. New York: Columbia UP, 1979.

Henke, Suzette A. "Sexuality and Silence in Women's Literature." Power, Gender, Values. Ed. Judith Genova. Edmonton: Academic, 1987. 45-62. 
Hogue, W. Lawrence. "Literary Production: A Silence in Afro-American Critical Practice." Belief vs. Theory in Black American Literary Criticism. Greenwood:

Penkevill, 1986. 31-45. Vol. 2 of Studies in Black American Literature.

Hopkins, Pauline E. Contending Forces: A Romance Illustrative of Negro Life North and South. 1900. Introd. Richard Yarborough. Schomburg Library of NineteenthCentury Black Women Writers. New York: Oxford UP, 1988.

---. "Famous Women of the Negro Race. V. Literary Workers (Concluded)." Colored American Magazine Apr. 1902: 366-71.

--- Hagar's Daughter: A Story of Southern Caste Prejudice. 1901-02. Carby 1-284.

--- Of One Blood: Or, the Hidden Self. 1902-03. Carby 439-621.

---. Winona: A Tale of Negro Life in the South and Southwest. 1902. The Magazine Novels of Pauline Hopkins. Introd. Hazel V. Carby. Schomburg Library of Nineteenth-Century Black Women Writers. New York: Oxford UP, 1988. 285437.

Hymowitz, Carol, and Michaele Weissman. A History of Women in America. New York: Free, 1989.

Jackson, Byron K. "Kay Boyle." DLB: American Novelists, 1910-1945. 1981 ed.

Jacobs, Harriet A. Incidents in the Life of a Slave Girl: Written by Herself. 1861. Ed. and introd. Jean Fagan Yellin. Cambridge: Harvard UP, 1987.

Johnson, Joyce. Minor Characters. Boston: Houghton, 1983.

Jones, Ann Rosalind. "Writing the Body: Toward an Understanding of L'ecriture Feminine." Feminist Criticism and Social Change: Sex. Class and Race in Literature and Culture. Ed. Judith Newton and Deborah Rosenfelt. New York: Methuen, 1985. 86-101.

Jones, Jacqueline. Labor of Love, Labor of Sorrow: Black Women, Work, and the Family from Slavery to the Present. New York: Basic, 1985.

Jones, Suzanne W. "Place, Perception and Identity in The Awakening." Southern Quarterly 25 (1987): 108-19.

Kalamaras, George. Reclaiming the Tacit Dimension: Symbolic Form in the Rhetoric of Silence. SUNY Ser., Literacy, Culture, and Learning: Theory and Practice. Albany: State U of New York P, 1994.

Kaplan, E. Ann. Motherhood and Representation: The Mother in Popular Culture and Melodrama. London: Routledge, 1992.

Keating, AnnLouise. "Interrogating 'Whiteness,' (De)Constructing 'Race."' College English 57 (1995): $901-18$.

Koloski, Bernard, ed. Approaches to Teaching Chopin's The Awakening. Approaches to Teaching World Literature 16. New York: MLA, 1988. 
Kramarae, Cheris, Muriel Schulz, and William M. O'Barr, eds. Language and Power. Beverly Hills: Sage, 1984.

Lashgari, Deirdre, ed. Violence, Silence, and Anger: Women's Writing as Transgression. Feminist Issues: Practice, Politics, Theory. Charlottesville: UP of Virginia, 1995.

Laurence, Patricia. "Women's Silence as a Ritual of Truth: A Study of Literary

Expressions in Austen, Bronte, and Woolf." Listening to Silences: New Essays in Feminist Criticism. Ed. Elaine Hedges and Shelley Fisher Fishkin. New York: Oxford UP, 1994. 156-67.

Lauretis, Teresa de. Alice Doesn't: Feminism, Semiotics, Cinema. Bloomington: Indiana UP, 1984.

Levi-Strauss, Claude. The Elementary Structures of Kinship. Trans. James Harle Bell, John Richard von Sturmer, and Rodney Needham. Ed. Rodney Needham.

Boston: Beacon, 1969. Trans. of Les Structures elementaires de la Parente. Rev. ed. 1967.

Lorde, Audre. "The Transformation of Silence into Language and Action." Sister Outsider. N.p.: Crossing, 1984. N. pag. Rpt. in American Women Writers: Diverse Voices in Prose Since 1845. Ed. Eileen Barrett and Mary Cullinan. New York: St. Martin's, 1992. 629-32.

Malpezzi, Frances M. "Silence and Captivity in Babylon: Harriette Arnow's The Dollmaker." Southern Studies 20 (1981): 84-90.

Marshall, Paule. Brown Girl, Brownstones. 1959. Awd. Mary Ellen Washington. New York: Feminist, 1981.

---. Praisesong for the Widow. 1983. New York: Dutton, 1984.

McAlmon, Robert. Being Geniuses Together. Ed. Kay Boyle. Rev. ed. Garden City: Doubleday, 1968.

McCann, Carole R. Birth Control Politics in the United States, 1916-1945. Ithaca: Cornell UP, 1994.

McDowell, Deborah E. "'The Changing Same': Generational Connections and Black Women Novelists." New Literary History 18 (1987): 281-302. Rpt. in Reading Black, Reading Feminist: A Critical Anthology. Ed. Henry Louis Gates, Jr. New York: Meridian, 1990. 91-115.

McFeely, William S. Frederick Douglass. New York: Norton, 1991.

Mellen, Joan. Kay Boyle: Author of Herself. New York: Farrar, 1994.

Moreau, Noelle Bisseret. "Education, Ideology, and Class/Sex Identity." Kramarae 4361.

Olsen, Tillie. Silences. New York: Delacorte, 1978.

Pettis, Joyce. Toward Wholeness in Paule Marshall's Fiction. Charlottesville: UP of Virginia, 1995. 
Portch, Stephen R. Literature's Silent Language: Nonverbal Communication. English Language and Literature 4. New York: Lang, 1985.

Porter, Carolyn. "Ann Beattie: The Art of the Missing." Rainwater 9-25.

Rainwater, Catherine. "Anne Redmon: The Fugal Procedure of Music and Silence." Rainwater 69-83.

Rainwater, Catherine, and William J. Scheick, eds. Contemporary American Women Writers: Narrative Strategies. Lexington: UP of Kentucky, 1985.

Raub, Patricia. Yesterday's Stories: Popular Women's Novels of the Twenties and Thirties. Contributions in American Studies 104. Westport: Greenwood, 1994.

Rogers, Nancy. "Stylistic Categories in The Awakening." Koloski 132-37.

Rosenberg, Rosalind. Divided Lives: American Women in the Twentieth Century. New York: Hill, 1992.

Scheick, William J. "Annie Dillard: Narrative Fringe." Rainwater 51-64.

Schleifer, Ronald. "Grace Paley: Chaste Compactness." Rainwater 31-48.

Scott, Anne Firor. The Southern Lady: From Pedestal to Politics, 1830-1930. Chicago: U of Chicago P, 1970.

Seyersted, Per. Introduction. The Complete Works of Kate Chopin. Ed. Per Seyersted. Southern Literary Studies. Baton Rouge: Louisiana State UP, 1969. 21-33.

Showalter, Elaine. The Female Malady: Women, Madness, and English Culture, 18301980. New York: Pantheon, 1985.

Skaggs, Peggy. Kate Chopin. Ed. David J. Nordloh. Twayne's United States Authors Ser. 485. Boston: Twayne, 1985.

Smith, Barbara. "Toward a Black Feminist Criticism." Conditions: Two 1.2 (1977): n. pag. Rpt. in The New Feminist Criticism: Essays on Women, Literature, and Theory. Ed. Elaine Showalter. New York: Pantheon, 1985. 168-85.

Solomon, Barbara H. "Characters as Foils to Edna." Koloski 114-19.

Spanier, Sandra Whipple. Kay Boyle: Artist and Activist. Carbondale: Southern Illinois UP, 1986.

Spender, Dale. "Defining Reality: A Powerful Tool." Kramarae 194-205.

Sterling, Dorothy, ed. We Are Your Sisters: Black Women in the Nineteenth Century. New York: Norton, 1984.

Stout, Janis P. Strategies of Reticence: Silence and Meaning in the Works of Jane Austen. Willa Cather, Katherine Anne Porter, and Joan Didion. Charlottesville: UP of Virginia, 1990. 
Stowe, Harriet Beecher. Uncle Tom's Cabin. 1851-52. New York: Penguin, 1966.

Strom, Sharon H. Note to the author. N.d.

Sullivan, Ruth, and Stewart Smith. "Narrative Stance in Kate Chopin's The Awakening." Studies in American Fiction 1 (1973): 62-75.

Tate, Claudia. "Allegories of Black Female Desire; or, Rereading Nineteenth-Century Sentimental Narratives of Black Female Authority." Changing Our Own Words: Essays on Criticism, Theory, and Writing by Black Women. Ed. Cheryl A. Wall. New Brunswick: Rutgers UP, 1989. 98-126.

---. Domestic Allegories of Political Desire: The Black Heroine's Text at the Turn of the Century. New York: Oxford UP, 1992.

---. "Pauline Hopkins: Our Literary Foremother." Pryse 53-66.

Thorne, Barrie, Cheris Kramarae, and Nancy Henley. "Language, Gender and Society: Opening a Second Decade of Research." Language, Gender and Society. Ed. Thorne, Kramarae, and Henley. Rowley: Newbury, 1983. 7-24.

Toth, Emily. Kate Chopin. New York: Morrow, 1990.

Weedon, Chris. Feminist Practice and Poststructuralist Theory. Cambridge: Blackwell, 1987.

Wells, Ida B. A Red Record: Tabulated Statistics and Alleged Causes of Lynchings in the United States, 1892-1893-1894. Chicago: Donohue, 1895.

Wheeler, Marjorie Spruill. New Women of the New South: The Leaders of the Woman Suffrage Movement in the Southern States. New York: Oxford UP, 1993.

Yaeger, Patricia S. "'A Language Which Nobody Understood': Emancipatory Strategies in The Awakening." Novel: A Forum on Fiction 20 (1987): 197-219.

Yarborough, Richard. Introduction. Contending Forces: A Romance Illustrative of Negro Life North and South. By Pauline E. Hopkins. 1900. Schomburg Library of Nineteenth-Century Black Women Writers. New York: Oxford UP, 1988. xxvii-xlviii.

Yellin, Jean Fagan, ed. Notes. Incidents in the Life of a Slave Girl: Written by Herself. By Harriet A. Jacobs. 1861. Cambridge: Harvard UP, 1987. 253-92. 